\title{
Progress of acetone-butanol-ethanol (ABE) as biofuel in gasoline and diesel engine: $A$ review
}

\author{
Ibham Veza*, Mohd Farid Muhammad Said, Zulkarnain Abdul Latiff \\ Automotive Development Centre, School of Engineering, Faculty of Engineering, Universiti \\ Teknologi Malaysia, 81310, Johor Bahru, Malaysia.
}

* Corresponding author. Mailing address: Automotive Development Centre, School of Engineering, Faculty of Engineering, Universiti Teknologi Malaysia, 81310, Johor Bahru, Malaysia; E-mail address: veza.ibham@graduate.utm.my (Ibham Veza); Phone: +6075535449; Fax: +6075535811

\begin{abstract}
The properties of butanol offer more promising results compared to those of lower chain alcohol such as methanol or ethanol. However, butanol as a biofuel has not yet been commercially produced due to its costly process. Butanol is generally produced via the process of Acetone-Butanol-Ethanol (ABE) fermentation and can only be acquired after it was recovered from the $A B E$ solvent. Despite the efforts and recent developments, obtaining higher butanol concentration from $A B E$ fermentation is still relatively expensive and challenging. The idea of using $A B E$ directly in internal combustion engines is then proposed to eliminate the recovery process. Several preliminary studies have reported several promising results of using $A B E$ blends in both gasoline and diesel engines. However, researches in this area are still in the early stages, and thorough investigations are required. This review paper aims to provide essential findings from the latest development in the addition of $A B E$ both with gasoline and diesel fuel in Spark Ignition ( $\mathrm{SI}$ ) and Compression Ignition ( $\mathrm{Cl}$ ) engines. A brief discussion on $\mathrm{ABE}$ properties will be firstly given before the effects of its addition on $\mathrm{SI}$ and $\mathrm{Cl}$ engine is comprehensively reviewed. The end of this article highlights some possible contributions and research gaps.
\end{abstract}

Keywords: butanol; biofuel; acetone-butanol-ethanol (ABE); gasoline; diesel, $\mathrm{SI}, \mathrm{Cl}$

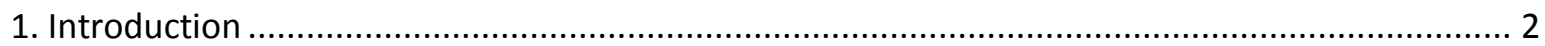

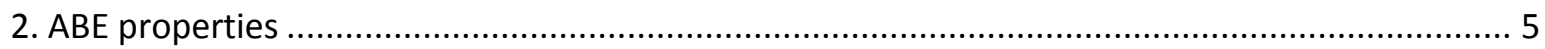

3. ABE addition in gasoline engine

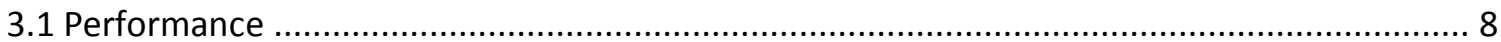

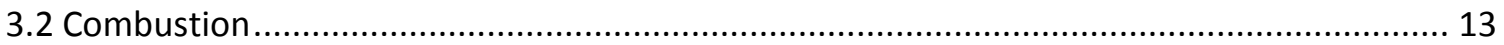

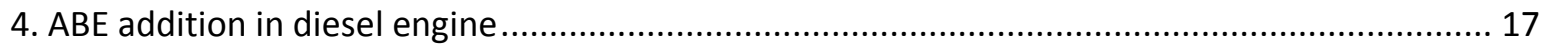

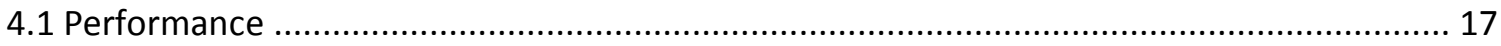

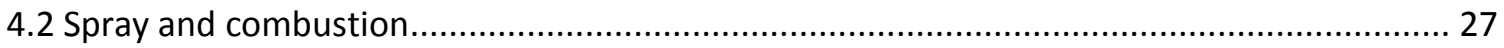

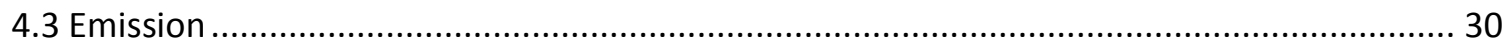

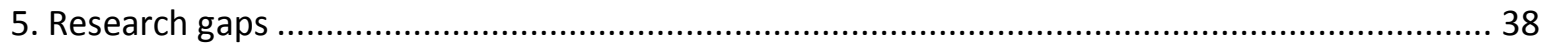

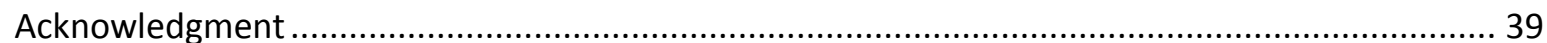

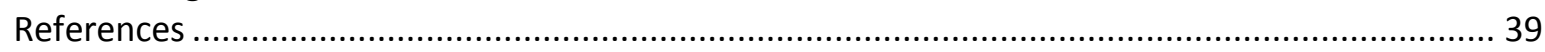

\section{Nomenclature}

$A B E \quad$ acetone-butanol-ethanol

B Biodiesel 
BA

BaPeq

$B P$

BSFC

BTE

$\mathrm{Bu}$

$\mathrm{Cl}$

$\mathrm{CO}$

$\mathrm{CO}_{2}$

DI

EGR

EGT

$\varnothing$

FLoL

$\mathrm{HC}$

LTC

ICD

ISFC

ITE

$M C D$

MFB

NOx

$\mathrm{PFI}$

PM

SI

SINL

SMD

SOC

TINL butanol-ethanol

toxicity equivalent of phase

brake power

brake specific fuel consumption

brake thermal efficiency

Butanol

compression ignition

carbon monoxide

carbon monoxide

direct injection

exhaust gas recirculation

Exhaust gas temperature

equivalence ratio

flame-lift off length

unburned hydrocarbons

low temperature combustion

Initial Combustion Duration

indicated specific fuel consumption

indicated thermal efficiency

Main Combustion Duration

Mass Fraction Burnt

nitrogen oxides

port fuel injection

particulate matter

spark ignition

space integrated natural luminosity

sauter mean diameter

start of combustion

time integrated natural luminosity

\section{Introduction}

Modern engines face challenging targets to meet the increasing emissions regulation and to increase the engine thermal efficiency [1, 2]. To address these two issues, the use of alcohol biofuels such as methanol, ethanol, and butanol has attracted many attentions because of their physico-chemical properties [3-7]. They can be produced using renewable sources and agricultural waste material [812]. Unlike bio-diesel that can only be used in $\mathrm{Cl}$ engine, alcohol fuels can be used both in $\mathrm{Cl}$ and $\mathrm{SI}$ engines despite blending more easily with gasoline [13-15]. Ethanol is arguably the most successful alcohol fuel that has been mass produced and used in large scale [16-19]. Brazil has developed ethanol from sugarcane since 1975 with the PRO-ALCOOL programme and has reduced its dependency on fossil fuel imports [20-25]. However, ethanol has several problems to solve. It can only be used in small concentrations caused by its hygroscopicity and lower energy density than those of conventional fuel $[26,27]$. In terms of fuel properties, higher alcohol such as butanol is a more favourable alcohol fuel compared to ethanol due to its higher heating value, good solubility and less corrosive to the existing pipelines [28-32].

Butanol emerges as a promising biofuel to achieve a clean, efficient and affordable combustion engine [33-35]. It is produced through Acetone-Butanol-Ethanol (ABE) fermentation process with a typical ratio of 3:6:1 or known as bio-butanol [36-40], while that of produced from petrochemical process is called petro-butanol $[41,42]$. However, although butanol properties offer more promising results compared to ethanol, its application as a biofuel has not yet been commercially mass-produced. While 
petro-butanol is strongly affected by the global oil prices, bio-butanol suffers from its low production capacity. The use of butanol in the internal combustion engine is hindered by its low production efficiency and high production cost [43-45]. The butanol quantity and productivity from the typical $A B E$ fermentation process are exceptionally low, only $12-18 \mathrm{~g} / \mathrm{l}$ [46-49]. In addition to that, $A B E$ fermentation also produces large amounts of organic wastewater where one-ton ABE production produces around 45 tons of wastewater comprising various organic acids [50]. Although several efforts have been done, its production efficiency is still relatively low [29]. For comparison, the production rate of yeast ethanol is 10-30 times higher than butanol [46]. Besides its low production, the dehydration and recovery of butanol from $A B E$ fermentation mixture requires a considerable amount of energy $[29,51]$. The conventional distillation of butanol from $A B E$ is expensive since the boiling point of butanol is $118^{\circ} \mathrm{C}$ [52-54], which requires high-energy input in the distillation process caused by different boiling points of each butanol's isomers [55]. Several alternative recovery methods have been proposed [56-58]. These include adsorption [59-62], gas stripping [63-67] and pervaporation [6879]. Despite being relatively efficient processes, such proposed recovery approaches are still not widely implemented in large scale [52]. Therefore, butanol's low productivity and expensive recovery process have delayed its application as the next biofuel.

Upon requirements, the $A B E$ ratio can be altered. Some straightforward non-in-situ $A B E$ recovery methods could modify $A B E$ ratio at will. Liu et al. used a nonconventional method to generate an optimised downstream process of ABE fermentation [80]. It was found that the optimal and nearoptimal flowsheets could be achieved using several separation techniques including gas stripping, distillation and extraction. This study implied that in some cases, building new recovery process could be less economically feasible than merely modifying the existing process. For instance, the direct sequence of distillation columns could be simply modified to the indirect sequence, which would increase its economic value by $33 \%$. However, despite being more efficient compared to the simple traditional distillation process, the energy required for recovery process was still significantly higher than the energy content of butanol at a factor of $10 \%$, a target for energy efficiency in the ABE recovery process [55]. Moreover, gas striping may be a straightforward method compared to liquid-liquid extraction, but the overall process could be less economically viable due to the expensive of azeotropic systems to obtain pure ABE final products from stripped gas.

Liu et al. used a more complex biochemical production in their subsequent study [81]. The P-graph was still used, due to its excellent insight, to retrofit the recovery process of ABE fermentation so that its energy efficiency could be improved. This study combined the adsorption with conventional recovery methods such as distillation, liquid-liquid extraction and gas striping. It was found that the optimal flowsheet was comprised of a gas-stripper, two adsorption columns and two distillation columns as illustrated in Fig. 1 . This optimal flowsheet could reduce its total cost by $44 \%$ compared to the group's previous study. This is because the gas stripping was used before adsorption. As a result, only a few fermentation broths were fed to the adsorption unit, thus significantly minimising the size of the equipment as well as reducing its capital cost. Note that this study assumed that most of the products were recovered by gas striping, while the excess water was removed by adsorption. 


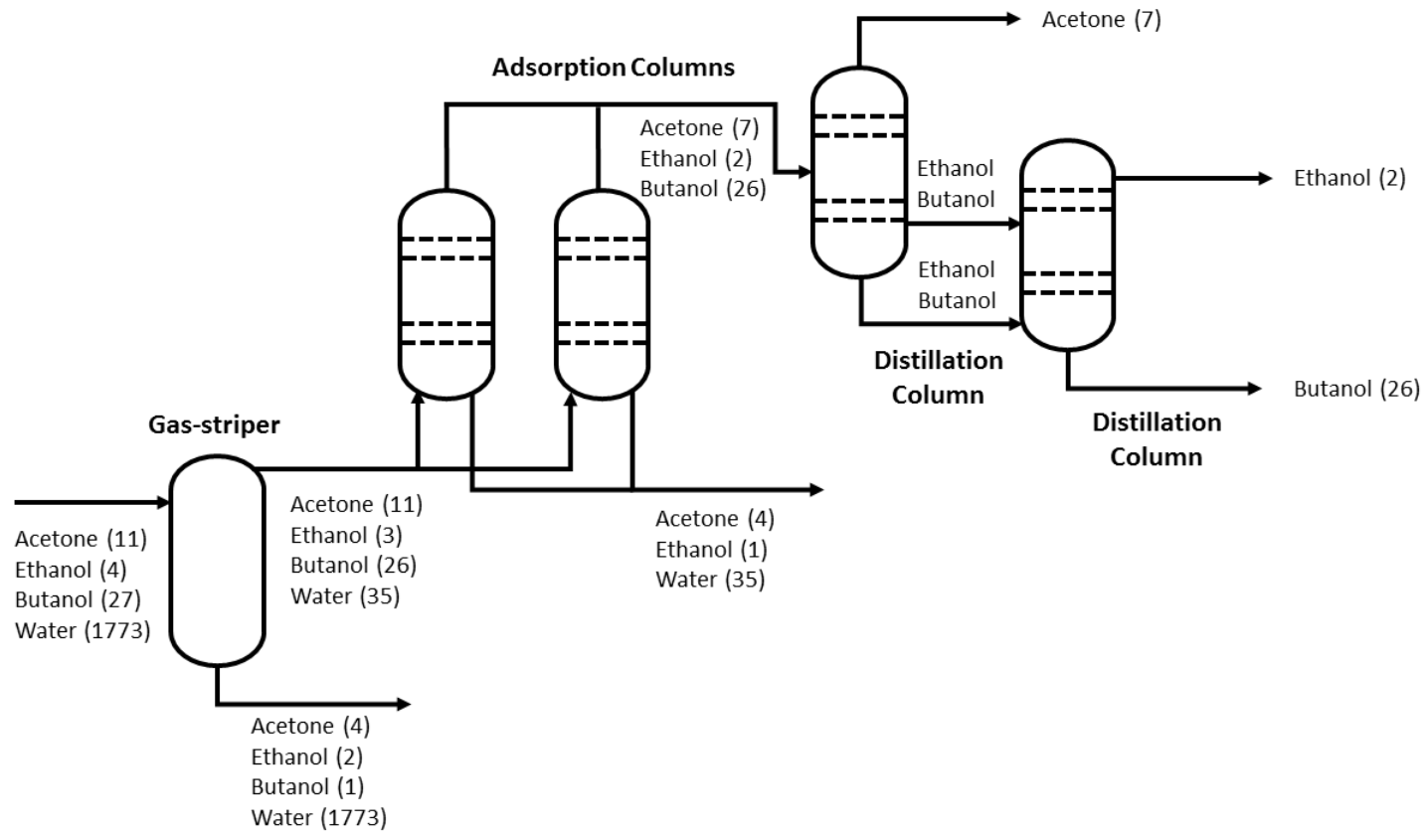

Fig. 1. Optimal flowsheet for downstream processing of $A B E$ fermentation with values in bracket being on mass basis, reproduced from [81]

As the major by-product of ABE fermentation (the second metabolite after butanol), acetone plays an important role in the economics of $A B E$ industry due to its valuable chemical content. It can be regulated and maximised during $A B E$ fermentation. By using co-culturing Clostridium acetobutylicum/Saccharomyces cerevisiae with the addition of exogenous acetate addition, Luo et al. found that the survival of $\mathrm{C}$. acetobutylicum in the cells was improved, while NADH synthesis rate was successfully limited at moderately low level to increase acetone synthesis. Both acetone and butanol concentrations increased from $5.86 \mathrm{~g} / \mathrm{L}$ to $8.27-8.55 \mathrm{~g} / \mathrm{L}$ and from $11.63 \mathrm{~g} / \mathrm{L}$ to $13.91-14.23 \mathrm{~g} / \mathrm{L}$, respectively [82]. In another study, Luo et al. reported that by using a glucose/acetone co-substrate system combined with $\mathrm{C}$. acetobutylicum/S. cerevisiae co-culturing with glucose limitation, the acetone production was improved [83]. The acetone concentration and the ratio of acetone/butanol could reach $11.74 \mathrm{~g} / \mathrm{l}$ and 1.02 without sacrificing the production of butanol. The normal butanol synthesis could be maintained; thus total $A B E$ concentration could be improved by $38 \%-56 \%$. This finding indicates that the flexibility of $A B E$ fermentation products could be achieved where bioacetone could be produced utilising renewable feedstocks.

Low production of butanol due to its culture toxicity has increased the cost and energy requirement for the subsequent recovery process [84]. As a result, separation and purification of butanol contribute $14 \%$ of the total production cost, the second after feedstock cost $(79 \%)[85,86]$. Also, Qureshi and Blaschek found that major equipment for recovery processes such as distillation columns, boilers, heat exchangers and storage tanks made up almost $80 \%$ of the initial investment cost of butanol production from corn [87]. In terms of energy demand for the butanol recovery process, the well-established conventional distillation requires $79.5 \mathrm{MJ} / \mathrm{kg}$. Considering that the energy content of butanol is only $36 \mathrm{MJ} / \mathrm{kg}$, the energy demand for the recovery process alone reach a factor of $220 \%$ of the energy content of butanol itself [88].

Although several in situ and hybrid recovery techniques have been extensively studied to lower recovery cost and energy requirement of butanol, a significant amount of energy is still required. Huang et al. reported that by using a hybrid process gas-stripping/distillation, the energy demand 
could be reduced to $21 \mathrm{MJ} / \mathrm{kg}$ [89]. Kurkijärvi et al. found that by using a liquid-liquid extraction/distillation, the energy consumption for the recovery process was as low as $3.76 \mathrm{MJ} / \mathrm{kg}$ [90]. Furthermore, Águeda et al. investigated the use of an adsorption/drying/desorption and found that only $3.4 \mathrm{MJ} / \mathrm{kg}$ was required for the recovery process [91]. Despite being able to reduce energy demand for the butanol recovery process, achieving higher butanol production with lower energy consumption is challenging, and a significant amount of energy is still required. Therefore, the idea of using $A B E$ solvent as biofuel instead of butanol would eliminate such process. The whole process of $A B E$ fermentation can be grouped into five main steps as illustrated in Fig. 2. The first process $A B E$ fermentation begins with the selection of feedstock and ends with acetone, butanol and ethanol being produced. By using ABE directly, the fourth step (the downstream process) that typically requires high cost and energy demand could be eliminated.

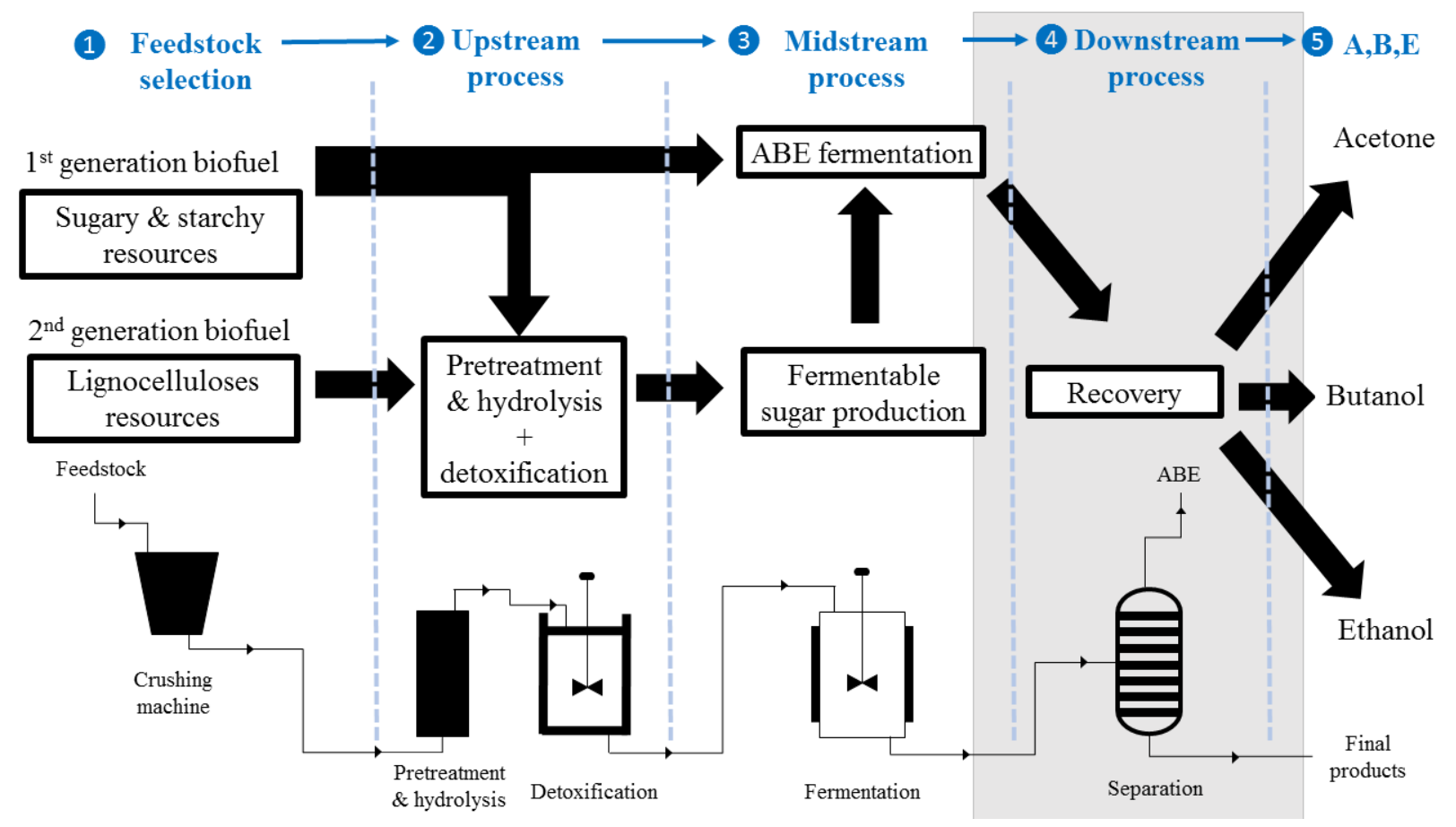

Fig. 2. Schematic overview of ABE process from raw material to final product

Given the challenges with bio-butanol production process mentioned above, using ABE directly as a biofuel is considered as a promising approach as it can eliminate the recovery step resulting in considerable cost and energy savings [92-94]. A slight difference between ABE's molecular structure and butanol's may not significantly affect important combustion characteristics such as heat release and the main combustion products [95]. Two review articles have been published on the use of ABE as biofuel $[95,96]$. However, the emphasis of its use as an alternative fuel on the internal combustion engine was moderately discussed since some sections were devoted to ABE's production process and historical development. This review article aims to focus on the addition of $A B E$ in an internal combustion engine, both in $\mathrm{SI}$ and $\mathrm{Cl}$ engines. The term of butanol and bio-butanol are used interchangeably in this article. Discussion on ABE properties will be firstly given before the effects of its addition on the engine is comprehensively reviewed.

\section{ABE properties}

Since a typical of $A B E$ is produced at a volumetric ratio of 3:6:1, the butanol content is the dominant factor in $A B E$ composition [29, 97, 98]. However, recent development in ABE fermentation technology 
has allowed the volumetric percentage of acetone, butanol, and ethanol to be controlled precisely [99-102]. It is possible to designate a specific volumetric ratio such as 6:3:1, 5:14:1 and 0:10:0 to achieve better engine performance, combustion and emission characteristics $[103,104]$. By eliminating the ethanol content, recent studies have also reported the use of BA (butanol-ethanol) mixtures [105-107].

It is important to note that with the addition of multi-component fuels such as $A B E$ into the conventional petrol fuel, the physico-chemical of the fuel will also change. Table 1 shows the properties of $A B E$ components compared to conventional petrol fossil fuels. No information can be found in the literature regarding the cetane number of acetone, but considering its high octane number, it is speculated that the cetane number of acetone will be reasonably low [108-110]. This will reduce the overall of $A B E$ 's cetane number, particularly with the addition of $A B E$ using high acetone content such as 5:4:1 or 6:3:1. Besides its low cetane number, another noticeable characteristic of $A B E$ is its high latent heat of vaporisation. With higher latent heat compared to gasoline or diesel fuel, it is expected that the engine volumetric efficiency will increase as the charge density increases with the addition of alcohol fuel $[111,112]$. High latent heat will also cause the charge cooling effect that will retard the fuel vaporisation [113-117]. The fuel is vaporized in the compression stroke, and the mixture will be more easily to compress.

In the diesel engine, the lower cetane number and higher latent evaporation are expected to retard the start of combustion due to a longer ignition delay and charge cooling effect, respectively [118122]. Also, the lower density and viscosity of alcohol fuel $A B E$ could enhance the spray characteristics and improve the mixing process of air and fuel [123-126]. As a result, more fuel is burned at the premixed stage, and higher maximum pressure is expected to occur [127-130]. Moreover, the presence of oxygen content in ABE can increase the air-fuel ratio, improve the combustion efficiency and increase the thermal efficiency [131-134]. As for gasoline engine, Van Geem et al. [135] found that the ABE had relatively higher laminar flames speed. In fact, the laminar flame speed of ethanol and butanol were found higher than iso-octane [136-140] and n-heptane [138]. Therefore, the higher flame speeds of $A B E$ will result in faster flame propagation and more complete combustion of a gasoline engine, thus reducing the heat losses and increasing the thermal efficiency [30, 141]. However, the fuel consumption of both diesel and gasoline engine are expected to increase due to $A B E$ 's lower heating value [142-144].

Factors that can improve engine performance, combustion and emissions are expected to compete with factors that can deteriorate them. Higher volatility characteristics represented by fuel's low viscosity, boiling point, and high saturation pressure, for instance, may lead to better fuel atomization and air-fuel mixing, thus improving its spray and combustion characteristics [145-147]. However, $A B E$ 's higher latent heat may also result in evaporative cooling effect and will offset the improvement caused by its higher volatility qualities. Further details on the impact of those factors will be discussed in the following section. Table 2 shows the calculated properties of $A B E$ based on their component ratios. The use of $A B E$ is expected to change the spray and flame characteristics; thus engine characteristics will also be affected to some extent. 
Table 1. Properties of conventional fuels and ABE components

\begin{tabular}{|c|c|c|c|c|c|c|c|}
\hline \multirow{2}{*}{ Properties } & \multirow{2}{*}{$\begin{array}{c}\text { Gasoline [148, } \\
149]\end{array}$} & \multirow{2}{*}{ Diesel [150] } & \multicolumn{2}{|c|}{$\mathrm{ABE}^{*}$} & \multirow{2}{*}{$\begin{array}{l}\text { Acetone } \\
\text { [151] }\end{array}$} & \multirow{2}{*}{$\begin{array}{c}\text { Butanol [150, } \\
152]\end{array}$} & \multirow{2}{*}{$\begin{array}{c}\text { Ethanol [148, } \\
153]\end{array}$} \\
\hline & & & $3: 6: 1$ & $6: 3: 1$ & & & \\
\hline Chemical formula & $\mathrm{C}_{4}-\mathrm{C}_{12}$ & $C_{12}-C_{25}$ & $\mathrm{C}_{3.5} \mathrm{H}_{8.4} \mathrm{O}$ & $\mathrm{C}_{3.2} \mathrm{H}_{7.2} \mathrm{O}$ & $\mathrm{C}_{3} \mathrm{H}_{6} \mathrm{O}$ & $\mathrm{C}_{4} \mathrm{H}_{9} \mathrm{OH}$ & $\mathrm{C}_{2} \mathrm{H}_{5} \mathrm{OH}$ \\
\hline Octane number & $88-99$ & $20-30$ & 102.7 & 109 & 117 & 96 & 100 \\
\hline Cetane number & $0-10$ & $40-55$ & - & - & - & 25 & $5-8$ \\
\hline $\mathrm{C} / \mathrm{H}$ atom ratio & 0.44 (octane) & 0.44 (n-heptane) & 0.42 & 0.45 & 0.50 & 0.40 & 0.33 \\
\hline Oxygen content (wt\%) & - & - & 24.73 & 26.52 & 27.59 & 21.62 & 34.78 \\
\hline Density at $288 \mathrm{~K}(\mathrm{~g} / \mathrm{mL})$ & 0.77 & $0.82-0.86$ & 0.80 & 0.80 & 0.79 & 0.81 & 0.80 \\
\hline Lower heating value (MJ/kg) & 43.40 & 42.70 & 31.42 & 30.37 & 29.60 & 33.10 & 26.80 \\
\hline Energy density (MJ/I) & $31.0-33.2$ & $35.0-36.7$ & 25.29 & 24.24 & 23.40 & 26.90 & 21.30 \\
\hline Viscosity at $413 \mathrm{~K}\left(\mathrm{~mm}^{2} / \mathrm{s}\right)$ & 0.49 & $1.90-4.10$ & 1.79 & 1.11 & 0.35 & 2.63 & 1.08 \\
\hline Stoichiometric AFR & 14.70 & 14.30 & 10.49 & 9.99 & 9.54 & 11.21 & 9.02 \\
\hline Boiling point $\left({ }^{\circ} \mathrm{C}\right)$ & $38-204$ & $200-400$ & 94.95 & 76.80 & $55.5-57.5$ & 117 & 78 \\
\hline Auto-ignition temp $\left({ }^{\circ} \mathrm{K}\right)$ & 300 & 210 & 389 & 425 & 465 & 343 & 434 \\
\hline Latent heat at $298 \mathrm{~K}(\mathrm{~kJ} / \mathrm{kg})$ & $380-500$ & 270 & 595 & 576 & 518 & 582 & 904 \\
\hline Saturation pressure $(\mathrm{kPa})$ at $38^{\circ} \mathrm{C}$ & 31.00 & 1.90 & 18.51 & 33.57 & 52.50 & 2.30 & 13.80 \\
\hline Laminar flame speed $(\mathrm{cm} / \mathrm{s})$ & $33^{a}$ & - & - & - & $34^{\mathrm{b}}$ & $48^{c}$ & $39^{a}$ \\
\hline Solubility in water $(\mathrm{g} / \mathrm{l})$ at $25^{\circ} \mathrm{C}$ & Immiscible & Immiscible & - & - & Miscible & 73 & Miscible \\
\hline
\end{tabular}

*ABE properties are calculated based on components ratios and their chemical formulas are from [154].

${ }^{a} p=1 \mathrm{~atm}, T=325 \mathrm{~K} \cdot{ }^{b} p=1 \mathrm{~atm}, T=298 \mathrm{~K} .{ }^{c} p=1 \mathrm{~atm}, T=343 \mathrm{~K}$ 
Table 2. Calculated ABE's properties blends with a typical ratio of 3:6:1

\begin{tabular}{lcccccc}
\hline \multirow{2}{*}{\multicolumn{1}{c}{ Properties }} & \multicolumn{3}{c}{ ABE-diesel } & \multicolumn{3}{c}{ ABE-gasoline } \\
\cline { 2 - 7 } & ABE20 & ABE50 & ABE80 & ABE20 & ABE50 & ABE80 \\
\hline Oxygen content $(\mathrm{wt} \%)$ & 4.95 & 12.36 & 19.78 & 4.95 & 12.36 & 19.78 \\
Density at 288 $\mathrm{K}(\mathrm{g} / \mathrm{mL})$ & 0.83 & 0.82 & 0.81 & 0.77 & 0.78 & 0.80 \\
Lower heating value $(\mathrm{MJ} / \mathrm{kg})$ & 40.44 & 37.06 & 33.68 & 41.00 & 37.41 & 33.82 \\
Stoichiometric AFR & 13.54 & 12.40 & 11.25 & 13.86 & 12.60 & 11.33 \\
Latent heat at $298 \mathrm{~K}(\mathrm{~kJ} / \mathrm{kg})$ & 335 & 433 & 530 & 471 & 518 & 564 \\
\hline
\end{tabular}

\section{ABE addition in gasoline engine}

Table 3 summarises several novelties of recent studies using ABE-gasoline blends in SI engine. Important findings are highlighted and detail discussions are presented in this section.

\subsection{Performance}

\subsubsection{Torque}

Due to ABE's higher latent heat of vaporisation, the mixture temperature is expected to reduce due to the charge cooling effect. This will lead to an increase in charge density and as a result, engine torque will increase [155-157]. At a wide equivalence ratios region, the ABE-gasoline blends have the potential to increase the engine torque. A small amount of water addition can also improve the engine torque. With just $0.5 \%$ water addition, Li et al. [158] found that ABE29.5W0.5 increased the engine torque by $9.6 \%-12.7 \%$ and $7.9 \%-10.9 \%$ compared to that of gasoline and ABE30 (ABE without water addition) at various equivalence ratios. At stoichiometric condition, the engine torque of $A B E 29.5 W 0.5$ increased by $12.7 \%$ and $10.9 \%$ than gasoline and $A B E 30$, respectively. The $A B E 30$ obtained its maximum engine torque at the equivalence ratio of 1.11 , while the $A B E 29.5 W 0.5$ and gasoline achieved its highest torque at the equivalence ratio of 1.0. Li et al. [159] found that the torque of $A B E 30$ and $A B E 85$ increased by $3.1 \%$ and $4.6 \%$ compared to gasoline, but when $1 \%$ water is added, the ABE29W1 increased the torque even further by $3.1-8.2 \%$.

In general, torque will increase with the addition of $A B E$ and water due to a higher charge density resulted from its higher latent heat of vaporisation. The improvement in torque may also be caused due to the higher octane number of ABE. Higher octane number will prolong the fuel ignition delay, leading to a shorter flame and slower energy release rate [160]. The engine heat loss may reduce as the heat does not have sufficient time to reach the coolant. However, this may affect the maximum pressure and reduce the engine power and increase the fuel consumption, yet the extra oxygen content of $A B E$ may improve the combustion efficiency, thus producing a leaner mixture and achieving complete combustion. Therefore, $A B E$ 's higher latent heat, octane number, and extra oxygen contribute to the increase of gasoline engine torque. 
Table 3. Contributions and main findings of recent studies using ABE-gasoline blends

\begin{tabular}{|c|c|c|c|c|c|}
\hline $\begin{array}{l}\text { Operating } \\
\text { Conditions }\end{array}$ & $\begin{array}{c}\text { Reference } \\
\text { fuel }\end{array}$ & $\begin{array}{c}\text { ABE } \\
\text { Percentage }\end{array}$ & $\begin{array}{c}\text { Contribution and } \\
\text { novelty }\end{array}$ & $\begin{array}{l}\text { Main } \\
\text { Findings }\end{array}$ & Refs. \\
\hline $\begin{array}{l}\text { SI PFI, } 1500 \text { rpm, } \\
20^{\circ} \text { BTDC, } 3.5 \text { bar } \\
\text { BMEP, wide open } \\
\text { throttle }\end{array}$ & Gasoline & $\begin{array}{l}\text { ABE20 (3:6:1), } \\
\text { ABE40 }\end{array}$ & $\begin{array}{l}\text { The first to investigate } \\
A B E \text { in SI engine without } \\
\text { major modifications }\end{array}$ & $\begin{aligned}> & \text { ABE20 shows higher and advanced in-cylinder peak pressure } \\
& \text { ABE40 shows lower but advanced peak pressure } \\
> & \text { ABE20 gives shorter ignition delay } \\
& \text { ABE40 gives longer ignition delay } \\
> & \text { BSFC } \uparrow \text { with increasing ABE percentage } \\
> & \text { CO: } A B E 20-->\uparrow \\
& \text { ABE40 --> } \downarrow \\
> & \text { HC: } A B E 20-->\uparrow \\
& A B E 40-->\uparrow \\
> & \text { NOx: } A B E 20-->\text { No changes } \\
& \text { ABE40 --> No changes }\end{aligned}$ & [161] \\
\hline $\begin{array}{l}\text { SI PFI, } 1200 \mathrm{rpm}, \\
20^{\circ} \text { BTDC, } 3 \text { bar } \\
\text { BMEP, } \varnothing=0.83-1.2\end{array}$ & Gasoline & $\begin{array}{l}\text { ABE20 (3:6:1), } \\
\text { ABE40, ABE60, } \\
\text { ABE80 }\end{array}$ & $\begin{array}{l}\text { One of the early studies } \\
\text { investigating ABE- } \\
\text { gasoline blends in SI } \\
\text { engine with various } A B E \\
\text { concentration; from low, } \\
\text { mid to a high percentage }\end{array}$ & $\begin{array}{l}>\text { Lower ABE ratio gives a longer ignition delay \& retarded } 50 \% \\
\text { MFB } \\
>\text { ABE80 has similar combustion phasing with gasoline } \\
>\text { BSFC } \uparrow \text { with increasing ABE percentage } \\
>\text { ABE } 20 \& A B E 40 \text { displayed } \uparrow \text { efficiency than gasoline } \\
>\downarrow C O \& H C \& \text { no major changes in NOx for all blends }\end{array}$ & [162] \\
\hline
\end{tabular}


SI PFI, 1200 rpm, MBT, 3 and 5 bar BMEP, $\varnothing=0.83-1.25$
SI PFI, 1200 rpm, $18^{\circ}$ BTDC \& MBT, 3 bar BMEP, $\varnothing=0.83$ -

1.25

Gasoline

E85, B85, ABE85 $(3: 6: 1)$
$\operatorname{ABE30}(3: 6: 1)$, ABE30 (6:3:1)
Investigating the effect of acetone by increasing its ratio from $30 \%$ to $60 \%$
$>$ Combustion phasing: $\operatorname{ABE30}(6: 3: 1)-->$ similar to gasoline
ABE30 (3:6:1) --> advanced phasing

$>$ BSFC: ABE30 (6:3:1) --> the lowest ABE30 (3:6:1) --> the highest

$>$ BTE: ABE30 (6:3:1) --> 1.6\% higher than gasoline ABE30 (3:6:1) --> 0.5\% lower than gasoline

$>$ CO: ABE30 (6:3:1) --> similar to gasoline ABE30 (3:6:1) --> 个

$>$ HC: ABE30 (6:3:1) --> $\uparrow$ due to high evaporability if acetone $\operatorname{ABE30}(3: 6: 1)-->\downarrow$

$>$ NOx: ABE30 (6:3:1) --> No major changes ABE30 (3:6:1) --> No major changes

SI PFI, 1200 rpm, ABE29W1
Comparatively studying higher $A B E$ percentage (ABE85) with higher concentration of ethanol (E85) and butanol (B85)

ABE30 (3:6:1), ABE29.5W0.5

MBT, 3 bar BMEP $\emptyset=0.83-1.25$ Gasoline

ABE30 (3:6:1), ABE85, ABE29.5W0.5,

$>$ In-cylinder peak pressure:

The highest --> E85, the lowest --> B85

$>$ Combustion phasing:

The most advanced --> E85, the most retarded: B85

$>$ Ignition delay and combustion duration in the sequence of B85>Gasoline $>$ ABE85>E85

$>$ All blends have $\downarrow$ BTE and $\uparrow$ BSFC

$>$ All blends have $\downarrow$ NOx, but B85 gives the highest CO \& HC

The first to investigate water-containing $A B E-$ gasoline blends

ABE29.5W0.5 performed better than ABE30

ner ignition delay \& combustion duration

> Torque: $\uparrow$ 9.6-12.7\%

$>$ BTE: $\uparrow$ 5.2-11.6\%

$>\downarrow \mathrm{CO}, \uparrow \mathrm{HC}, \downarrow \mathrm{NOx}$

Investigating $A B E$ -

ABE29W1 performed better with $\uparrow$ engine torque (3.1-8.2\%), $\mathrm{MBT}, 3$ and 5 bar BMEP, $\varnothing=0.83-1.25$ water addition
$>$ BSFC: similar to gasoline

gasoline blends up to $1 \%$ 
SI PFI, 1200 rpm, MBT, 3 and 5 bar BMEP , $\varnothing=0.83-1.25$

SI PFI, 1200 rpm, MBT, 3 and 5 bar BMEP, $\varnothing=0.83-1.25$

1200 rpm, MBT, 3 and 5 bar BMEP, $\varnothing=0.83-1.25$

SI, PFI, 1200 rpm, each fuel's MBT,

3,4,5,6 bar BMEP,

$\emptyset=0.83-1.25$
Gasoline

ABE100 (3:6:1), ABE100 (6:3:1)

ABE100 (5:14:1)

Gasoline

ABE10 (3:6:1), $\operatorname{ABE30}(3: 6: 1)$, ABE60 (3:6:1), E30,

B30

ABE30 (1:8:1),

$\operatorname{ABE} 30(5: 4: 1)$,

ABE29.5W0.5

(3:6:1), ABE29W1

Gasoline

ABE30 (3:6:1),

$\operatorname{ABE} 30(6: 3: 1)$

Gasoline

ABE30 (3:6:1),

ABE30 (6:3:1),

ABE30 (5:14:1),

E30, B30
Examining pure $A B E$

blends (100\% ABE)

Investigating $A B E$

concentrations with

different volumetric

ratios

The first to examine

unregulated emissions of

ABE-gasoline blends in SI

\section{engine}

Investigating

unregulated emissions

classified as air toxics by

USEPA
$>$ The closest combustion phasing to gasoline --> ABE (6:3:1) 100

$>\uparrow \mathrm{CO} \& \mathrm{HC}$ emissions with increasing butanol ratio

$>A B E$ with higher acetone ratio, i.e. $A B E$ (6:3:1) was preferred ABE30 (3:6:1) performed better with 个 BTE (0.2-1.4\%), $\downarrow$ CO (1.4-4.4\%), $\downarrow$ HC (0.3-9.9\%) and $\downarrow$ NOx emissions $(4.2-14.6 \%)$ compared to those of gasoline

$>$ ABE30 (3:6:1) gives the lowest ethylbenzene, $\downarrow$ toluene, and

$\downarrow$ xylene

$>$ ABE30 (6:3:1) gives the lowest CO, $\downarrow$ HC, $\downarrow$ benzene, similar NOx to gasoline

The lowest CO \& HC --> ABE30 (6:3:1)

The highest acetaldehyde --> B30

The lowest acetaldehyde --> ABE30 (6:3:1)

The lowest BTEX --> ABE30 (3:6:1)
[165] 


\subsubsection{Fuel consumption}

Brake specific fuel consumption (BSFC) represents the ratio of mass fuel consumption to the brake power. The use of oxygenated fuel, including the $A B E$, may increase the BSFC due to its low heating values as shown in Table 1. As a result, the amount of $A B E$ should be increased to obtain the same energy output of gasoline, thus increasing the BSFC. Zhang et al. [164] reported that the ABE85 had higher BSFC ( $543 \mathrm{~g} / \mathrm{kWhr}$ ) compared to gasoline ( $382 \mathrm{~g} / \mathrm{kWhr}$ ) and $85 \%$ Butanol ( $509 \mathrm{~g} / \mathrm{kWhr}$ ), but still lower than $85 \%$ Ethanol ( $584 \mathrm{~g} / \mathrm{kWhr}$ ) as shown in Fig. 3. Nithyanandan et al. [162] found an increasing trend of BSFC with the increase of ABE ratio. The increase in BSFC was around $5 \%$ for ABE20 and $25 \%$ for ABE80 compared to gasoline. Also, Li et al. [159] found that ABE30 and ABE85 increased the indicated specific fuel consumption (ISFC) by $10.1 \%$ and $29.4 \%$ compared to gasoline. Moreover, Li et al. [166] compared $A B E 30$ with different volumetric ratio and it was found that the $A B E 30$ (3:6:1) gave the lowest BSFC compared to that of $A B E(1: 8: 1)$ and $A B E(5: 4: 1)$ due to its relatively shorter combustion duration and higher thermal efficiency.

(a)

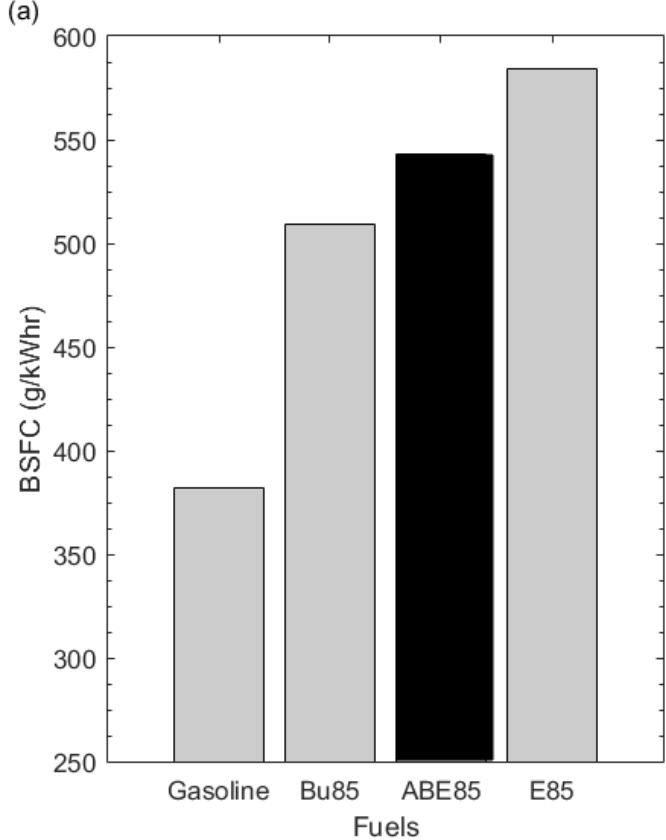

(b)

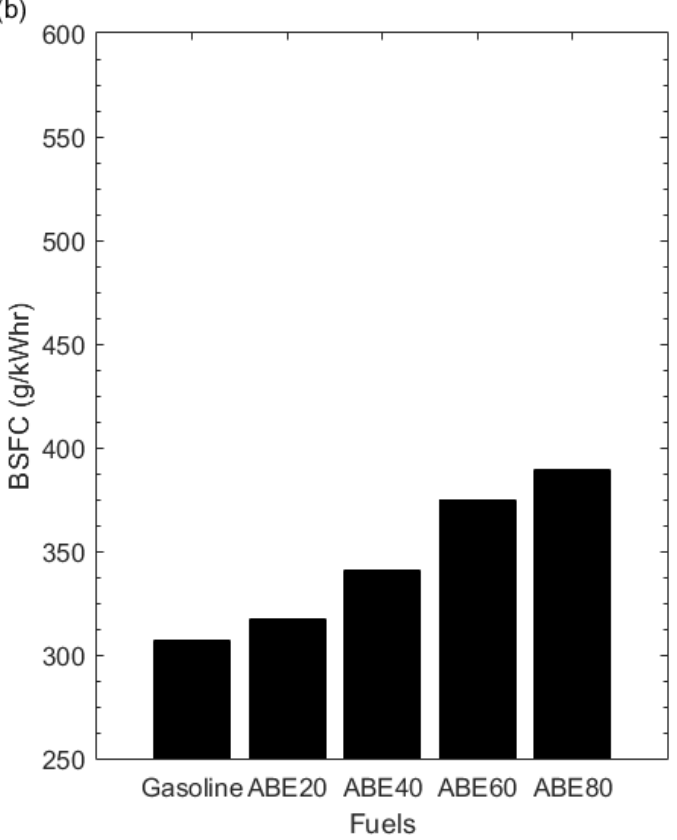

Fig. 3. (a) BSFC of ABE compared to other alcohol fuels at $\varnothing=1$, reproduced from [164] and (b) BSFC of various percentage $A B E[162]$

One crucial factor that may increase BSFC is less fuel conversion efficiency. The start of combustion may be changed with the addition of $A B E$. In this case, the fuel conversion efficiency may be deteriorated due to altered combustion phasing, thus increasing the BSFC. Nithyanandan et al. [161] found that the centre combustion of $A B E 20$ and $A B E 40$, represented by $50 \%$ MFB, were advanced about $1.2^{\circ}$ and $0.3^{\circ}$, respectively. Therefore, to achieve the maximum brake torque, the spark timing should be adjusted to avoid the reduction in fuel conversion efficiency that would later increase the BSFC. Li [167] found that equivalence ratio also influenced the BSFC. At lower stoichiometric air/fuel ratio, the ABE-gasoline blends required more fuel, thus increasing the BSFC. Also, Li et al. [158] found that the addition of water was found to reduce the BSFC. It was observed that the BSFC was around $12.1 \%$ higher with $A B E 30$ compared to that of gasoline, but with $0.5 \%$ water addition, the ABE29.5W0.5 only increased it by $1.4 \%$ or similar with that of gasoline, resulted from its higher combustion and thermal efficiency. 


\subsubsection{Thermal efficiency}

Brake thermal efficiency (BTE) shows how efficient the fuel was converted into mechanical energy. $B T E$ may increase with the increasing ABE ratio. Three main factors may contribute to the increase in BTE using ABE in SI engine; (1) its higher latent heat of vaporisation, (2) oxygen content and (3) higher laminar flame speeds compared to those of gasoline fuel. When $0.5 \%$ and $1 \%$ water was added into the ABE blends, an improvement in BTE was observed, Li et al. [158] reported that ABE29.5W0.5 gave higher BTE by $5.2 \%-11.6 \%$ and $10.7 \%-12.4 \%$ compared to gasoline and ABE30, respectively. Also, Li [167] found that equivalence ratio affected the BTE. At higher stoichiometric air/fuel ratio, it was found that the ABE-gasoline bends gave higher BTE than that of a lower ratio. Nithyanandan et al. [161] reported a slight increase in the BTE for $A B E 20$, while a decrease was observed for ABE40. Nithyanandan et al. [163] found an increase by $1.6 \%$ and a reduction by $0.5 \%$ in $B$ TE for ABE30 (6:3:1) and $A B E 30$ (3:6:1), respectively. $A B E$ with higher acetone content, i.e. $A B E 30$ (6:3:1) gave higher $B T E$ due to its improved combustion compared to $A B E$ with less acetone and higher butanol i.e. ABE30 (3:6:1). This is because blends with lower carbon number (less butanol ratio) have more oxygen, thus enhancing its combustion and increasing its thermal efficiency. However, although its enhanced combustion resulted from extra oxygen, Li et al. [166] found a BTE reduction in ABE addition. The reduction was because the engine was operated at the spark timing of gasoline's Maximum Brake Torque which was $18^{\circ} \mathrm{BTDC}$ at $310.33 \mathrm{kPa}$ BMEP and $15^{\circ} \mathrm{BTDC}$ at $524.07 \mathrm{kPa}$ BMEP. Therefore, the $A B E$ reduction was attributed to improper combustion phasing. Among the tested fuels, $A B E 30(3: 6: 1)$ gave a marginal BTE reduction by $0.2-1.4 \%$ than gasoline, but it still offered a higher BTE compared to $\operatorname{ABE} 30(1: 8: 1)$ and ABE30 (5:4:1).

\subsubsection{Exhaust gas temperature (EGT)}

EGT represents the cylinder temperature and an indicator of combustion efficiency and NOx emissions. The use of ABE blends is expected to lower the exhaust gas temperature, and this is caused by its lower heating value and higher latent heat. Higher latent heat means that ABE will generate a significant temperature drop during the intake stroke, thus reducing the temperature at the end of the compression stroke. As a result, for the same heat release, the EGT will be lower after the combustion. Nithyanandan et al. [161] reported a slight decrease in EGT with the addition of ABE. It was found that gasoline gave the highest EGT with $429.5^{\circ} \mathrm{C}$, while $A B E 20$ and ABE40 showed a slight decrease which stood at $426{ }^{\circ} \mathrm{C}$ and $420.6{ }^{\circ} \mathrm{C}$, respectively. Nithyanandan et al. [163]observed no significant changes in exhaust gas temperature. The EGT of ABE30 (3:6:1) and ABE30 (6:3:1) had a similar temperature of around $430^{\circ} \mathrm{C}$ with gasoline.

\subsection{Combustion}

Since each ABE component has higher laminar flame speed compared to gasoline, the combustion duration is more likely to be faster. Nithyanandan et al. [161] found that the ABE20 gave a shorter ignition delay and an advanced 50\% Mass Fraction Burnt (MFB) location compared to the ABE40, resulted from the higher laminar flame speed of $A B E$. However, the $A B E 40$ showed deteriorated combustion quality because of improper combustion phasing and high latent heat of vaporisation. In another study, compared to higher ABE ratio, Nithyanandan et al. [162] reported that lower ABE ratio gave a longer ignition delay and retarded $50 \%$ MFB location caused by the reduction in laminar flame speed resulted from ABE's evaporative cooling effect. Therefore, higher ABE ratio such as ABE80 was found to have similar combustion phasing with gasoline with shorter ignition delay because of its higher laminar flame speed. Li et al. [166] found that the use of ABE30 (3:6:1) and ABE60 (3:6:1) displayed a relatively early combustion phasing with a shorter Initial Combustion Duration (ICD) and Main Combustion Duration (MCD) than those of gasoline. Comparable results were found by Li et al. 
[159] when comparing $A B E 30$ and $A B E 85$ with gasoline. Fig. 4 shows that the ICD and MCD reduce with increasing $A B E$ concentration. However, when water was added, the ICD and MCD were increased for $0.5 \%$ water addition but decreased for $1 \%$ water. At equivalence ratios $(\varnothing=0.83-1.25)$ and engine loads ( 3 and 5 bar BMEP), the ABE29 with $1 \%$ water addition gave a faster combustion rate than gasoline for leaner mixtures, while the opposite trend was observed for richer mixtures. Also, Li et al. [158] found that ABE29.5W0.5 displayed a longer ignition delay and combustion duration. Water addition was believed to reduce the combustion temperature and led to a lower combustion rate. It is important to note that at higher engine loads, faster combustion duration is expected due to the faster heat release rate.
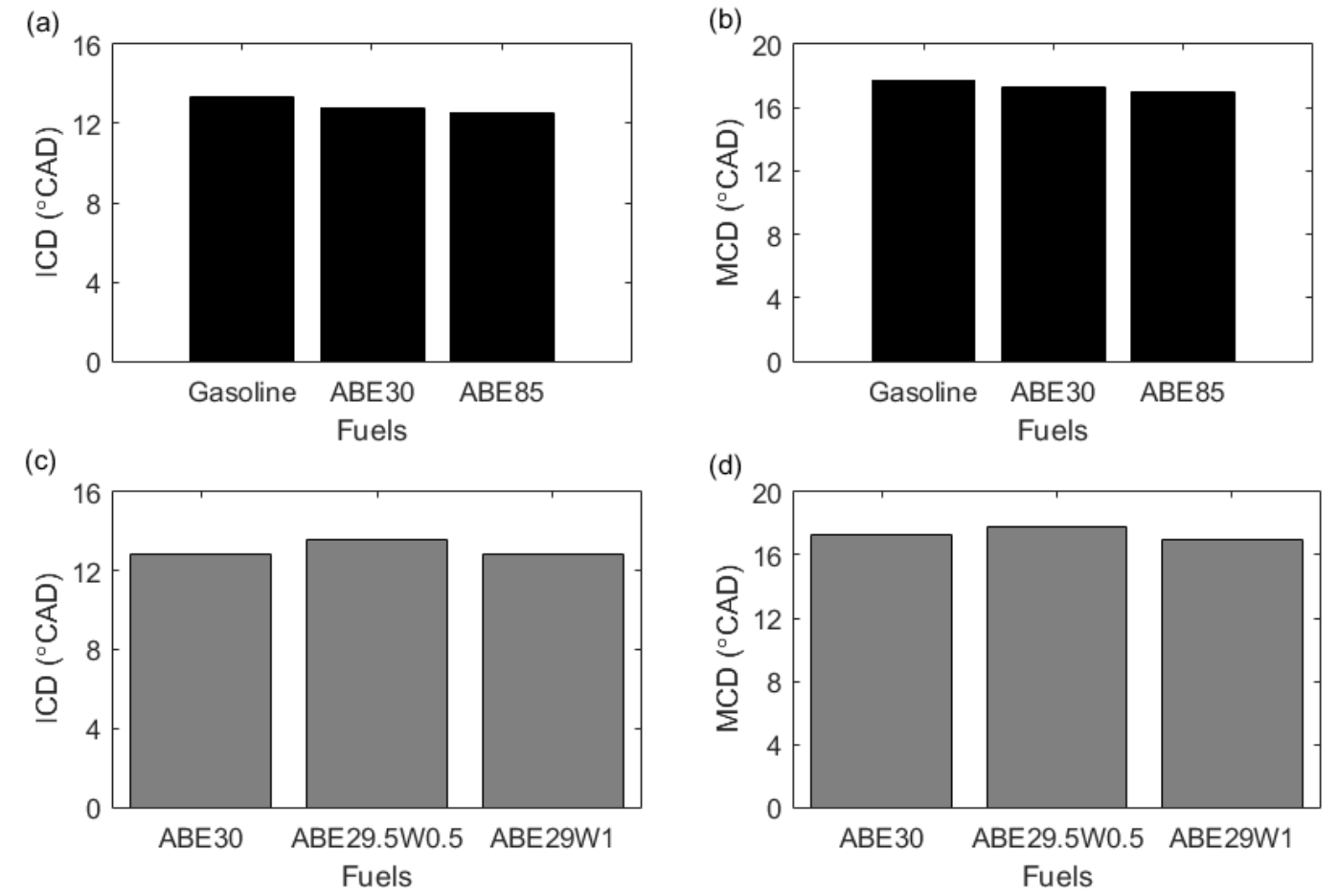

Fig. 4. Comparisons of combustion characteristics between $A B E$ ( $a$ and $b$ ) and water-containing $A B E$ (c and d) at $\varnothing=1$ and 3 bar BMEP, reproduced from [159]

\subsection{Emission}

\subsection{1 $\mathrm{CO}$ and $\mathrm{HC}$ emission}

$A B E$ has the potential to reduce both the $\mathrm{CO}$ and $\mathrm{HC}$ emissions. Oxygen content found in $\mathrm{ABE}$ will generate the leaning effect, improve the combustion efficiency, reduce $\mathrm{HC}$ emissions and allow in greater conversion of $\mathrm{CO}$ to $\mathrm{CO}_{2}$, resulting in higher $\mathrm{CO}_{2}$ emissions of $\mathrm{ABE}$ than gasoline. Also, the higher laminar flame speed of $A B E$ can help to achieve complete combustion. However, the lower LHV of $A B E$ may avoid the blends achieving complete combustion. Various operating conditions may also affect the $\mathrm{CO}$ and $\mathrm{HC}$ emissions.

Li et al. [166] found that ABE30 (3:6:1) gave a lower CO and HC emissions by 1.4-4.4\% and 0.3-9.9\%, respectively compared to gasoline. Li et al. [167] found that acetone's higher volatility and improved post-flame oxidation are beneficial to reduce $\mathrm{CO}$ and $\mathrm{HC}$ emissions. It was found that $\mathrm{ABE} 30$ (6:3:1) gave lower $\mathrm{CO}$ and $\mathrm{HC}$ emissions compared to $\mathrm{ABE} 30$ (3:6:1) and gasoline as shown in Fig. 5. Also, Li et al. [168] found the lowest $\mathrm{CO}$ and $\mathrm{HC}$ emissions were achieved at higher acetone content, i.e. ABE30 
(6:3:1), compared to ABE30 (3:6:1), and ABE30 (5:14:1). Nithyanandan et al. [163] found decreased $\mathrm{HC}$ emissions for $\mathrm{ABE} 30$ (3:6:1) due to incomplete combustion. However, when the acetone content was increased to $A B E 30$ (6:3:1), an increased in $\mathrm{HC}$ emissions was reported, believed to be from high evaporability of acetone that increased the unburned hydrocarbons in the crevice. Moreover, Nithyanandan et al. [165] found that by increasing the butanol content from $A B E$ (6:3:1) to ABE (3:6:1) and $A B E(5: 14: 1)$, the $C O$ and $H C$ emissions were found to increase due to incomplete combustion. Nithyanandan et al. [161] found higher $\mathrm{CO}$ emission for $\mathrm{ABE} 20$ as some fuels were only partly oxidized. Regarding water containing ABE, Li et al. [158] found reduced $C O$ emissions with ABE29.5W0.5 but increased $\mathrm{HC}$ emissions due to a retarded $\mathrm{HC}$ oxidation resulted from reduced combustion temperature caused by water addition. When water was added up to $1 \%$, Li et al. [159] found that ABE29W1 displayed a more significant reduction of $\mathrm{CO}$ and $\mathrm{HC}$ emissions by $9.8-35.1 \%$ and $27.4-$ $78.2 \%$, respectively.
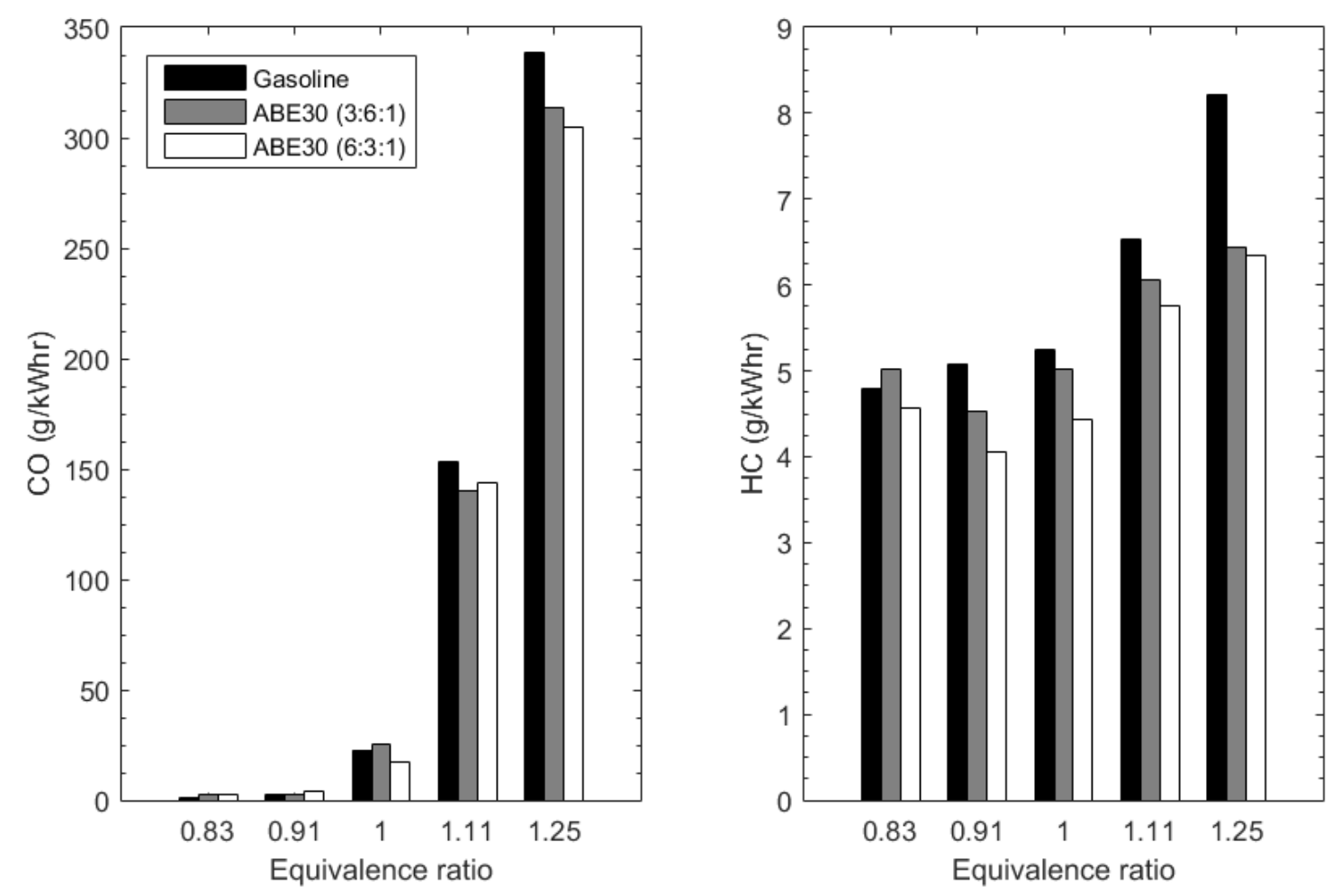

Fig. 5. $\mathrm{CO}$ and $\mathrm{HC}$ emissions at 3 bar BMEP at different equivalence ratios, reproduced from [167]

In general, the addition of $\mathrm{ABE}$ could decrease the $\mathrm{CO}$ and $\mathrm{HC}$ emissions compared to gasoline fuel due to its leaning effect. It is important to note that different engine operating conditions may also affect such emissions. In a gasoline engine, at high engine loads, the lack of oxygen in the richer region may increase the $\mathrm{CO}$ and $\mathrm{HC}$ emissions. However, at low engine loads, higher emissions can also still be observed since the mixture is too lean to burn and it is difficult to maintain the flames because of low flame propagation speed. This is where the extra oxygen and higher flame speed provided by the addition of $\mathrm{ABE}$ play a vital role to reduce $\mathrm{CO}$ and $\mathrm{HC}$ emissions at various engine loads. At high engine speeds, although the engine does not have sufficient time to complete combustion, the higher flame speed of $A B E$ is expected to help achieve complete combustion. Moreover, the mixture at high engine speed may be more homogeneous leading to improve combustion and higher in-cylinder temperature. As a result, both $\mathrm{CO}$ and $\mathrm{HC}$ will reduce at high engine speeds. The trend may be the 
opposite for low engine speed as the higher latent heat of $A B E$ may reduce the in-cylinder temperature, thus increasing $\mathrm{CO}$ and $\mathrm{HC}$ emissions.

\subsubsection{NOx emission}

Higher in-cylinder temperature is considered as the significant reason of thermal NOx formation in a gasoline engine [155]. The oxygen content in ABE fuel may increase the in-cylinder temperature, but the charge cooling effect from ABE's high latent of heat vaporisation may outweigh such effect, thus reducing the in-cylinder temperature. No major changes in NOx emissions were observed by Li et al. [167] for ABE30 (3:6:1) and ABE30 (6:3:1). Comparable results were also observed in [161], [162], [163] and [167] where ABE blends gave nearly similar NOx emissions compared to gasoline. However, some studies reported reductions in NOx emissions. Li et al. [166] reported a reduction in NOx emissions by 4.2-14.6\% using ABE30 (3:6:1) than gasoline. However, Fig. 6 shows the highest NOx emissions are found at $\varnothing$ between 0.9 and 1.0 due to more complete combustion close to the stoichiometric region that leads to a higher peak combustion temperature. Regarding watercontaining ABE blends, Li et al. [158] found lower NOx emissions resulted from reduced combustion temperature caused by $0.5 \%$ water addition into the $A B E$ blend. With $1 \%$ water content in the $A B E$ blend, Li et al. [159] found that ABE29W1 displayed a more significant reduction of NOx emissions by 4.1-39.4\%. In general, NOx formation from ABE addition can be reduced or maintained the same level as that of a gasoline engine. This is attributed to ABE's higher latent heat that results in the cooling effect inside the combustion chamber.

(a)

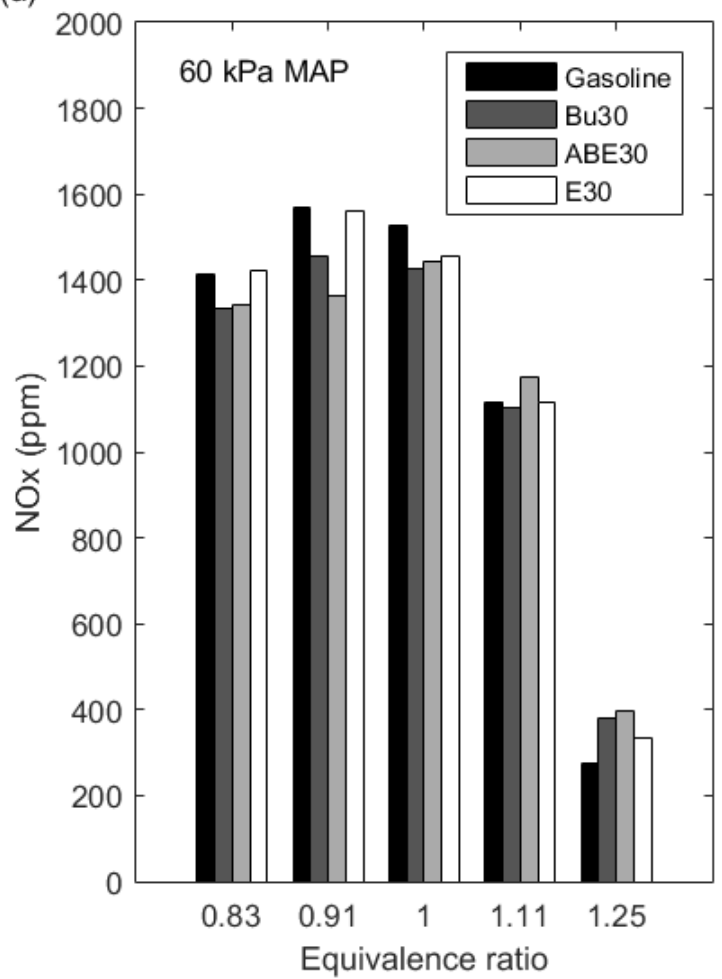

(b)

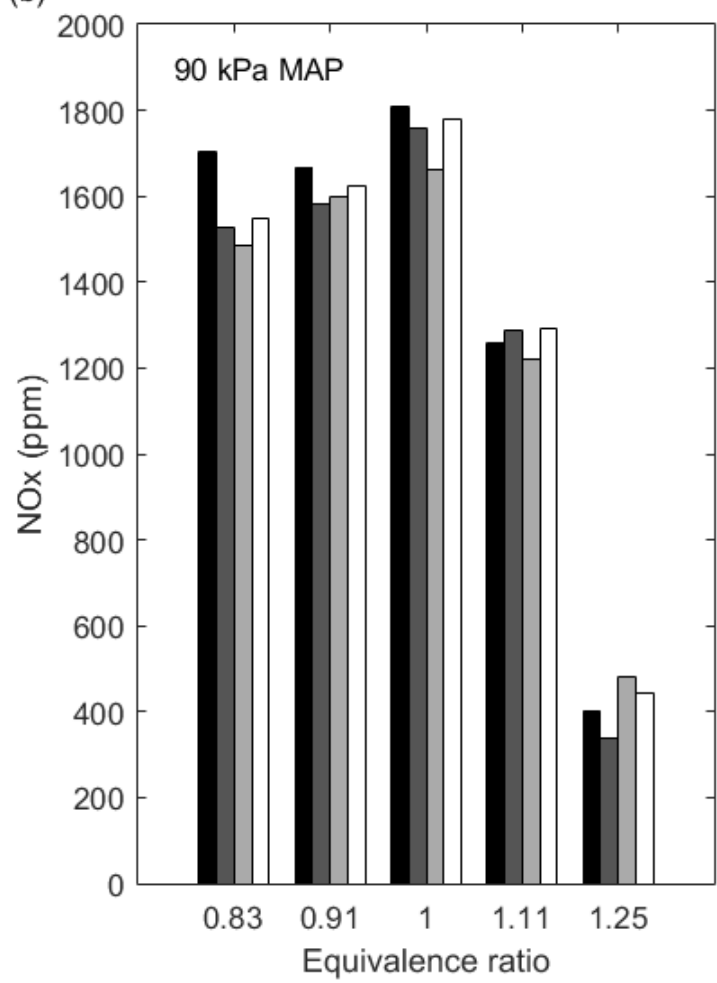

Fig. 6. NOx emissions of $A B E 30$ in comparison with other alcohol fuels at different equivalence ratios and engine loads; (a) $60 \mathrm{kPa}$ and (b) $90 \mathrm{kPa}$, reproduced from [166] 


\subsubsection{Particulate matter (PM) emission}

No studies can be found in the literature examining the effect of ABE on PM emissions of a gasoline engine. It is known that conventional port-fuel injection (PFI) gasoline engine produces less soot emission than diesel engine thus more attention to investigate PM emission is directed towards diesel engine. However, gasoline direct injection (GDI) engine may produce higher PM emissions compared to traditional PFI gasoline engine, as a result of its fuel-rich regions and local high temperature from incomplete combustion [169]. Therefore, more researches are needed to examine PM emissions of the GDI engine.

Although previous studies have not yet examined the effect of $A B E$ on PM emissions of a gasoline engine, the effect of its individual component i.e. ethanol and butanol could be found in the literature. Luo et al. found that ethanol/gasoline blend could reduce PM emissions of GDI engine effectively [170]. It was observed that the soot activity was enhanced, and particle number concentrations were successfully decreased. Furthermore, a study by Graves et al. [171] found that particle number concentration reduced with the increase of ethanol fraction. By using $20 \%$ ethanol, Peña et al. [172] found reductions in the rate of soot production, the sizes of polycyclic aromatic hydrocarbons and primary particles in soot, and its aromatic character resulting in higher soot oxidative reactivity.

Similar to the combustion of other oxygenated fuels such as ethanol, butanol could decrease the particulate production due to the involvement of the oxygenated compound in the particulate formation. Russo et al. [173] found that a substantial reduction of the soot particles' total amount and size were achieved using butanol isomers. Of four isomers, t-butanol was found as the most effective to reduce particle formation. Furthermore, Hergueta et al. [174] investigated 33\% of butanol containing $5 \%$ of ethanol (B33) in a gasoline engine. It was found that the gaseous and particle emissions were successfully decreased with primary particle diameter being unaffected. Yu et al. [175] also reported reductions of gaseous emissions using $\mathrm{n}$-butanol/gasoline blends in $\mathrm{Sl}$ engine. $\mathrm{N}$-butanol could decrease the accumulation mode of particle number, while at the same time increasing its nucleation mode. The lowest total particle number was achieved under a rich mixture with $20 \% \mathrm{n}$ butanol.

Despite lacking some fundamental studies, the use of $A B E$ is expected to lower the particle production in gasoline engine due to its oxygen content. Generally, the presence of oxygen atoms in $A B E$ is expected to alter the oxidation pathway by enhancing carbon oxidation to the growth pathways, thus forming high molecular mass compounds $[176,177]$. However, it is important to note that fuels with comparable oxygen content may affect particle production differently such as found in diesel engine $[178,179]$. This is because other factors may affect fuels' properties such as the oxygenated functional groups.

\section{ABE addition in diesel engine}

Table 3 summarises several novelties of recent studies using ABE-diesel blends in $\mathrm{Cl}$ engine. Important findings are highlighted, and detail discussions are presented in this section.

\subsection{Performance}

\subsubsection{Power and torque}

Engine power represents the amount of work produced by the engine per unit time, while torque measures rotational work by the piston on the engine crankshaft. ABE may reduce both the engine power and torque due to their lower LHV compared to diesel fuel. Lee et al. [180] found that the use of $\mathrm{ABE}(3: 6: 1)$ in $\mathrm{Cl}$ engine was found to reduce engine power by $5 \%$ at $1200 \mathrm{rpm}$ as shown in Fig. 7 . 
When the acetone content was increased, and the butanol was decreased from a typical ratio of 3:6:1 to $6: 3: 1$, the $A B E(6: 3: 1)$ reduced the engine power even further up to $8 \%$. According to table 1 , the heating value of $A B E(3: 6: 1)$ is not much different from $A B E(6: 3: 1)$, but boiling point of $A B E(6: 3: 1)$ is far higher than $A B E(3: 6: 1)$ due to increased acetone and reduced butanol content. Therefore, the reason $A B E$ (6:3:1) gave lower power was not only caused by its lower heating value (3.3\% lower) but it was also caused by its far lower boiling point (19.1\% lower). The lower boiling point may lead to faster evaporation and better fuel efficiency $[105,181]$, but it may also result in less penetration, thus reducing the power output. It is important note that the extra oxygen of ABE may improve combustion at higher speeds and offset the power loss caused by its lower heating value and boiling points.

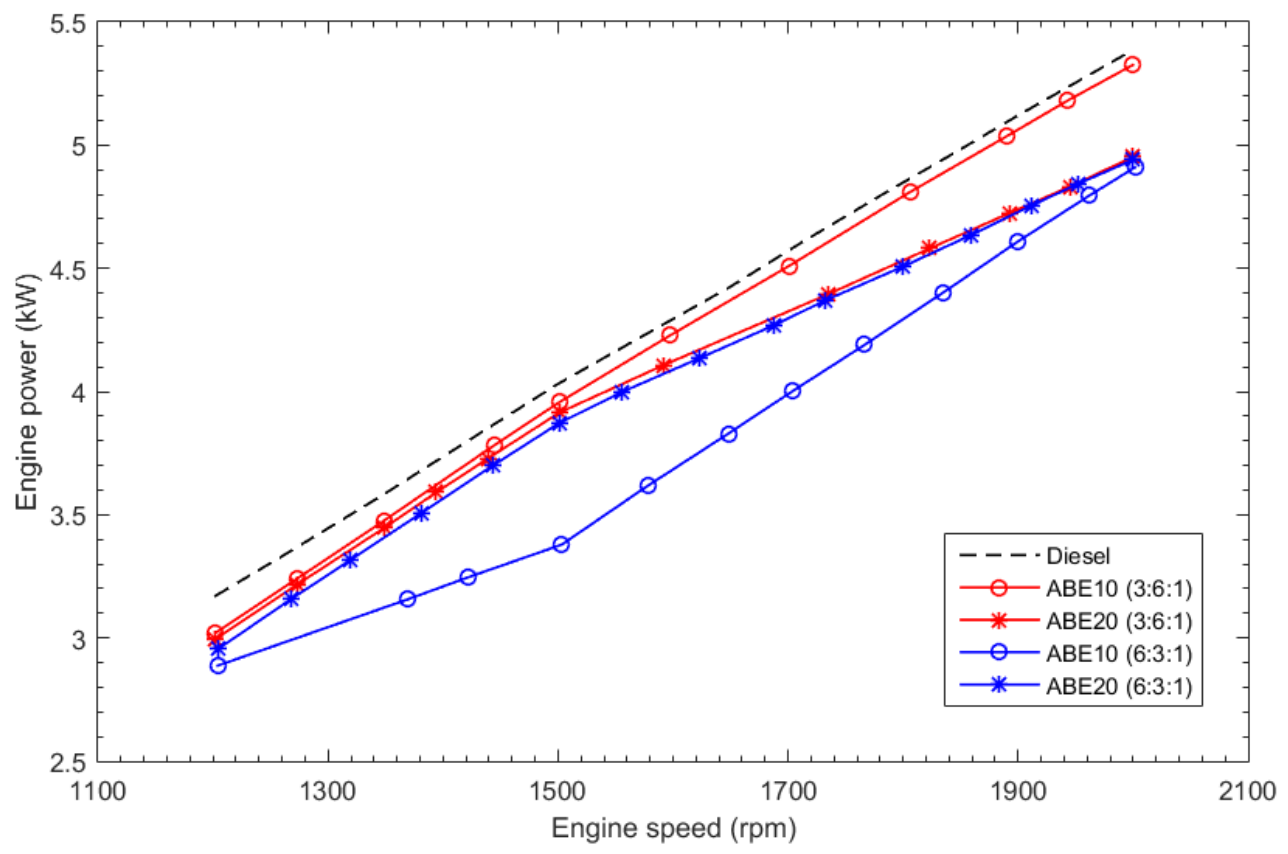

Fig. 7. Engine power of different $A B E$ volumetric ratio at various engine speed, reproduced from [180]

Algayyim et al. [107] compared the use of $n$-butanol and iso-butanol in butanol-acetone (BA) mixture. For $10 \%$ and $20 \%$ concentrations of $\mathrm{BA}$, the iso-BA and $\mathrm{n}-\mathrm{BA}$ reduced the brake power (BP) and torque at all engine speeds; 1400,2000 and $2600 \mathrm{rpm}$, except for iso-BA with $10 \%$ concentration at the medium speed where $4 \%$ increase was observed than those of diesel. In another study, the same author also found comparable results in which $20 \%$ and $30 \%$ BA mixtures gave lower BP and torque [106]. Only BA with $10 \%$ concentration increased the BP and torque. The torque increased slightly, while $\mathrm{BP}$ rose by $5 \%$ compared to that of diesel at all engine speed.

Reduction of engine power using ABE may be attributed to its lower LHV and boiling points, but other factors may also worsen such power loss. Lower cetane number of ABE for example. Low cetane number will prolong the ignition delay and achieve better fuel-air mixing with stronger premixed combustion. This may result in higher maximum in-cylinder pressure [182], but the mean effective pressure is expected to decrease, thus reducing the overall engine power and torque. Furthermore, lower viscosities of ABE may result in more leakage in the injector where fuel delivery may be affected and decrease the power output [183-186]. More results are required in terms of engine power or torque, but only a few studies reported these two parameters using ABE blends. This is because when 
the injection is based on the equal-mass instead of equal-energy, the engine performance is given in efficiency for better comparison. 
Table 4. Contributions and main findings of recent studies using ABE-diesel blends

\begin{tabular}{|c|c|c|c|c|}
\hline Operating Conditions & ABE\% & Contribution and novelty & Main Findings & Refs. \\
\hline $\begin{array}{l}\text { Direct Injection } \mathrm{Cl} \text { engine, } \\
\text { (1) Generator } 1.6 \text { \& } 3.2 \mathrm{~kW} \text {, } \\
\text { (2) Dynamometer: } 1500 \& 1800 \mathrm{rpm} \text {, } \\
40 \& 80 \mathrm{Nm}\end{array}$ & $\begin{array}{l}\text { ABE10 }(5: 14: 1) \\
\text { ABE20, ABE30 } \\
\text { ABE10W0.5, } \\
\text { ABE20W0.5, } \\
\text { ABE30W0.5 } \\
\text { ABE20W1, } \\
\text { ABE30W1 }\end{array}$ & $\begin{array}{l}\text { The first to investigate water- } \\
\text { containing } \mathrm{ABE} \text {-diesel blends } \\
\text { in } \mathrm{Cl} \text { engine }\end{array}$ & $\begin{array}{l}\text { > Clear stable phase of ABE with } 0.5-1.0 \% \text { water addition } \\
>\text { ABE20W0.5 shows superior results: } \\
\quad \uparrow \text { BTE by } 3.26-8.56 \% \\
\downarrow \text { PM by } 5.82-61.6 \% \\
\downarrow \text { NOx } 3.69-16.4 \% \\
\downarrow \text { PAHs by } 0.699-31.1 \% \\
\downarrow \text { BaPeq by } 2.58-40.2 \%\end{array}$ & [103] \\
\hline
\end{tabular}

Constant volume chamber

Ambient temperature: $900 \& 1100 \mathrm{~K}$

Ambient oxygen concentration: $21 \%$
ABE20 (6:3:1), ABE20 (3:6:1), ABE20 (0:10:0)
Exploring the optimal $A B E$ ratio by changing its volumetric ratio
$>$ Ignition delay and the combustion duration are $\downarrow$ with $\uparrow$ acetone content

$>$ ABE20 (6:3:1) has the shortest combustion duration, may $\uparrow$ fuel efficiency in real $\mathrm{Cl}$ engine

$>$ ABE20 (6:3:1) has the same ignition delay and premixed combustion with diesel

$>$ At $900 \mathrm{~K}$, soot is $\downarrow$ due to $\uparrow$ soot lift-off length (SLoL) and $\uparrow$ ignition delay for all the tested fuels

$>$ At $900 \mathrm{~K}$, max combustion pressure is $\uparrow$, may $\uparrow$ ITE $>$ Natural luminosity is $\downarrow$ for ABE20 (3:6:1) and ABE20 $(6: 3: 1)$

Biodiesel25

B50, B75

ABE25B25

(5:14:1),

ABE25B50,

ABE25B75
Investigating the mix of water- $>$ Water containing ABE lead to $\uparrow$ BSFC

containing ABE ( $2 \%$ water) $\quad>$ ABE-biodiesel-diesel blends result in $\uparrow$ BTE by 0.372

with biodiesel. 
Constant volume chamber

Ambient temperature: 800, 1000, \&

1200 K, Ambient oxygen: 11, 16 \& 21\%

Constant volume chamber

Ambient temperature: 700, 800, 900

$1000,1100 \& 1200 \mathrm{~K}$, Ambient oxygen:

$11,16 \& 21 \%$

Constant volume chamber

Ambient temperature: $800 \mathrm{~K}$

Ambient oxygen: 11, 16 \& 21\%
ABE100 (3:6:1), Investigating the spray and B100 combustion of pure ABE in both conventional and low temperature combustion (LTC) with various oxygen concentration to represent the variations of EGR

ABE20 (3:6:1) Investigating LTC of the spray and combustion of ABE-diesel blends

ABE20 (6:3:1), ABE20 (3:6:1), ABE20 (0:10:0)
Examining the effect of acetone in ABE blends by changing the volumetric ratio from typical fermentation ratio of $3: 6: 1$ to $6: 3: 1$ and $0: 10: 0$ in LTC
$>$ ABE100 shows:

$\uparrow$ flame lift-off length

$\downarrow$ liquid penetration

$\downarrow$ local equivalence ratio

$\downarrow$ flame luminosity

$\downarrow$ combustion duration with $\downarrow$ ambient temperature because of stronger premixed combustion

$\uparrow$ combustion duration with $\downarrow$ ambient oxygen as a result of a dilution effect retarded combustion phasing like butanol under LTC with $\uparrow$ EGR

$>$ Under all test conditions, ABE20 shows longer ignition delay and soot lift-oft length compared to diesel

$>$ At low ambient temperature of $800 \mathrm{~K}$ and ambient oxygen of $11 \%$, ABE20 shows flameless combustion with almost zero soot luminosity

$>$ The multi-component of ABE blends with different volatilities produce micro-explosion that lead to better atomization and air-fuel mixing, thus achieving improved combustion efficiency

$>$ SOC retarded with decreasing ambient oxygen concentration for all fuels, but $\operatorname{ABE} 20(6: 3: 1)$ is similar to that of diesel

$>$ ABE20 (6:3:1) shows similar combustion to diesel with shorter ignition delay due to higher acetone content $>$ ABE20 (6:3:1) shows $\downarrow$ natural flame luminosity (soot formation) compared to diesel due to its $\downarrow$ combustion duration and stronger premixed combustion 
Various ambient temperatures (423$823 \mathrm{~K}$ ) under normal gravity and atmospheric pressure

Constant volume chamber

Ambient temperature: 800, 1000 \&

$1200 \mathrm{~K}$, Ambient oxygen: 11, 16 \& 21\%

Constant volume chamber

Ambient temperature: $1000 \mathrm{~K}$, Ambient

oxygen: $11,16 \& 21 \%$
ABE10 (3:6:1),

ABE20, ABE30

ABE20 (3:6:1),

ABE50, ABE80

Investigating the spray and combustion of ABE-diesel blends in both traditional and LTC with heavy EGR condition
ABE100 (3:6:1) Investigating a

phenomenological soot model for $A B E$ both experimentally and numerically
$>$ The droplet lifespan of ABE and diesel are $\downarrow$ with $\uparrow$ ambient temperature

$>$ ABE's droplet lifespan is $\downarrow$ than diesel with no bubble nucleation, but the difference is smaller at $\uparrow$ temperature

$>$ ABE droplets evaporate faster than diesel but vary with ambient temperature; two-phase at $\downarrow$ temperature and three-phase at $\uparrow$ temperature $>$ ABE droplets show bubble formation and rupture at $\uparrow$ temperature with strong puffing being observed at $823 \mathrm{~K}$

$>$ Spray characteristics are influenced by competing factors between volatility and latent heat with $\mathrm{ABE} 20=$ diesel and $A B E 50=A B E 80$. Therefore, critical ratio occurs between $A B E 20$ and $A B E 50$

$>$ Except for ABE50, ignition delay $\uparrow$ with $\downarrow$ ambient temperature, $\downarrow$ oxygen concentration, and $\uparrow \mathrm{ABE} \%$ $>$ Combustion characteristics ABE50 = diesel with the shortest combustion duration of all blends --> may lead to $\uparrow$ ITE

$>$ Soot (natural flame luminosity) $\downarrow$ with $\uparrow$ ABE\%

$>$ Ignition delay retarded and temperature become more homogeneous with $\downarrow$ ambient oxygen

$>$ Compared to $21 \%$ ambient oxygen, the $16 \%$ gives $\uparrow$ total soot mass due to the $\downarrow$ soot oxidation --> $\uparrow$ soot $>$ At $11 \%$ ambient oxygen, both soot formation and oxidation are $\downarrow$, with more $\downarrow$ for the soot formation --> $\downarrow$ soot 
Direct Injection $\mathrm{Cl}$ engine,

Speed: 1200, 1500, 2000 rpm,

Load: 15, 20, $25 \mathrm{mg}$ fuel/cycle

Equivalence ratio: $0.323,0.431,0.539$

Injection timing $8,4,0,-4{ }^{\circ} \mathrm{CA}$ BTDC

Fuel rail pressure: 600 bar

Constant volume chamber

Ambient temperature: $800 \mathrm{~K}$

Simulation with KIVA-3V Release 2 code

Direct Injection $\mathrm{Cl}$ engine,

Speed: $1200,1500 \& 2000 \mathrm{rpm}$,

Load: 15, 20 \& $25 \mathrm{mg}$ fuel/cycle

Equivalence ratio: $0.323,0.431 \& 0.539$

Injection timing $8,4,0,-4{ }^{\circ} \mathrm{CA}$ BTDC

Fuel rail pressure: 600 bar

Constant volume chamber

Ambient temperature: $800 \& 1200 \mathrm{~K}$

Ambient oxygen: 16 \& 21\%
$\operatorname{ABE} 10(3: 6: 1)$

ABE20 (3:6:1)

Focusing on the $\mathrm{HC}$ emissions and on the improvement of efficiency with $A B E$ addition that has not yet reported in the previous paper

ABE20 (6:3:1), ABE20 (3:6:1), ABE20 (0:10:0)

$\operatorname{ABE} 10(3: 6: 1)$ ABE20 (3:6:1) ABE10 (6:3:1), ABE20 (6:3:1)

Investigating fundamental numerical methods and chemical kinetic mechanisms for ABE-diesel blends

The first to investigate $A B E$ with volumetric ratio of $6: 3: 1$ in $\mathrm{Cl}$ engine (not in volume constant chamber) and compare it with $A B E$ with a 3:6:1 ratio

ABE100 (3:6:1) The first to study the different soot formation between diese and $A B E$ using

phenomenological soot mode simulated by KIVA-3V Release 2 code
$>\mathrm{ABE}$ retard the start of auto-ignition

At premixed mode: $\downarrow$ combustion duration

At mixing-controlled mode: $\uparrow$ combustion duration $>$ ABE blends have $\uparrow$ thermal efficiency due to $\uparrow$ pressure rise rate during CA10-CA50 leading to a dominant premixed combustion

$>\mathrm{ABE}$ have $\downarrow$ polytrophic \& $\uparrow \mathrm{HC}$

$>\uparrow$ acetone content leads to advanced combustion phasing

$>\uparrow$ butanol content leads to retarded combustion phasing

$>\mathrm{ABE}$ (6:3:1) have retarded combustion, $\uparrow$ ignition delay $\& \downarrow$ emissions compared to ABE (3:6:1)

$>$ Small amount of ABE (10\%) results in $\uparrow$ ITE by $12 \%$

$>$ ABE addition cause $\uparrow$ heat release during CA10-CA50 as a result of $\uparrow$ premixed combustion

$>$ NOx is $\downarrow$ with ABE addition and can be reduced even further by tuning the injection timing

$>$ ABE100 gives $\downarrow$ soot generation compared to diesel $>$ At $800 \mathrm{~K}$ and $21 \%$ oxygen concentration, soot mass peak of $A B E$ is $1 / 12$ of diesel's, but when oxygen concentration $\downarrow$ to $16 \%$, the soot mass peak $\uparrow$ by $25 \%$ 
Direct Injection $\mathrm{Cl}$ engine,

Speed: 1400, 2000 \& 2600 rpm,

Full loads diffusion flame

$47 \mathrm{~mm}$ filter assembly --> collect the soot particles

Direct Injection $\mathrm{Cl}$ engine, Speed: $1400,2000 \& 2600$ rpm,
(1) n-butanol: n-BA10,

n-BA20

(2) iso-butanol:

iso-BA10,

iso-BA20

ABE10 (3:6:1), ABE20, ABE30

Comparing the use of $n$ butanol and iso-butanol in BA (1:2.9) mixtures on the spray, combustion, performance and emission characteristics

Investigating the soot oxidation reactivity of $\mathrm{ABE}-$ diesel blends

BA10 (1:2.9), BA20, BA30
> Spray penetration: $\uparrow$ with n-BA and iso-BA $n-B A$ is slightly $\uparrow$ than iso- $B A$

$>$ BSFC: $\uparrow$ with increasing $\mathrm{n}-\mathrm{BA}$ and iso-BA

$>$ BP: iso-BA10 shows slight $\uparrow$ at low \& medium speeds $>$ In-cylinder pressure: iso-BA shows $\uparrow$ peak led to $\uparrow$ HRR

$>\mathrm{CO}: \downarrow$ with increasing $\mathrm{n}-\mathrm{BA}$ and iso-BA iso-BA has a lower NOx than n-BA

$>\mathrm{HC}: \mathrm{n}-\mathrm{BA}: \downarrow$ or the same with diesel iso-BA: $\uparrow$

$>\mathrm{EGT}: \downarrow$ with increasing $n-\mathrm{BA}$ and iso-BA

$>$ NOx: $\downarrow$ with increasing $n-B A$ and iso-BA $n-B A$ has a lower NOx than iso-BA

With increasing $A B E$ concentration, the size of primary particles $\downarrow$, nanocrystallites length $\downarrow$, and amount of aromatic $\mathrm{C}=\mathrm{C}$ functional groups in the soot $\downarrow$, while nanocrystallites tortuosity $\uparrow$, amount of oxygenated functional groups $\uparrow$, and atomic $\mathrm{O} / \mathrm{C}$ and $\mathrm{H} / \mathrm{C}$ ratios $\uparrow$

$>$ Advanced combustion phasing with increasing BA content

> BP: BA10 --> 个 5\% than diesel

BA20 --> no change

BA20 --> no change

$>$ BTE: BA10 --> no change

BA20 --> $6 \%$ than diesel

BA20 --> $18 \%$

$>\mathrm{CO}: \downarrow 64.5 \%$ (maximum)

$>\mathrm{HC}: \uparrow 37.3 \%$ (maximum)

$>$ NOx: $\downarrow 10 \%$ (maximum)

$>\mathrm{EGT}: \downarrow 15.6 \%$ (maximum) 


\subsubsection{Thermal efficiency}

The improvement in thermal efficiency may be attributed to the factors that help the completeness of the combustion, shorten the combustion process and improve combustion efficiency. Changing the operating condition will also affect the characteristics of engine thermal efficiency. The thermal efficiency is expected to increase with increasing engine load due to the higher gas temperature inside the cylinder, thus increasing its combustion and thermal efficiency. This is because more fuel is burned and combusted at high engine loads; thus a higher in-cylinder gas temperature is observed.

Slight increase in thermal efficiency can be achieved with a small amount of $A B E$ addition to diesel fuel due to $A B E$ 's oxygen content and low boiling points. Extra oxygen of $A B E$ is expected to lower its equivalence ratio, while the low boiling points will enhance its spray characteristics, thus more complete combustion can be achieved in the fuel-rich zone. As a result, engine thermal efficiency will improve. Lee et al. [180] found that with ABE10 (3:6:1), the indicated thermal efficiency (ITE) increased by 4-6\% than diesel as shown in Fig. 8. The ITE increased even further up to $7 \%$ higher when ABE ratio was increased to $20 \%$. Its nearly similar engine power compared to diesel fuel as discussed in 4.1.1 may also explain the increase in thermal efficiency from the addition of $A B E$ blends. That $A B E$ with its lower heating value can achieve engine power comparable to diesel fuel indicates that there is some improvement in its thermal efficiency. However, by changing the volumetric ratio of $A B E$ from a typical of 3:6:1 to 6:3:1, the ITE was found to reduce. The authors believed that the longer ignition delay of $A B E(6: 3: 1)$ resulted in a retarded start of combustion. As a result, the SOC extended into expansion stroke and the combustion did not burn to completion, thus reducing ITE.
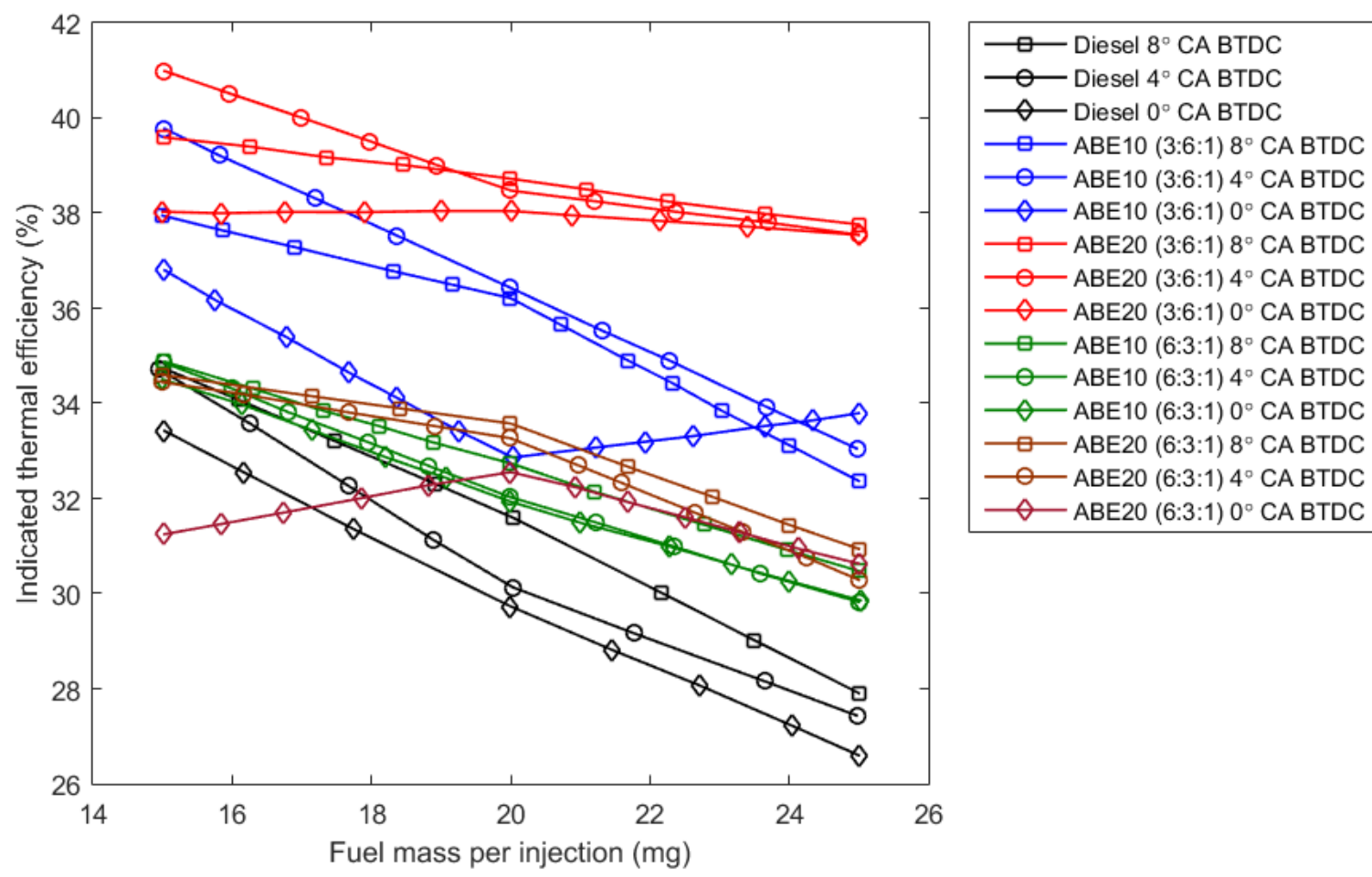

Fig. 8. ITE of different ABE volumetric ratio, reproduced from [180] 
The use of water containing $A B E$ can be considered as a favourable approach as it will remove the dehydration process and eliminate the need to add surfactant $[103,187,190]$. Chang [103] found that the addition of $20 \%$ ABE with $0.5 \%$ water increased higher BTE compared to diesel fuel when running both on engine dynamometer and generator. At dynamometer load of 40 and $80 \mathrm{Nm}$, the BTE of ABE20W0.5 increased by $3.26-4.52 \%$ and $13.0-14.7 \%$, respectively. However, when it was operated on engine generator, while the ABE20W0.5 and ABE30W0.5 were found to increase the BTE, the ABE10W0.5 decreased it. Also, when the water concentration was further increased up to $1 \%$, the ABE2OW1 and ABE30W1 gave significant reductions of BTE. The inhomogeneity of the fuel from $1 \%$ water addition resulted in a cooling effect and misfiring that caused the unstable condition of the mixtures and incomplete combustion. Based on the fuel stability results conducted in this study, ABE10W0.5 was at the edge between stable and unstable condition.

Only few studies were found investigating ABE with biodiesel addition. Biodiesel is considered a promising biofuel, but its high viscosity may deteriorate engine thermal efficiency [196]. The kinematic viscosity of biodiesel at $40^{\circ} \mathrm{C}$ is $4.41 \mathrm{~mm}^{2} / \mathrm{s}$, compared to $2.63,0.35,2.22$ and $1.08 \mathrm{~mm}^{2} / \mathrm{s}$ for diesel, acetone, butanol, and ethanol, respectively [187]. An et al. [197] have reported the decrease of BTE with biodiesel at low load conditions. They believed that the high viscosity of biodiesel caused poor combustion resulted from less efficient atomization and as a result, decreased BTE was observed. However, the BTE of biodiesel blends may be improved with the addition of ABE due to its extra oxygen content. Chang et al. [187] mixed $A B E$ containing $2 \%$ of water with biodiesel in the diesel engine. At various loads and engine speeds, biodiesel addition of 25,50 and $75 \%$ increased the BTE by $0.372-2.74,3.54-7.88$, and $2.44-4.96 \%$, respectively. These results indicate that the extra oxygen content of the $A B E$ and its low viscosity were found to outweigh the negative effect of biodiesel addition.

As for the BA mixtures, the BA-diesel blends gave higher BTE compared to diesel fuel. Algayyim et al. [107] found that the increase BTE of BA with $n$-butanol was higher than BA with iso-butanol. Higher cetane number and density of $n$-butanol than those of iso-butanol were believed as the reasons. The cetane number of $n$-butanol is 25 [198] compared to $<15$ of iso-butanol [119], while the density of $n$-butanol is 0.810 compared to $0.802 \mathrm{~kg} / \mathrm{m}^{3}$ of iso-butanol [4]. Higher cetane number of $\mathrm{n}$-butanol may decrease the BTE due to deteriorated air/fuel mixing as a result of shorter ignition delay. However, it is important to note that the lower cetane number may also decrease the BTE. The longer ignition delay of iso-butanol caused by its low cetane number may result in the retarded start of combustion. This would extend the SOC into expansion stroke, and the combustion would not burn to completion, thus reducing BTE. In another study by the same authors using BA mixture with n-butanol [106], the BA20 and BA30 increased the BTE by $6 \%$ and $8 \%$, while BA10 show similar results with diesel fuel. This time, the authors believed that lower cetane number as the reason higher BTE was observed with BA-diesel blends. Lower cetane number caused longer ignition delay; thus more fuel was burned in the premixed combustion mode, leading to shorter combustion and higher BTE.

The combustion characteristic can provide valuable information regarding engine thermal efficiency. Wu et al. [108] reported that $A B E 50$ had the shortest combustion duration and better thermal efficiency compared to $A B E 20$ and $A B E 80$ due to its similar combustion characteristics with diesel fuel. The microexplosion may answer why ABE50 had more similar combustion characteristics to diesel as Shen et al. [199] reported that the micro-explosions would be more likely to occur when the blends consist of a $50 \%$ high and low boiling point. Therefore, the shorter combustion of ABE50 and better thermal efficiency was observed in [108]. 
In general, the thermal efficiency of ABE blends is expected to increase due to three significant reasons. The first reason is due to more complete combustion resulted from its oxygen content and low boiling points of each $A B E$ components. Extra oxygen will lower its equivalence ratio, while the low boiling points will improve its spray quality, thus more complete combustion can be achieved. As a result, the combustion efficiency will improve and so will the thermal efficiency. The second reason is caused by its strong premixed combustions due to a longer ignition delay resulted from ABE's low cetane number. Such a lower cetane number is expected to prolong the ignition delay and improve the air/fuel mixing and allowing rapid energy release. Therefore, combustion efficiency will increase. The third reason is due to micro-explosions that can accelerate the combustion rate of $A B E$ blends. $A s A B E$ is a multi-component fuel, the different boiling point between each fuel components triggers micro-explosions. Furthermore, higher thermal efficiency may also be caused by the reduction in heat losses. This is because of the cooling effect resulted from ABE's high latent heat, thus reducing the flame temperature. However, the effect of the charge cooling effect may deteriorate the combustion characteristics of the ABE blends and decrease the engine thermal efficiency. The lower heating value of each $A B E$ components compared to diesel may also lower the thermal efficiency. As the ABE concentration increases, the effects from its high latent heat and lower heating value will be more significant.

\subsubsection{Fuel consumption}

Most results have agreed that the addition of $A B E$ will increase fuel consumption due to its lower calorific values. Chang et al. [103] investigated the BSFC of $A B E$ at two generator engine loads; 1.6 and $3.2 \mathrm{~kW}$. They found that the addition of 20 and $30 \%$ ABE increased the BSFC by $4.25-5.71 \%$ and $5.47-7.03 \%$, respectively. The BSFC was reported to increase with increasing $A B E$ concentration. This is because the heating value of the blend will decrease with more addition of $A B E$. However, when water was added into the $A B E$ and ran on a dynamometer engine, the fuel consumption was found to decrease. The BSFC of ABE20W0.5 reduced by $1.76-3.39 \%$ and $7.28-8.56 \%$ compared to diesel at an engine load of 40 and 80 $\mathrm{Nm}$, respectively. However, the effect of water containing ABE did not seem to give the same effect when blended with biodiesel. Chang et al. [187] reported that the use of $25 \%$ water containing ABE with 25,50 and $75 \%$ of biodiesel increased the BSFC by $9.52-13.2,12.8-15.1$ and $20.3-23.0 \%$, respectively. Similar results were shown with BA-diesel blends where the BSFC increased with the increasing BA ratio due to its reduced calorific values $[106,107]$. At higher engine loads, the fuel consumption is expected to improve; thus BSFC is more likely to decrease because of high in-cylinder gas temperature.

Overall, several factors may influence the BSFC of ABE. These include higher latent heat, lower heating values, cetane number, viscosity and molecular weight of $A B E$ components compared to diesel fuel. The higher latent of $A B E$ blends may deteriorate the combustion due to its cooling effect. Its lower heating value also means that more fuel is required to match the power output of using diesel fuel, while its lower cetane number indicates that longer ignition delay may cause incomplete combustion. As for ABE's lower viscosity and molecular weight, improved fuel atomization and high volatility are expected, respectively. The lower viscosity will reduce the droplet's Sauter Mean Diameter (SMD). Therefore, the droplets surface area will increase, thus affecting the evaporation time [200, 201].

\subsection{Spray and combustion \\ 4.2.1 Spray}

$A B E$ may improve the spray characteristics of the $A B E$-diesel blends. The spray is predicted to become shorter and narrower as the $A B E$ ratio increases, caused by the high volatility of the ABE components. The 
properties of $A B E$ as shown in Table 1 show that each component ABE has a higher saturation pressure, lower boiling point and lower viscosity compared to diesel fuel. The saturated vapour of acetone is far higher, $52.5 \mathrm{kPa}$ compared to merely $1.9 \mathrm{kPa}$ of diesel. As the ABE ratio increases, the difference in those values becomes more significant. As a result, the overall volatility increases and its evaporation rate will be faster than diesel fuel. As a result, the size of the ABE spray becomes shorter and narrower. Several studies have confirmed this finding, but some reported that this effect is not linear with the increase of ABE.

Wu et al. [108] used ABE-diesel blends from ABE20, ABE50, ABE80 in a constant volume chamber and compared the results with pure diesel. They found that the $A B E 50$ offered better spray characteristics (shorter and narrower) compared to ABE20. The improvement in spray quality of ABE50 than the ABE20 was believed due to enhanced fuel droplet evaporation rate and spray atomization with the increase $A B E$ ratio, resulted from its higher volatility characteristics as mentioned in the previous paragraph. However, when the ratio of $A B E$ was further increased up to $80 \%$, the spray of $A B E 80$ exhibited a similar characteristic with $A B E 50$. One of the reason might be attributed to the high latent heat of $A B E$ component. As shown in Table 1, each ABE component has a far higher latent heating value (Acetone$518 \mathrm{~kJ} / \mathrm{kg}$, Butanol-582 kJ/kg, Ethanol-904 kJ/kg) compared to diesel fuel whose value is just $270 \mathrm{~kJ} / \mathrm{kg}$. It is known that high latent heating value will result in a cooling effect inside the combustion chamber. Increasing $A B E$ ratio to a high ratio will reduce the local temperature and decrease the evaporation rate, thus deteriorating spray qualities. Therefore, the factors that improve the spray quality (higher volatility) are competing with the factors that deteriorate it (higher latent heat). This finding showed that there seems a critical ratio of $A B E$ concentration between $20 \%$ and $50 \%$. Less than $20 \%$ of $A B E$ did not significantly improve its spray characteristics, while more than $50 \%$ ABE did not further improve its spray characteristics.

The spray is the evaporation of large droplets and considering the difficulty to examine the evaporation of $A B E$ droplets in a spray, investigating its single droplet is considered a more realistic approach. Ma et al. [190] examined the droplet evaporation of ABE-diesel fuel in a non-combusting droplet chamber at ambient temperatures ranging from 423 to $823 \mathrm{~K}$. The results showed that adding $A B E$ could increase the evaporation speed of droplet, thus decreasing its lifespan. The ABE-diesel blends droplets evaporate faster than diesel but vary with temperature. With increasing ambient temperature, the droplet lifespan of $A B E$ and diesel were decreasing, and smaller different was observed at a higher temperature. At $623 \mathrm{~K}$, the normalised square droplet diameter of $A B E$-diesel blends gave comparable results with diesel fuel, and at 823 , various $A B E$-diesel blends also had similar droplet lifespan with diesel fuel. This study did not observe the micro-explosions with the addition of ABE-diesel blends. This is in contrast with the finding found in [109] where micro-explosion was reported with the addition of multi-components fuel such as ABE. However, the addition of water may be the reason for such micro-explosion due to water-in-oil droplets phenomena in the combustion chamber [103].

\subsubsection{Combustion}

The lower cetane number and higher latent evaporation of $A B E$ are expected to retard the start of combustion due to a longer ignition delay and charge cooling effect. As a result, more fuel is burned at the premixed stage, and higher maximum pressure is expected to occur. Also, the lower density and viscosity of $A B E$ could enhance the spray characteristics and improve the mixing process of air and fuel. Consequently, the maximum pressure and premixed heat release rate will increase. Lin et al. [192] found that the start of auto-ignition was retarded with shorter premixed combustion duration and longer 
mixing-controlled duration being observed. $A B E-d i e s e l$ blends had higher pressure rise rate during CA10CA50 compared to diesel, showing more premixed-dominant combustion [180]. This is because higher oxygen content in the spray is known to decrease the pyrolysis and increase the oxidation, thereby reducing the combustion duration at premixed mode. However, the increase in pressure rise rate may result in increased engine noise and vibration. Also, with faster premixed combustion rate, higher combustion temperature will increase the NOx emissions. While the premixed combustion duration was shortened, the mixing-controlled duration was longer. The duration of CA50-CA90 was higher at all speeds, showing a slower heat release rate in mixing-control combustion stage. This will cause higher combustion inefficiency leading to increased HC emissions. Under LTC conditions and high EGR, the retardation of combustion phasing was also observed, Wu et al. [188] reported a retarded combustion phasing with the use of neat ABE. However, at $800 \mathrm{~K}$ and ambient oxygen of $11 \%$, Zhou et al. [109] found that $A B E 20$ gave improved combustion efficiency than diesel fuel.

Due to its higher volatility, increasing the acetone content can be considered as a promising approach to overcome the ABE's retarded combustion phasing. This would enhance the vaporisation of the fuel mixture and shorten the ignition delay. $A B E$ component ratios could be controlled during the fermentation process, thus allowing the acetone content to be controlled. To get the optimized volumetric ratio for ABE-diesel blends, Wu et al. [104] investigated the various volumetric ratio of $A B E(6: 3: 1 ; 3: 6: 1 ; 0: 10: 0$, vol.\%) in a constant volume chamber. The results showed that an increased acetone percentage resulted in an advanced combustion phasing, while butanol would do the opposite. With higher acetone ratio, the ignition delay reduced and the combustion duration become shorter. Faster combustion duration is beneficial to increase the fuel efficiency of diesel engines. The ABE20 (6:3:1) had the shortest combustion duration of all tested fuels with the same ignition delay and premixed combustion with diesel fuel [104].

To understand the combustion characteristic of ABE-diesel blend, both the dynamic of spray and chemistry reaction needs investigating. Similar to their previous study [104], Wu et al. [189] changed the ratio of $A B E$ components ratios to investigate the effect of acetone and single components of $A B E$ in the blends. They focused on the effect of acetone and altered the ABE volumetric ratio from 3:6:1 to 6:3:1 and 0:10:0. The investigation was performed under LTC conditions with optical access. Heat release rate showed that $A B E(6: 3: 1)$ gave similar combustion characteristics to pure diesel but with a much shorter ignition delay than that of $A B E(3: 6: 1)$ and $A B E(0: 10: 0)$, resulted from its higher acetone content. High evaporability of acetone, as well as its low viscosity, accelerated the mixture formation. $A B E(6: 3: 1)$ gave the shortest combustion duration, whereas the $A B E(0: 10: 0)$ gave the longest. The start of combustion $(\mathrm{SOC})$ retarded and the peak heat release rate decreased with decreasing ambient oxygen concentration. The ABE (6:3:1) and diesel fuel gave comparable SOC and heat release rate curve, but both fuels were less influenced by the ambient oxygen concentration. $A B E$ with lower acetone ratio such as $A B E(3: 6: 1)$ and $A B E(0: 10: 0)$ were more affected by the effect of oxygen concentration.

Zhang et al. [193] constructed a semi-detailed chemical mechanism to model ABE-diesel spray combustion in a constant volume chamber. Results from the literature were used to validate the mechanism comprising $A B E$ and $n$-heptane as surrogate fuel species. KIVA-3V program combined with the validated mechanism was used to simulate the spray dynamic and combustion characteristics inside the chamber. The results of ignition delay, cylinder pressures and heat release rates from both the simulation in a shock tube and constant volume chamber showed reasonable agreements between the experimental and calculated. The proposed semi-detailed chemical mechanism in this study could maintain the kinetic 
behaviour of $A B E$-diesel blends. It was found that with the increasing of acetone percentage; the combustion phasing advanced significantly, while butanol would offset the advancing effect.

\subsection{Emission}

\subsubsection{CO emission}

$\mathrm{CO}$ emission is mainly formed as a result of incomplete combustion due to lack of oxygen. ABE may provide extra oxygen content to help the completeness of combustion, but Chang et al. [103] found that CO emissions increased with increasing $A B E$ concentration. For 0.5 and $1 \%$ water addition, $C O$ emissions skyrocketed by $34.1-117 \%$ and $64.2-197 \%$, respectively. ABE addition may achieve complete combustion resulted from its higher combustion efficiency from extra oxygen [202]. However, most of this oxygen reduced the gross heating value of the mixture. The combustion temperature will decrease and retard the oxidation reaction, thus increasing $\mathrm{CO}$ emissions. While the study by Chang et al. reported an increase of CO emissions, Algayyim et al. [106] found a significant decrease of CO emission with BA10, BA20, and BA30 by $18.5-41 \%, 39.8-64.5 \%$, and $35.6-39.9 \%$, respectively, compared to diesel fuel. The higher oxygen content of BA mixtures was believed to promote the oxidation of $\mathrm{CO}$ and assist the completeness of the combustion, thus decreasing $\mathrm{CO}$ emissions. The same reason was also attributed to the decrease of $\mathrm{CO}$ emissions with the addition of iso-BA and n-BA conducted by the same authors in another study [107]. Higher $\mathrm{BA}$ ratio would reduce the $\mathrm{CO}$ emissions at all engine speeds. Iso-BA gave lower reduction compared to $\mathrm{n}-\mathrm{BA}$ with the addition of $20 \%$ of iso-BA achieving maximum reduction of $\mathrm{CO}$ emission by 35 $60 \%$ compared to regular diesel. The $\mathrm{CO}_{2}$ emission was also reported to be higher at medium and high engine speeds compared to diesel, resulted from the enhanced conversion of $\mathrm{CO}$ to $\mathrm{CO}_{2}$. However, at low speed, $\mathrm{CO}_{2}$ emissions were lower for both iso-BA and $\mathrm{n}$-BA compared to diesel due to their leaner mixture.

In general, the incomplete combustion takes place in locally rich conditions, have inadequate oxidizers and have low combustion temperatures [203]. Conventional diesel fuel, containing zero oxygen in their molecular structure, is therefore expected to produce $\mathrm{CO}$ emissions. The oxygen content of ABE blends could improve the combustion and assist its completeness. Furthermore, lower viscosity and density of $A B E$ will lead to better spray thus a faster and better combustion process could be achieved. As a result, the $\mathrm{CO}$ emissions will reduce where leaner combustion is expected to occur resulting from the partially oxidized nature of $A B E$ compared to diesel. This will lead to enough oxygen to allow a higher conversion of $\mathrm{CO}$ to $\mathrm{CO}_{2}$.

\subsubsection{HC emission}

$\mathrm{HC}$ emission is mainly caused by the engine configuration, fuel structure, combustion temperature, oxygen availability and residence time [204, 205]. Lin et al. [192] found that HC emissions increased with the addition of $A B E$. As the $A B E$ percentage from $10 \%$ to $20 \%$, the $\mathrm{HC}$ emissions increased even more. The authors believed that such an increase was caused by the charge cooling effect leading to combustion incompleteness resulting in retarded combustion phasing. The increased $\mathrm{HC}$ emissions can be an indication of combustion inefficiency. However, the increase was still at a relatively low level with the highest being around 64 ppm for ABE20 at low engine speed. Chang et al. [103] also reported an increase when using $20 \% \mathrm{ABE}$ that contained $0.5 \%$ water. The increase was believed to be caused by a higher latent heat value and a lower cetane number of ABE20W0.5 that led to higher HC emissions [150, 206]. However, 
despite the increase with $\mathrm{ABE}$ addition, the $\mathrm{HC}$ emissions were still at a low level and can be eliminated using conventional catalytic converters.

Compared to diesel fuel, Algayyim et al. [106] found that the BA10, BA20, and BA30 increased HC emissions by $8-16.3 \%, 11.4-37.3 \%$, and $3-12 \%$, respectively at 1400 and $2600 \mathrm{rpm}$. The lower cetane number of BA was responsible for the longer ignition delay, thus allowing more time for the blends to evaporate. However, the higher latent heat caused slower evaporation that resulted in less time available to complete the reaction. Algayyim et al. also found the same trends with $\mathrm{BA}$ addition using $\mathrm{n}$-butanol and iso-butanol [107]. While the iso-BA increased the $\mathrm{HC}$ emission, the $\mathrm{n}$-BA gave comparable or fewer $\mathrm{HC}$ emissions compared to diesel. This is an interesting finding as the latent heat of n-butanol $(582 \mathrm{~kJ} / \mathrm{kg})$ is higher than iso-butanol $(566 \mathrm{~kJ} / \mathrm{kg})$. Therefore, the addition of $\mathrm{n}-\mathrm{BA}$ was supposed to result in a more cooling effect that will slow the evaporation process and increase the $\mathrm{HC}$ emission. There are several possible reasons for the $\mathrm{HC}$ emission reduction with n-BA despite its higher latent heat of vaporisation. The higher cetane number of $n$-butanol could be one potential reason for its lower HC emission. Also, the viscosity of $n$-butanol $\left(2.22 \mathrm{~mm}^{2} / \mathrm{s}\right)$ is lower than iso-butanol $\left(2.63 \mathrm{~mm}^{2} / \mathrm{s}\right)[4,46,198]$. This led to a longer and deeper spray penetration resulting in relatively smaller droplets and more contact surface compared to iso-butanol. As a result, improved air-fuel mixing and higher overall reaction rate were achieved for $n$ BA. However, the authors believed that it was the different molecular chain structure between $n$-butanol and iso-butanol that influenced the $\mathrm{HC}$ emissions. $\mathrm{N}$-butanol is a straight chain isomer with the most inner $\mathrm{C}-\mathrm{H}$ bonds, while iso-butanol is a branched isomer with the most terminal $\mathrm{C}-\mathrm{H}$ bonds $[119,207]$. The reaction rate is influenced by the $\mathrm{C}-\mathrm{H}$ bond as different bonds need different energy to crack the bonds [208]. Inner C-H bonds have less energy than terminal bonds [209]. Also, the H-abstraction reaction is higher for a less bond energy leading to a higher overall reaction rate $[208,209]$. Therefore, the reaction rate of $\mathrm{n}-\mathrm{BA}$ is higher with enough time to complete the reaction, thus decreasing the overall $\mathrm{HC}$ emission.

Overall, higher latent heat of $A B E$ is expected to lower the combustion temperature, thus lowering the chemical reaction and making it difficult for the fuel to react with the oxygen. However, the change in operating conditions may also affect the HC emissions. At high speeds, the fast combustion with its high temperature characteristics will improve the combustion process so that the reduction in $\mathrm{HC}$ emissions may be observed.

\subsubsection{NOx emission}

The NOx formation is mainly affected by the combustion temperature, local oxygen concentration and residence time in the high temperature zone [210]. Lin et al. [192] reported higher NO emissions with ABE addition. They believed that the higher volatility or lower boiling points of $A B E$ components resulted in premixed-dominant combustion that led to faster combustion rate and higher combustion temperature. As a result, higher NOx emission was reported despite better oxidation resulted from extra oxygen of $A B E$ where reduced local equivalence ratio was observed at the flame front area. Higher NOx emissions when using $A B E$ was also reported by Lee et al. [180]. However, with retarded injection timing, NOx was successfully decreased. At $0^{\circ} \mathrm{CA} B T D C$, the $\mathrm{ABE}$ blends had higher NOx than diesel, but from $4^{\circ} \mathrm{CA}$ and $8^{\circ} \mathrm{CA}$, a significant reduction of NOx emissions started to occur. Findings from this study show that by tuning the injection timing, fewer NOx emissions can be achieved.

Besides tuning the injection timing, using water-containing $A B E$ is also considered as an effective way to reduce NOx emissions. The actual ABE fermentation product contains a small amount of water [187]. 
Despite its water content, a study conducted by Chang et al. [103] showed that a stable fuel blend using ABE was achieved without separation. ABE20W0.5 was found to reduce NOx emissions by $3.69-16.4 \%$. Three factors were attributed to the NOx reductions; (1) micro explosion resulted from the water-in-oil droplets, (2) extra oxygen content of ABE and (3) evaporative cooling effect. In another study by the same author, water-containing ABE-diesel blends were also investigated and mixed with biodiesel.

Even though biodiesel has a higher NOx emission, but the addition of $25 \%$ water containing ABE showed a significant NOx reduction [187]. It is worth discussing here that the increase in NOx emissions of biodiesel may not solely be caused by its higher thermal NOx resulted from longer ignition delay due to its low cetane number [211]. This is because the ignition timing of biodiesel was found to be similar to the diesel fuel and its in-cylinder temperature was only marginally higher. This finding shows that other NOx mechanisms increased its overall NOx emissions other than thermal NOx. Prompt NOx formation and $\mathrm{N}_{2} \mathrm{O}$ pathway were believed to be the reasons. Prompt NOx was enhanced since biodiesel produces more fuelderived radical compared to regular diesel [212], while the $\mathrm{N}_{2} \mathrm{O}$ pathway was enhanced for NOx formation as the experiment was conducted in lean condition with equivalence ratio lower than 0.4 [213]. However, since the addition of biodiesel increased the equivalence ratio, the thermal NOx may still contribute to the increase of overall NOx emissions. Therefore, several mechanisms were responsible for the increase in NOx emissions with biodiesel addition; thermal, prompt NOx, and $\mathrm{N}_{2} \mathrm{O}$. With the addition of $25 \%$ water containing ABE to biodiesel blends, Chang et al. [187] found that NOx emissions were reduced significantly by 15.6-22.7, 10.1-21.3 and 9.50-19.3\% with biodiesel addition of 25, 50 and $75 \%$, respectively. Given that $A B E$ is similar to biodiesel in terms of high oxygen content, low cetane number and more fuel-derived radical, higher NOx emissions were supposed to be observed. However, high latent heat and low heating value of $A B E$ caused significant evaporative cooling effect, thus reducing the combustion temperature [214]. Moreover, ABE-biodiesel's leaner combustion can reduce the thermal, intermediate and prompt NOx. Also, water-containing ABE was beneficial to decrease the NOx formation region, i.e. the resident time at high temperature. Therefore, these factors outweighed those that increased NOx. As a result, overall NOx reduction was achieved with the addition of water-containing ABE to biodiesel blends.

Since NOx emission is formed at high temperature combustion, it is essential to investigate the exhaust gas temperature (EGT). Compared to diesel at three engine speeds, Algayyim et al. [106] found that the EGT reduced by $2.1-3.5 \%, 3.4-7.3 \%$, and $4.6-15.6 \%$ for BA10, BA20, and BA30, respectively. This reduction was consistent with the reduction of NOx emission. The BA10, BA20, and BA30 gave similar decreases by $2.2-10 \%, 2.2-7.5 \%$ and $2.64-6.6 \%$, respectively. The EGT and NOx emission were decreasing with the increase of BA ratio. This is because the latent heat of $n$-butanol $(585 \mathrm{~kJ} / \mathrm{kg}$ ) is more than double compared to diesel $(250 \mathrm{~kJ} / \mathrm{kg}$ ) [203]. Furthermore, the ratio of butanol used in the BA mixture for this study was $75 \%$. Therefore, further reduction of EGT and NOx was expected with the increase BA ratio. In another study investigating BA mixture, the same trends were also reported. This time, Algayyim et al. [107] compared the use of $n$-butanol and iso-butanol for BA mixture. However, the $n$-BA gave lower EGT and NOx compared to iso-BA due to a higher latent heat of n-butanol. Moreover, n-butanol has a higher cetane number than iso-butanol, thus decreasing EGT and NOx emission even more [208, 215].

In general, the addition of $A B E$, the extra oxygen from each of $A B E$ components is expected to achieve complete combustion, increase the combustion temperature and increase the NOx emissions. The low cetane number of $A B E$ blends will also prolong the ignition delay; thus more fuel is burned at the premixed combustion stage. However, ABE's lower calorific value and higher latent heat may reduce the NOx emissions and balance the effects resulted from its extra oxygen content and low cetane number. 
Therefore, both factors are competing with each other, and the dominant one will determine the overall NOx emissions. If the effect of oxygen content and low cetane number outweigh the high latent heat of $A B E$, the temperature of the cylinder will be higher; thus more NOx emissions will be produced. Also, given that the temperature will increase with the increase in the engine loads and speeds, it is therefore expected that the NOx will increase at higher engine loads and speeds.

\subsubsection{Soot emission}

Soot is an important emission characteristic of a diesel engine. The natural flame luminosity is often used to quantify soot emissions. This is because both chemiluminescence and soot incandescence contribute to the natural luminosity, but the effect from soot incandescence is much significant to the luminosity than that of from chemiluminescence. Therefore, the soot is characterised by broadband luminosity. Although the oxygenated fuels tend to produce less soot emission than diesel, the soot formation mechanism of $A B E$ blends is still not comprehensively understood. However, most of the results found in the literature seem to agree that $\mathrm{ABE}$-diesel blends can reduce soot emissions.

Three factors play significant roles in the soot reduction of ABE-diesel blends. First, it may be contributed to the oxygen content in $\mathrm{ABE}$ blends that accelerate soot oxidation during combustion. Second, compared to diesel fuel, the physical properties of $A B E$ as shown in Table 1 show that each ABE component has a higher volatility (lower boiling point, higher saturated vapour, lower viscosity) and lower stoichiometric ratio, thus leading to leaner combustion and as a result, the diffusion combustion will be significantly reduced. Third, the combustion region may affect the soot emissions. If the flame takes place far from the injector tip, the fuel is more likely to mix with the ambient oxygen and reduce the local equivalence ratio.

The general trends show that natural flame luminosity decreases with the increase of ABE concentration. With the increase of $A B E$ ratio, Wu et al. [108] reported that natural flame luminosity was reduced. It was also found that with the addition of $80 \%$ ABE ratio, the initial flame was seen farther from the injector tip. The soot reduction was believed not only resulted from the oxygen content that accelerates the soot oxidation but also from the longer flame lift-off length (FLoL) which reduces the local equivalence ratio. Longer FLoL is thought to be from ABE's low cetane number. Table 1 shows that each ABE component has relatively a lower cetane number compared to diesel fuel. The FLoL itself is controlled by cetane number and represents the overall equivalence ratio. Lower cetane number tends to give longer FLoL and lower equivalence ratio [216]. Therefore, by adding fuel with a low cetane number, the equivalence ratio can be reduced, thus suppressing the soot formation. When the overall equivalence ratio was reduced to around two near the lift-off area, soot-free combustion would be achieved [217]. Hence, with the addition of $A B E$, the ignition delay is expected to be longer due to its low cetane number, and this will result in a longer flame lift-off length. It was also found that longer FLoL was observed with decreasing ambient oxygen concentration and temperature, resulting from longer ignition delay. As longer FLoL allows fuel droplet to mix with ambient air in an extended period and prominent space, soot emission was significantly reduced.

Similar results regarding the FLoL was reported by Wu et al. [188] when comparing $100 \%$ ABE and pure butanol to investigate the spray and combustion characteristics on an optical constant volume chamber. Although $A B E$ and butanol have similar characteristics on spray and combustion performance, $A B E$ provided better soot reduction with a longer FLoL and shorter liquid penetration. Longer FLoL and shorter liquid penetration led to a longer gap between the liquid spray and the flame, allowing more time and space for the fuel droplets to evaporate and mix with the ambient air, thus reducing the local equivalence 
ratio. As a result, reduced natural flame luminosity was observed for $A B E$. Another study investigating the soot formation process using $100 \%$ ABE was conducted by Fu et al. [194], focusing on the soot generation of $A B E$ and diesel. They found that $A B E$ has a lower tendency of generating soot than diesel fuel. Initial temperature and oxygen concentration have a negligible impact on their soot due to the fuel composition, molecular structure and physicochemical characteristics. However, ambient conditions affected the soot mass peak of ABE. At $800 \mathrm{~K}$ and $21 \%$ oxygen concentration, the soot mass peak was a $1 / 12$ of the diesel's, but it soared by $25 \%$ when the oxygen concentration was reduced to $16 \%$. Zhao et al. also found the same trends where the soot generation mass of $A B E$ increased with decreasing oxygen concentration [191]. At $16 \%$ oxygen concentration, high total soot mass was higher compared to that of $21 \%$ due to the inhibited soot oxidation. However, at $11 \%$ oxygen concentration, although both soot formation and oxidation were suppressed, the soot formation was inhibited more. As a result, soot reduction was achieved at a diluted oxygen condition.

By changing ambient oxygen concentration from $21 \%$ to $11 \%$, Zhou et al. [109] found that ABE20 offered lower soot emission with better combustion efficiency compared to the diesel at low ambient temperatures and low ambient oxygen concentrations. This study found that the ignition delays of ABE20 were longer than those of D100 (pure diesel) at low ambient temperatures with longer soot lift-off length, providing more air entrainment of the spray and achieving improved air-fuel mixing, thus lowering soot emissions. At a low ambient temperature of $800 \mathrm{~K}$ and ambient oxygen of $11 \%$, ABE20 showed flameless combustion with almost zero soot luminosity. Although previous studies have shown the potential of $A B E$ to reduce soot emissions, it is necessary to examine the variation in the soot oxidation reactivity of $A B E-$ diesel blends. A recent study by Luo et al. [195] has confirmed that the average soot activation energies of the ABE were lower than diesel. The soot particles of ABE blends were more prone to oxidize by oxygen.

Different acetone content and temperature combustion may affect soot emissions. Lower natural luminosity with $A B E$ addition was reported by Wu et al. [104] when examining the optimal ratio of $A B E$ by changing its volumetric ratio. It was found that both the Space Integrated Natural Luminosity (SINL) and Time Integrated Natural Luminosity (TINL) were lower for ABE20 (3:6:1) and ABE20 (6:3:1), but slightly higher for $A B E$ (0:10:0) (Fig. 9). This is because the extra oxygen from $A B E$ addition cause the equivalence ratio to decrease in the diffusion combustion area. The same results were also reported by $\mathrm{Wu}$ et al. in another study [189]. The ABE20 (6:3:1) was found to give far lower natural flame luminosity than diesel. Shorter combustion duration and stronger premixed combustion were believed to be the reasons. Furthermore, Wu et al. [104] found that ABE with higher acetone ratio, i.e. ABE20 (6:3:1) had narrow plateau SINL because of its short combustion duration. This is because the low viscosity, low boiling point and high vapour pressure of acetone led to better fuel atomization and air-fuel mixing. At low ambient temperature $(900 \mathrm{~K}), \mathrm{ABE}$ blends gave longer soot lift-off length (SLoL) compared to that of high temperature $(1100 \mathrm{~K})$ as shown in Fig. 10. This finding shows that using ABE mixture on LTC can be an effective way to reduce its soot emission. However, Luo et al. [218] found that acetone could deteriorate sooting tendency due to its unsaturation degree, while butanol and ethanol may have a positive effect to reduce soot emissions due to their higher $\mathrm{H} / \mathrm{C}$ ratio and oxygen content. 


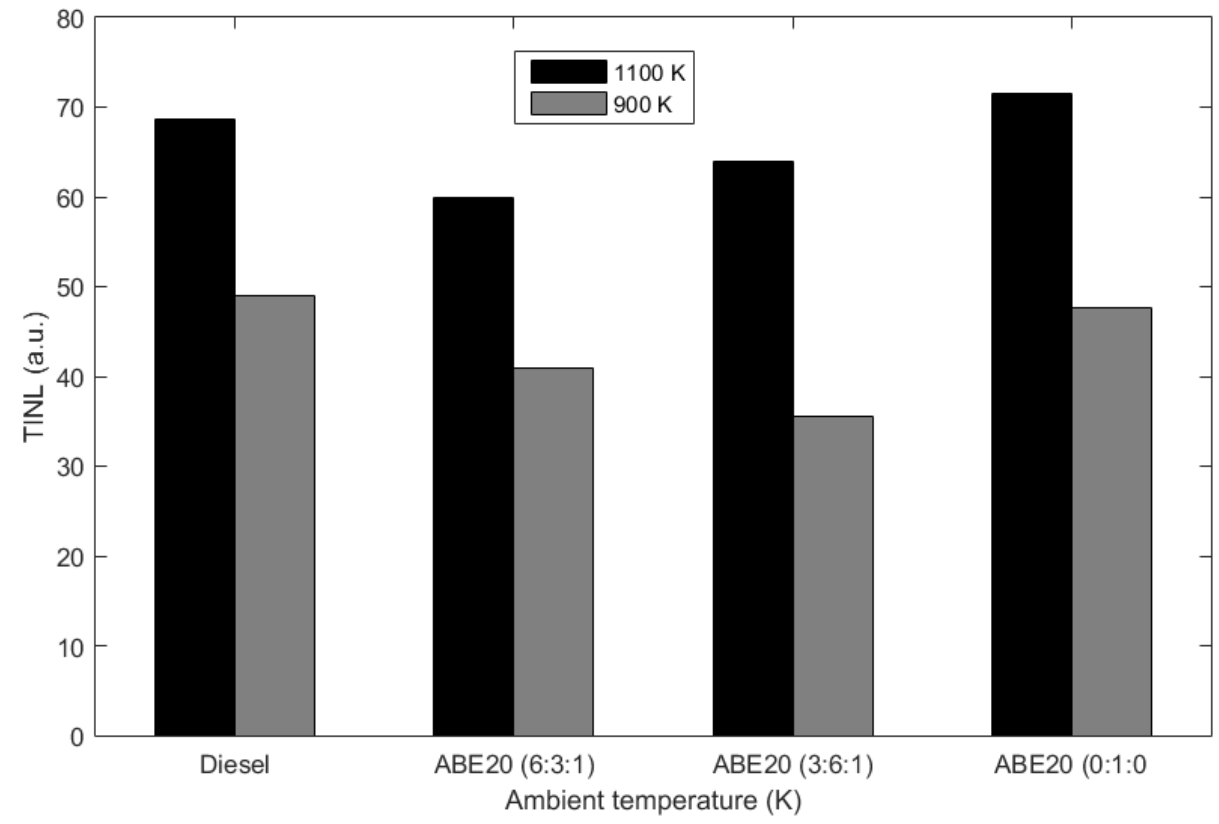

Fig. 9. Time integrated natural luminosity of three $A B E$ with different volumetric ratios compared to diesel fuel at two ambient temperatures, reproduced from [104]

(a)

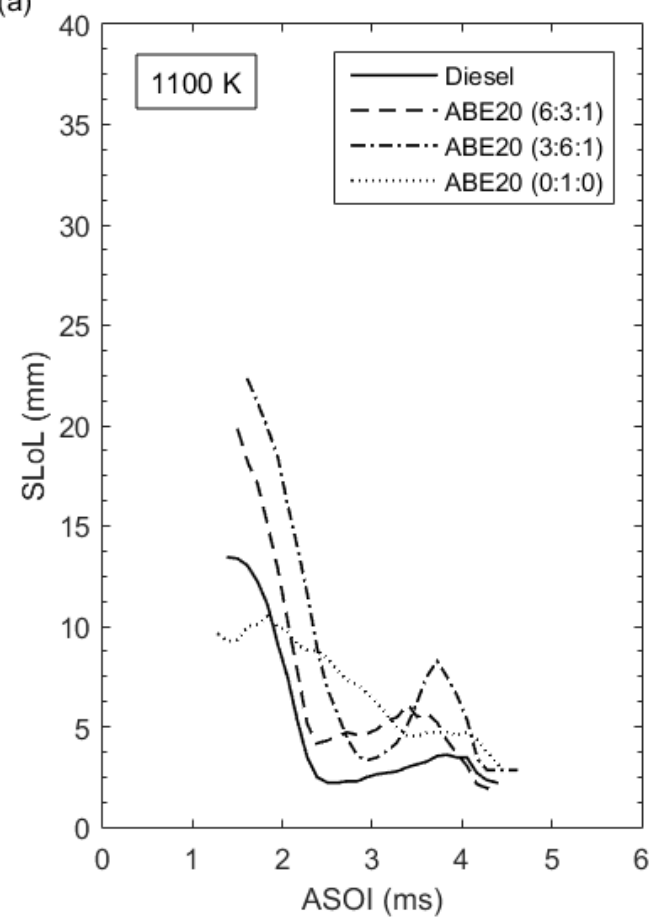

(b)

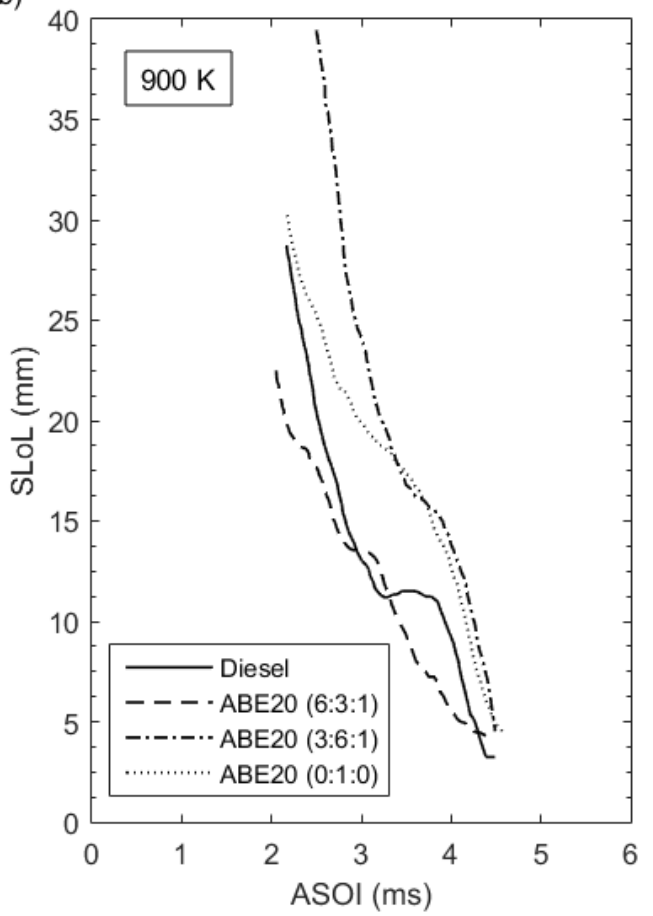

Fig. 10. Soot lift-off length of three ABE with different volumetric ratios compared to diesel fuel at ambient temperature of (a) $1100 \mathrm{~K}$ and (b) $900 \mathrm{~K}$, reproduced from [104] 
Micro-explosions may reduce the soot emission by improving the fuel atomization, increasing the reaction contact area, achieving complete combustion and suppressing the soot formation. Chang et al. [103] found that the use of $A B E 20$ with $0.5 \%$ water addition reduced the particulate matter (PM) emission factors by 5.82-61.6\% at various operating conditions. At $3.2 \mathrm{~kW}$ generator engine load, the PM emission reduced with the increasing percentage of $A B E$ and water. However, at $1.6 \mathrm{~kW}$, higher PM emission was observed when the water was increased to $1 \%$. This can be explained by the cooling effect of $A B E$ and water addition that retarded the oxidation of the soot and stimulated the condensation of PM emission. Despite an increase at some conditions, but in general, the PM was successfully reduced with increasing $A B E$ ratio. It is important to note that the addition of $A B E$ alone may not lead to the micro-explosions [190]. It is the addition of small water in the ABE mixture than can cause micro-explosions, thus achieving complete combustion and decreasing PM emissions [219, 220].

Although the effect of micro-explosions needs further investigating, three main reasons for PM formation are attributed to soot nucleation, unburned hydrocarbons condensation and sulphuric acid interaction with soot [221]. Several studies have reported fewer PM emissions using oxygenated fuels in diesel engine [222-225]. Additional oxygen content found in ABE can suppress the major precursor of PM nuclei [226] which are the aromatic rings formation and the $\mathrm{C}_{2}$-species interaction [227]. Both extra oxygen and oxygen radicals into the pyrolysis zone can oxidize the fuel and decrease PM where CO partially substitutes $\mathrm{C}_{2} \mathrm{H}_{2}$ in the pyrolysis reactions [228]. Also, since the interaction between sulphuric acid and soot can increase PM emission, adding ABE without sulphur content may help to reduce the PM formation. However, sulphuric acid condensation may not be affected as the sulphur content of diesel fuel is already low to meet the regulations.

Biodiesel can reduce PM emission, and with the addition of $A B E$ into biodiesel, a further reduction can be achieved. For biodiesel without ABE content, Chang et al. [187] found that the B25, B50, and B75 reduce PM emissions by 5.86-17.6, 11.5-27.7 and 18.6-32.5\%, respectively. These findings are consistent with other findings where two reasons are attributed to this reduction. First is the high oxygen content of biodiesel that results in complete combustion [224, 229, 230]. Second is the lower aromatic content of biodiesel that inhibits the soot formation as aromatic compounds are known to work as a soot precursor [231]. However, the high viscosity of biodiesel can deteriorate the atomization of the fuel, thus assisting the PM formation [230, 232]. Therefore, the PM reduction was not increasing with higher biodiesel ratio because a factor that helps to reduce soot formation (low aromatic content) is outweighed by a factor that helps to increase soot formation (higher viscosity). However, adding $25 \%$ water-containing $A B E$ into biodiesel may help to improve PM emissions [187]. It was found that B25ABE25, B50ABE25 and B75 ABE25 reduced $P M$ by $11.6-15.8,16.2-22.7$ and $10.9-18.5 \%$, respectively as shown in Fig. 11 . This is because $A B E$ has a lower cetane number, thus delaying the ignition and as a result, leaner conditions are achieved due to strong premixed combustion resulted from longer ignition delay [233, 234]. Given aromatic rings is the main precursor for PM nuclei, with the addition of water-containing $A B E$, its higher content assists the complete oxidation of the aromatic rings. Moreover, the soot precursors and black carbon can be oxidized by $\mathrm{OH}$ radicals that are normally produced by alcohol fuel [235]. The $\mathrm{OH}$ radicals can convert hydrogen atoms to molecular hydrogen. With reduced hydrogen atoms, the propagation of aromatic rings and the growth of soot will be slower [235]. Therefore, a significant reduction in PM emission was achieved. Considering the study by Chang et al. [187] also gave lower NOx emissions as discussed in 4.3.3, the use of ABE-biodiesel is, therefore, a promising approach to solve the NOx-PM trade-off in the diesel engine. 
Fig. 12 shows the NOx-PM trade-off emissions for the tested fuels. However, more in-depth studies are required because soot can serve as an effective heat radiator. Therefore, with lower soot resulted from the oxidation by extra oxygen content of $A B E$, higher in-cylinder temperature and NOx emissions may be observed [236, 237].

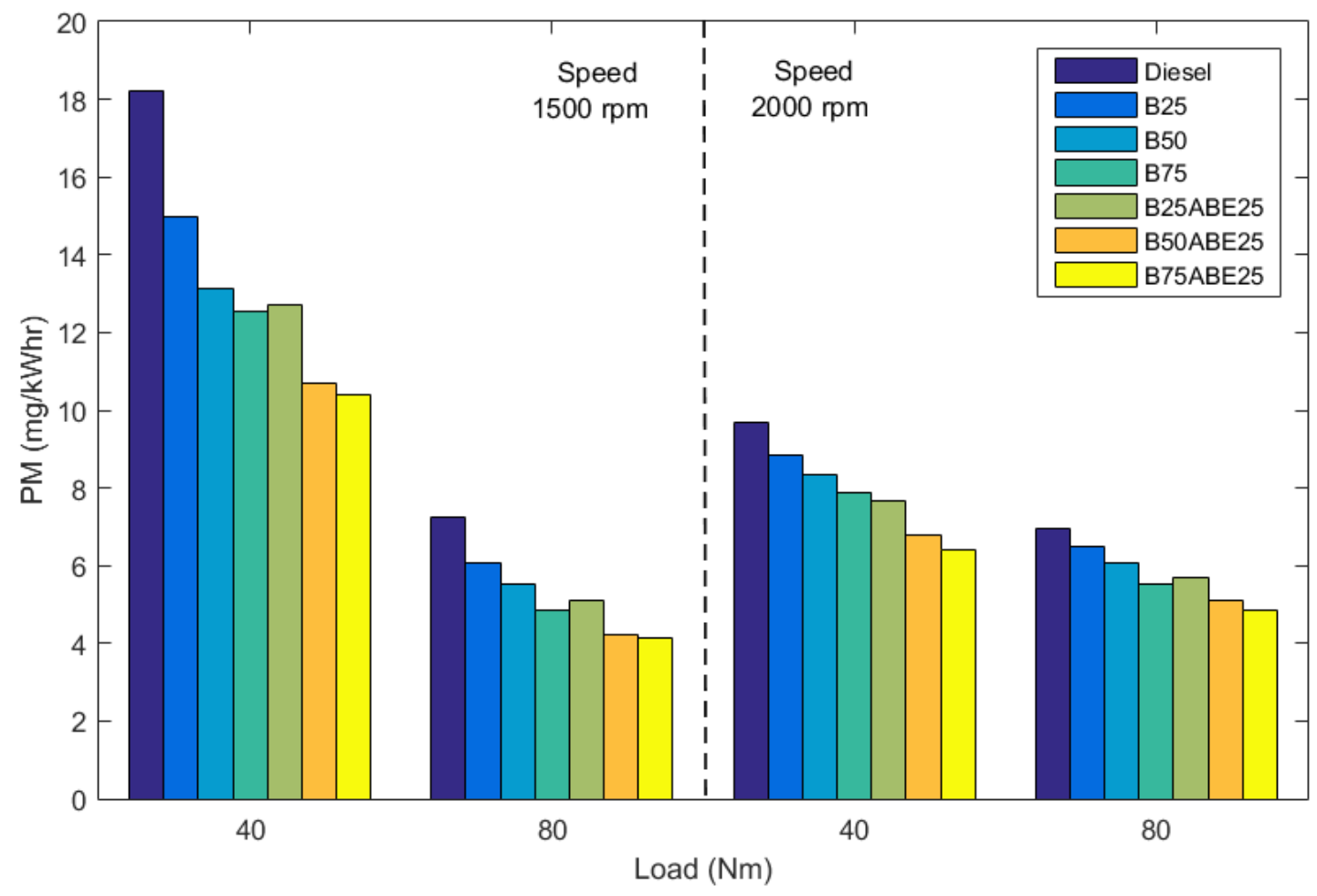

Fig. 11. Comparisons of PM emissions between diesel, biodiesel and biodiesel-ABE blends, reproduced from [187] 

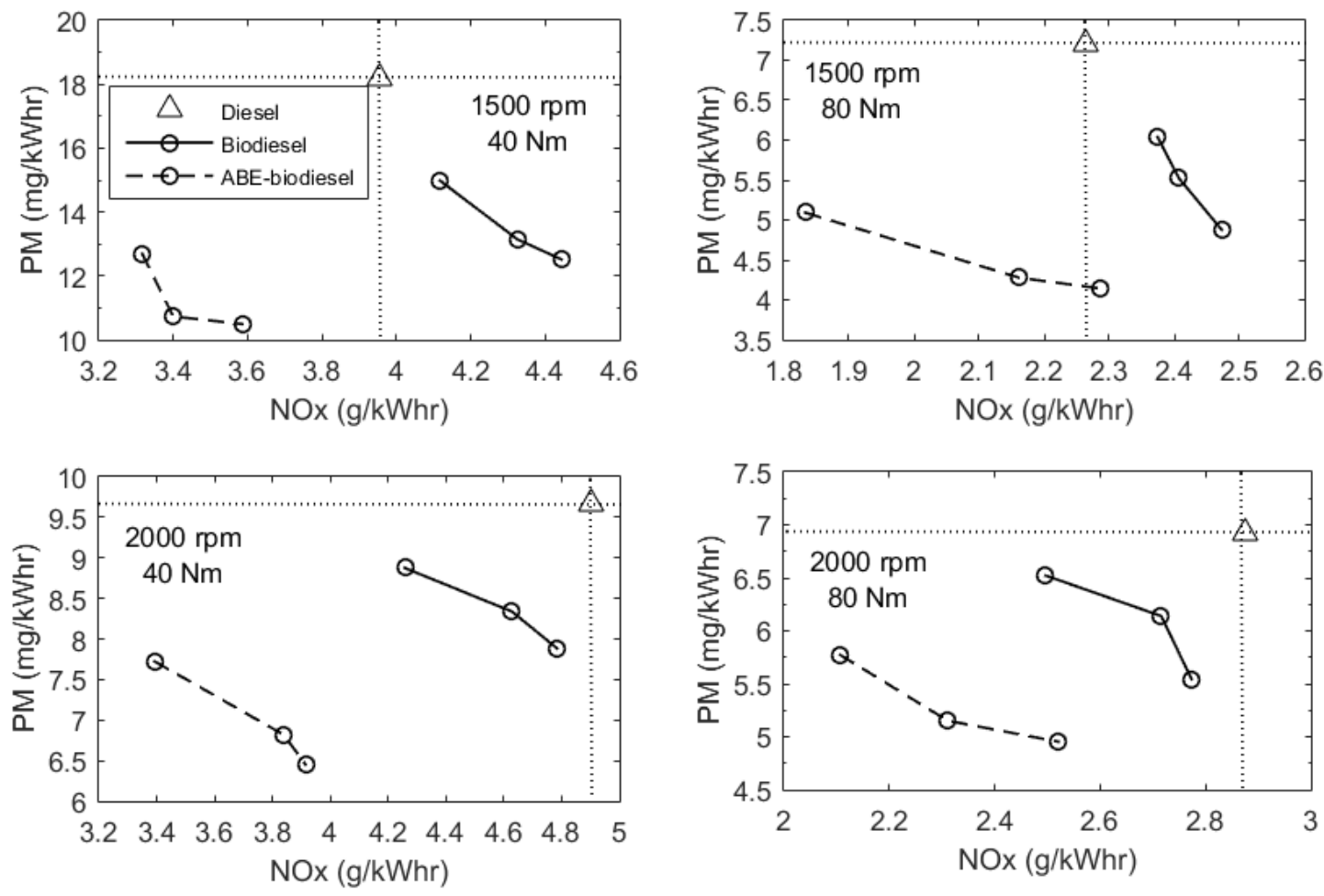

Fig. 12. Trade-off between NOx and PM emissions for two different engine speeds and loads, reproduced from [187]

Overall, the addition of $A B E$ into petrol diesel has the potential to lower its soot emissions. Lower natural flame luminosity is observed due to shorter combustion duration and stronger premixed combustion of $A B E$ blends. Strong premixed combustion rate is attributed to the retarded ignition timing caused by the increase of heat release rate in the premixed combustion stage. As a result, the soot formation is successfully reduced. Moreover, since each component of $\mathrm{ABE}$ produces $\mathrm{OH}$ radicals and contains less aromatic than diesel, less soot may also be attributed to the fewer soot precursors from the production of $\mathrm{OH}$ radicals and the dilution of aromatics of $\mathrm{ABE}$. Furthermore, the addition of $\mathrm{ABE}$ may decrease the soot precursors from the initial radicals for the aromatic rings to be formed by reducing the carbon amount for precursor species formation. Also, with the addition of $A B E$, the formation of rich zones with the high local fuel-air ratio is more likely to reduce, thus improving the soot oxidation of soot nuclei.

\section{Research gaps}

Fig. 13 generally outlines the next possible contribution of using $A B E$ as a biofuel. In addition to the issues addressed in the figure, several specific contributions are plausible to be conducted in gasoline and diesel engine. In a gasoline engine, the anti-knock ability of $A B E$ has not yet been investigated. The knock resistance may be improved due to significant cooling effect resulting from higher ABE's higher latent heat. With better knock resistance, further improvement in power and efficiency can be achieved using higher compression ratios, optimal spark timing, and significant downsizing. Moreover, despite its 
promising role in mitigating knock, studies conducted using EGR have not yet been found using $A B E$ as a biofuel in gasoline engines. In a diesel engine, most studies investigating $A B E$ were conducted on a constant volume combustion chamber to represent a real compression ignition engine characteristics. Also, by changing the ambient temperature and oxygen, the low combustion technology and EGR can be represented. However, direct application of $A B E$ on a real engine is required. In addition to that, more researches are needed to examine the effect of $A B E$ on unregulated emissions.

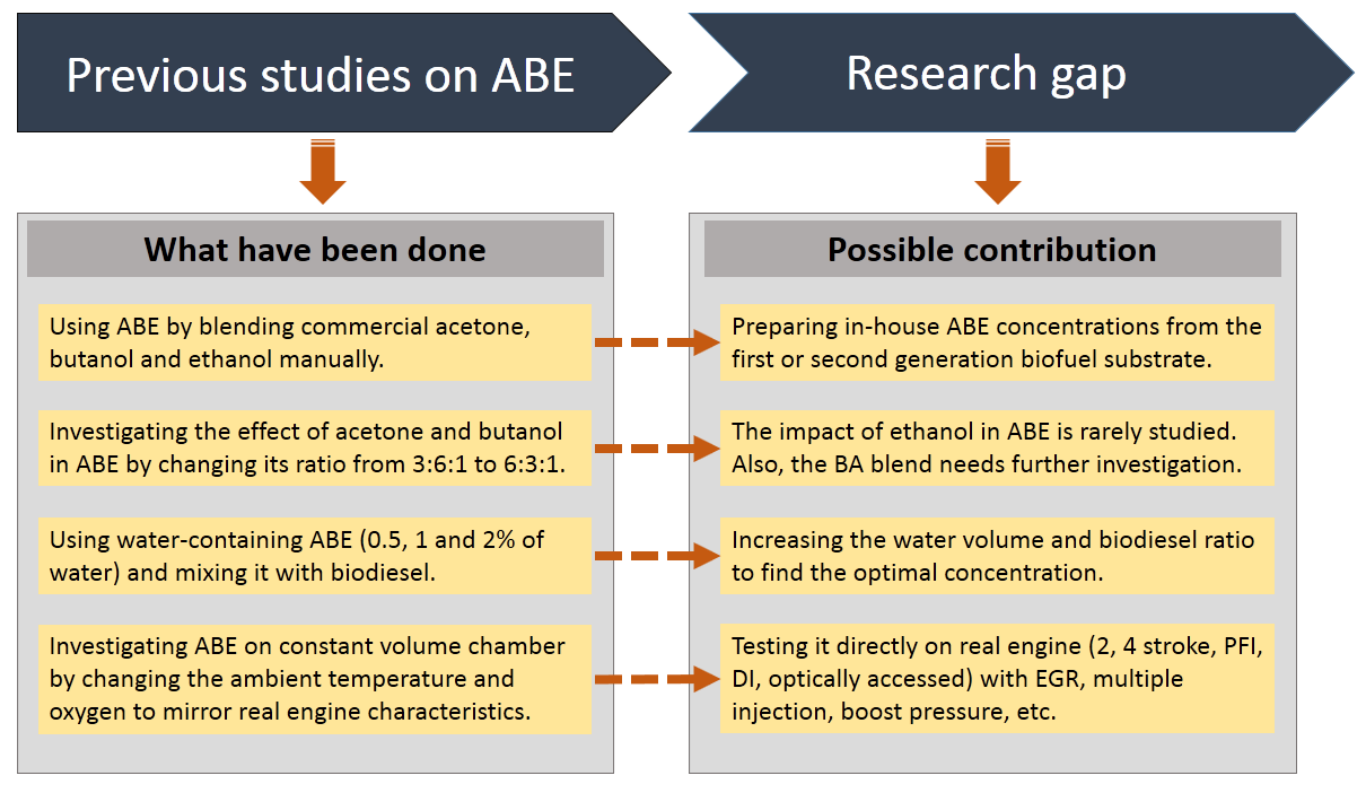

Fig. 13. Future research directions

\section{Acknowledgment}

The authors would like to acknowledge the Universiti Teknologi Malaysia (UTM) for financial support under the research university grant Q.J130000.3509.06G97.

\section{References}

[1] A. Alagumalai, Internal combustion engines: Progress and prospects, Renew. Sust. Energ. Rev. 38 (2014) 561-571.

[2] S. Imtenan, M. Varman, H. Masjuki, M. Kalam, H. Sajjad, M. Arbab, I.R. Fattah, Impact of low temperature combustion attaining strategies on diesel engine emissions for diesel and biodiesels: A review, Energ. Convers. Manage. 80 (2014) 329-356.

[3] Y. Li, J. Gong, Y. Deng, W. Yuan, J. Fu, B. Zhang, Experimental comparative study on combustion, performance and emissions characteristics of methanol, ethanol and butanol in a spark ignition engine, Appl. Therm. Eng. 115 (2017) 53-63. 
[4] A. Elfasakhany, Investigations on performance and pollutant emissions of spark-ignition engines fueled with n-butanol-, isobutanol-, ethanol-, methanol-, and acetone-gasoline blends: a comparative study, Renew. Sust. Energ. Rev. 71 (2017) 404-413.

[5] X. Zou, H. Wang, Z. Zheng, R. Reitz, M. Yao, Numerical study of the RCCl combustion processes fuelled with methanol, ethanol, n-butanol and diesel, SAE Tech. Pap. 2016-010777 (2016).

[6] M. Lapuerta, J. Rodríguez-Fernández, D. Fernández-Rodríguez, R. Patiño-Camino, Modeling viscosity of butanol and ethanol blends with diesel and biodiesel fuels, Fuel 199 (2017) 332-338.

[7] A. Elfasakhany, Exhaust emissions and performance of ternary iso-butanol-biomethanol-gasoline and n-butanol-bio-ethanol-gasoline fuel blends in spark-ignition engines: Assessment and comparison, Energy 158 (2018) 830-844.

[8] B.R. Kumar, S. Saravanan, Use of higher alcohol biofuels in diesel engines: A review, Renew. Sust. Energ. Rev. 60 (2016) 84-115.

[9] E. Sadeghinezhad, S. Kazi, F. Sadeghinejad, A. Badarudin, M. Mehrali, R. Sadri, M.R. Safaei, A comprehensive literature review of bio-fuel performance in internal combustion engine and relevant costs involvement, Renew. Sust. Energ. Rev. 30 (2014) 29-44.

[10] A. Gupta, J.P. Verma, Sustainable bio-ethanol production from agro-residues: A review, Renew. Sust. Energ. Rev. 41 (2015) 550-567.

[11] H. Zabed, J. Sahu, A. Boyce, G. Faruq, Fuel ethanol production from lignocellulosic biomass: An overview on feedstocks and technological approaches, Renew. Sust. Energ. Rev. 66 (2016) 751-774.

[12] J. Han, J.S. Luterbacher, D.M. Alonso, J.A. Dumesic, C.T. Maravelias, A lignocellulosic ethanol strategy via nonenzymatic sugar production: Process synthesis and analysis, Bioresour. Technol. 182 (2015) 258-266.

[13] N. Gaurav, S. Sivasankari, G. Kiran, A. Ninawe, J. Selvin, Utilization of bioresources for sustainable biofuels: A review, Renew. Sust. Energ. Rev. 73 (2017) 205-214.

[14] S.N. Naik, V.V. Goud, P.K. Rout, A.K. Dalai, Production of first and second generation biofuels: a comprehensive review, Renew. Sust. Energ. Rev. 14 (2010) 578-597.

[15] R.L. Patel, C. Sankhavara, Biodiesel production from Karanja oil and its use in diesel engine: A review, Renew. Sust. Energ. Rev. 71 (2017) 464-474.

[16] D. Khatiwada, S. Leduc, S. Silveira, I. McCallum, Optimizing ethanol and bioelectricity production in sugarcane biorefineries in Brazil, Renew. Energ. 85 (2016) 371-386.

[17] J. Jonker, F. Van Der Hilst, H. Junginger, O. Cavalett, M. Chagas, A. Faaij, Outlook for ethanol production costs in Brazil up to 2030, for different biomass crops and industrial technologies, Appl. Energ. 147 (2015) 593-610.

[18] P. Grad, Biofuelling Brazil: An overview of the bioethanol success story in Brazil, Refocus 7 (2006) 56-59. 
[19] M.L. Lopes, S.C. de Lima Paulillo, A. Godoy, R.A. Cherubin, M.S. Lorenzi, F.H.C. Giometti, C.D. Bernardino, H.B. de Amorim Neto, H.V. de Amorim, Ethanol production in Brazil: A bridge between science and industry, Braz. J. Microbiol. 47 (2016) 64-76.

[20] D. Golke, J.L.S. Fagundez, N.P.G. Salau, M.E.S. Martins, Combustion performance of nbutanol, hydrous ethanol and their blends as potential surrogates for the Brazilian gasoline, SAE Tech. Pap. 2016-36-0274 (2016).

[21] P. de Mattos Fagundes, A.D. Padula, A.C.M. Padilha, Interdependent international relations and the expansion of ethanol production and consumption: the Brazilian perspective, J. Clean. Prod. 133 (2016) 616-630.

[22] K. Halsnæs, P. Shukla, Sustainable development as a framework for developing country participation in international climate change policies, Mitig. Adapt. Strat. Gl. 13 (2008) 105130.

[23] A. de Oliveira, Reassessing the Brazilian alcohol programme, Energ. Policy 19 (1991) 47-55.

[24] F. Rosillo-Calle, L.A.B. Cortez, Towards ProAlcool II-A review of the Brazilian bioethanol programme, Biomass Bioenergy 14 (1998) 115-124.

[25] J.R. Moreira, Sugarcane for energy - Recent results and progress in Brazil, Energy Sustain. Dev. 4 (2000) 43-54.

[26] S.R. Golisz, J.S. Yang, R.D. Johnson, Understanding the effect of $\mathrm{CO} 2$ on the pHe of fuel ethanol, Fuel 199 (2017) 1-3.

[27] L. Caspeta, N.A. Buijs, J. Nielsen, The role of biofuels in the future energy supply, Energy Environ. Sci. 6 (2013) 1077-1082.

[28] B. Ndaba, I. Chiyanzu, S. Marx, n-Butanol derived from biochemical and chemical routes: A review, Biotechnology Reports 8 (2015) 1-9.

[29] J. Zheng, Y. Tashiro, Q. Wang, K. Sonomoto, Recent advances to improve fermentative butanol production: genetic engineering and fermentation technology, J. Biosci. Bioeng. 119 (2015) 1-9.

[30] J.M. Bergthorson, M.J. Thomson, A review of the combustion and emissions properties of advanced transportation biofuels and their impact on existing and future engines, Renew. Sust. Energ. Rev. 42 (2015) 1393-1417.

[31] H. Wei, D. Feng, J. Pan, A. Shao, M. Pan, Knock characteristics of SI engine fueled with n-butanol in combination with different EGR rate, Energy 118 (2017) 190-196.

[32] Q. Li, H. Liu, Y. Zhang, Z. Yan, F. Deng, Z. Huang, Experimental and kinetic modeling study of laminar flame characteristics of higher mixed alcohols, Fuel Process. Technol. 188 (2019) 30-42.

[33] F. Meng, X. Yu, L. He, Y. Liu, Y. Wang, Study on combustion and emission characteristics of a n-butanol engine with hydrogen direct injection under lean burn conditions, Int. J. Hydrogen Energ. 43 (2018) 7550-7561. 
[34] T. Su, C. Ji, S. Wang, X. Cong, L. Shi, J. Yang, Improving the lean performance of an nbutanol rotary engine by hydrogen enrichment, Energ. Convers. Manage. 157 (2018) 96102.

[35] J. Yadav, A. Ramesh, Injection strategies for reducing smoke and improving the performance of a butanol-diesel common rail dual fuel engine, Appl. Energ. 212 (2018) 112.

[36] S. Van Wyk, A. Van Der Ham, S. Kersten, Pervaporative separation and intensification of downstream recovery of acetone-butanol-ethanol (ABE), Chem. Eng. Process. 130 (2018) 148-159.

[37] S. Niglio, A. Marzocchella, L. Rehmann, Clostridial conversion of corn syrup to AcetoneButanol-Ethanol (ABE) via batch and fed-batch fermentation, Heliyon 5 (2019) e01401. [38] S. Xie, C. Fu, W. Song, Y. Zhang, C. Yi, Highly efficient synthesis and separation of fuel precursors from the concentrated ABE fermentation broth in a biphasic catalytic process, Fuel 242 (2019) 41-49.

[39] A. Jahanmiri, H. Rasooli, On-line states and parameter identification of acetonebutanol-ethanol fermentation process, Biochem. Eng. J. 24 (2005) 115-123.

[40] Y. Tashiro, K. Takeda, G. Kobayashi, K. Sonomoto, High production of acetonebutanol-ethanol with high cell density culture by cell-recycling and bleeding, J. Biotechnol. 120 (2005) 197-206.

[41] L. Qiu, X. Cheng, Z. Li, H. Wu, Experimental and numerical investigation on soot volume fractions and number densities in non-smoking laminar n-heptane/n-butanol coflow flames, Combust. Flame 191 (2018) 394-407.

[42] W.R. da Silva Trindade, R.G. dos Santos, 1D modeling of SI engine using n-butanol as fuel: Adjust of fuel properties and comparison between measurements and simulation, Energ. Convers. Manage. 157 (2018) 224-238.

[43] W. Luo, Z. Zhao, H. Pan, L. Zhao, C. Xu, X. Yu, Feasibility of butanol production from wheat starch wastewater by Clostridium acetobutylicum, Energy 154 (2018) 240-248.

[44] Y. Li, Y. Chen, G. Wu, F.L. Chia-fon, J. Liu, Experimental comparison of acetone-nbutanol-ethanol (ABE) and isopropanol-n-butanol-ethanol (IBE) as fuel candidate in sparkignition engine, Appl. Therm. Eng. 133 (2018) 179-187.

[45] Y. Jiang, T. Zhang, J. Lu, P. Dürre, W. Zhang, W. Dong, J. Zhou, M. Jiang, F. Xin, Microbial co-culturing systems: butanol production from organic wastes through consolidated bioprocessing, Appl. Microbiol. Biotechnol. 102 (2018) 5419-5425.

[46] C. Jin, M. Yao, H. Liu, F.L. Chia-fon, J. Ji, Progress in the production and application of n-butanol as a biofuel, Renew. Sust. Energ. Rev. 15 (2011) 4080-4106.

[47] S. Farmanbordar, K. Karimi, H. Amiri, Municipal solid waste as a suitable substrate for butanol production as an advanced biofuel, Energ. Convers. Manage. 157 (2018) 396-408. [48] J. Formanek, R. Mackie, H.P. Blaschek, Enhanced butanol production by Clostridium beijerinckii BA101 grown in semidefined P2 medium containing 6 percent maltodextrin or glucose, Appl. Environ. Microbiol. 63 (1997) 2306-2310. 
[49] B. Ennis, I. Maddox, The effect of $\mathrm{pH}$ and lactose concentration on solvent production from whey permeate using Clostridium acetobutylicum, Biotechnol. Bioeng. 29 (1987) 329334.

[50] C. Huang, X.Y. Yang, L. Xiong, H.J. Guo, J. Luo, B. Wang, H.R. Zhang, X.Q. Lin, X.D. Chen, Evaluating the possibility of using acetone-butanol-ethanol ( $A B E$ ) fermentation wastewater for bacterial cellulose production by G luconacetobacter xylinus, Lett. Appl. Microbiol. 60 (2015) 491-496.

[51] V.H.G. Diaz, G.O. Tost, Energy efficiency of acetone, butanol, and ethanol (ABE) recovery by heat-integrated distillation, Bioproc. Biosyst. Eng. 41 (2018) 395-405.

[52] A. Kujawska, J. Kujawski, M. Bryjak, W. Kujawski, ABE fermentation products recovery methods-A review, Renew. Sust. Energ. Rev. 48 (2015) 648-661.

[53] N. Qureshi, B.C. Saha, M.A. Cotta, V. Singh, An economic evaluation of biological conversion of wheat straw to butanol: A biofuel, Energ. Convers. Manage. 65 (2013) 456462.

[54] N. Qureshi, V. Singh, Chapter 12 - Process economics of renewable biorefineries: Butanol and ethanol production in integrated bioprocesses from lignocellulosics and other industrial by-products, in: N. Qureshi, D.B. Hodge, A.A. Vertès (Eds.) Biorefineries, Elsevier, Amsterdam, 2014, pp. 237-254.

[55] A. Oudshoorn, L.A. Van Der Wielen, A.J. Straathof, Assessment of options for selective 1-butanol recovery from aqueous solution, Ind. Eng. Chem. Res. 48 (2009) 7325-7336.

[56] I.S. Maddox, The acetone-butanol-ethanol fermentation: Recent progress in technology, Biotechnol. Genet. Eng. Rev. 7 (1989) 189-220.

[57] W. Groot, R. Van der Lans, K.C.A. Luyben, Technologies for butanol recovery integrated with fermentations, Process Biochem. 27 (1992) 61-75.

[58] L.M. Vane, Separation technologies for the recovery and dehydration of alcohols from fermentation broths, Biofuels, Bioproducts and Biorefining 2 (2008) 553-588.

[59] X. Lin, J. Wu, J. Fan, W. Qian, X. Zhou, C. Qian, X. Jin, L. Wang, J. Bai, H. Ying, Adsorption of butanol from aqueous solution onto a new type of macroporous adsorption resin: studies of adsorption isotherms and kinetics simulation, J. Chem. Technol. Biotechnol. 87 (2012) 924-931.

[60] T.J. Levario, M. Dai, W. Yuan, B.D. Vogt, D.R. Nielsen, Rapid adsorption of alcohol biofuels by high surface area mesoporous carbons, Micropor. Mesopor. Mat. 148 (2012) 107-114.

[61] A. Oudshoorn, L.A. van der Wielen, A.J. Straathof, Adsorption equilibria of bio-based butanol solutions using zeolite, Biochem. Eng. J. 48 (2009) 99-103.

[62] P. Sharma, W.-J. Chung, Synthesis of MEL type zeolite with different kinds of morphology for the recovery of 1-butanol from aqueous solution, Desalination 275 (2011) 172-180. 
[63] T. Ezeji, N. Qureshi, H. Blaschek, Production of acetone, butanol and ethanol by Clostridium beijerinckii BA101 and in situ recovery by gas stripping, World J. Microbiol. Biotechnol. 19 (2003) 595-603.

[64] C.H. Park, M.R. Okos, P.C. Wankat, Acetone-butanol-ethanol (ABE) fermentation and simultaneous separation in a trickle bed reactor, Biotechnol. Prog. 7 (1991) 185-194.

[65] T.C. Ezeji, P.M. Karcher, N. Qureshi, H.P. Blaschek, Improving performance of a gas stripping-based recovery system to remove butanol from Clostridium beijerinckii fermentation, Bioproc. Biosyst. Eng. 27 (2005) 207-214.

[66] N. Qureshi, H. Blaschek, Recovery of butanol from fermentation broth by gas stripping, Renew. Energ. 22 (2001) 557-564.

[67] M. Setlhaku, S. Heitmann, A. Górak, R. Wichmann, Investigation of gas stripping and pervaporation for improved feasibility of two-stage butanol production process, Bioresour. Technol. 136 (2013) 102-108.

[68] F. Liu, L. Liu, X. Feng, Separation of acetone-butanol-ethanol (ABE) from dilute aqueous solutions by pervaporation, Sep. Purif. Technol. 42 (2005) 273-282.

[69] A. Rozicka, J. Niemistö, R.L. Keiski, W. Kujawski, Apparent and intrinsic properties of commercial PDMS based membranes in pervaporative removal of acetone, butanol and ethanol from binary aqueous mixtures, J. Membr. Sci. 453 (2014) 108-118.

[70] L.M. Vane, A review of pervaporation for product recovery from biomass fermentation processes, J. Chem. Technol. Biotechnol. 80 (2005) 603-629.

[71] J. Niemistö, W. Kujawski, R.L. Keiski, Pervaporation performance of composite poly (dimethyl siloxane) membrane for butanol recovery from model solutions, J. Membr. Sci. 434 (2013) 55-64.

[72] W. Liu, S.L. Ji, H.X. Guo, J. Gao, Z.P. Qin, In situ cross-linked-PDMS/BPPO membrane for the recovery of butanol by pervaporation, J. Appl. Polym. Sci. 131 (2014).

[73] E.A. Fouad, X. Feng, Pervaporative separation of $n$-butanol from dilute aqueous solutions using silicalite-filled poly (dimethyl siloxane) membranes, J. Membr. Sci. 339 (2009) 120-125.

[74] S.-Y. Li, R. Srivastava, R.S. Parnas, Separation of 1-butanol by pervaporation using a novel tri-layer PDMS composite membrane, J. Membr. Sci. 363 (2010) 287-294.

[75] V. García, E. Pongrácz, E. Muurinen, R.L. Keiski, Recovery of n-butanol from salt containing solutions by pervaporation, Desalination 241 (2009) 201-211.

[76] H. Tan, Y. Wu, T. Li, Pervaporation of n-butanol aqueous solution through ZSM-5-PEBA composite membranes, J. Appl. Polym. Sci. 129 (2013) 105-112.

[77] C. Tong, Y. Bai, J. Wu, L. Zhang, L. Yang, J. Qian, Pervaporation recovery of acetonebutanol from aqueous solution and fermentation broth using HTPB-based polyurethaneurea membranes, Sep. Sci. Technol. 45 (2010) 751-761.

[78] S. Claes, P. Vandezande, S. Mullens, K. De Sitter, R. Peeters, M.K. Van Bael, Preparation and benchmarking of thin film supported PTMSP-silica pervaporation membranes, J. Membr. Sci. 389 (2012) 265-271. 
[79] D.L. Vrana, M.M. Meagher, R.W. Hutkins, B. Duffield, Pervaporation of model acetonebutanol-ethanol fermentation product solutions using polytetrafluoroethylene membranes, Sep. Sci. Technol. 28 (1993) 2167-2178.

[80] J. Liu, L. Fan, P. Seib, F. Friedler, B. Bertok, Downstream process synthesis for biochemical production of butanol, ethanol, and acetone from grains: generation of optimal and near-optimal flowsheets with conventional operating units, Biotechnol. Prog. 20 (2004) 1518-1527.

[81] J. Liu, L. Fan, P. Seib, F. Friedler, B. Bertok, Holistic approach to process retrofitting: Application to downstream process for biochemical production of organics, Ind. Eng. Chem. Res. 45 (2006) 4200-4207.

[82] H. Luo, L. Ge, J. Zhang, J. Ding, R. Chen, Z. Shi, Enhancing acetone biosynthesis and acetone-butanol-ethanol fermentation performance by co-culturing Clostridium acetobutylicum/Saccharomyces cerevisiae integrated with exogenous acetate addition, Bioresour. Technol. 200 (2016) 111-120.

[83] H. Luo, J. Zhang, H. Wang, R. Chen, Z. Shi, X. Li, J. Ding, Effectively enhancing acetone concentration and acetone/butanol ratio in ABE fermentation by a glucose/acetate cosubstrate system incorporating with glucose limitation and C. acetobutylicum/S. cerevisiae co-culturing, Biochem. Eng. J. 118 (2017) 132-142.

[84] P. Dürre, Fermentative Butanol Production, Ann. N. Y. Acad. Sci. 1125 (2008) 353-362. [85] E.M. Green, Fermentative production of butanol-the industrial perspective, Curr. Opin. Biotechnol. 22 (2011) 337-343.

[86] P.H. Pfromm, V. Amanor-Boadu, R. Nelson, P. Vadlani, R. Madl, Bio-butanol vs. bioethanol: A technical and economic assessment for corn and switchgrass fermented by yeast or Clostridium acetobutylicum, Biomass and Bioenergy 34 (2010) 515-524.

[87] N. Qureshi, H. Blaschek, ABE production from corn: a recent economic evaluation, J. Ind. Microbiol. Biotechnol. 27 (2001) 292-297.

[88] A. Friedl, Downstream process options for the ABE fermentation, FEMS Microbiol. Lett. 363 (2016).

[89] H.-J. Huang, S. Ramaswamy, Y. Liu, Separation and purification of biobutanol during bioconversion of biomass, Sep. Purif. Technol. 132 (2014) 513-540.

[90] A. Kurkijärvi, J. Lehtonen, J. Linnekoski, Novel dual extraction process for acetonebutanol-ethanol fermentation, Sep. Purif. Technol. 124 (2014) 18-25.

[91] V.I. Águeda, J.A. Delgado, M.A. Uguina, J.L. Sotelo, Á. García, Column dynamics of an adsorption-drying-desorption process for butanol recovery from aqueous solutions with silicalite pellets, Sep. Purif. Technol. 104 (2013) 307-321.

[92] S. Fournier, G. Simon, P. Seers, Evaluation of low concentrations of ethanol, butanol, $\mathrm{BE}$, and $\mathrm{ABE}$ blended with gasoline in a direct-injection, spark-ignition engine, Fuel 181 (2016) 396-407. 
[93] Y. Li, L. Meng, K. Nithyanandan, T.H. Lee, Y. Lin, F.L. Chia-fon, S. Liao, Combustion, performance and emissions characteristics of a spark-ignition engine fueled with isopropanol-n-butanol-ethanol and gasoline blends, Fuel 184 (2016) 864-872.

[94] N. Zhou, H. Wu, C.-F. Lee, Q. Wang, M. Huo, P. Wang, Different percentage of acetonebutanol-ethanol $(\mathrm{ABE})$ and diesel blends at low temperature condition in a constant volume chamber, SAE Tech. Pap. 2014-01-1257 (2014).

[95] S.J.M. Algayyim, A.P. Wandel, T. Yusaf, I. Hamawand, Production and application of ABE as a biofuel, Renew. Sust. Energ. Rev. 82 (2018) 1195-1214.

[96] Y. Li, W. Tang, Y. Chen, J. Liu, F.L. Chia-fon, Potential of acetone-butanol-ethanol (ABE) as a biofuel, Fuel 242 (2019) 673-686.

[97] K. Han, B. Pang, X. Ma, H. Chen, G. Song, Z. Ni, An experimental study of the burning characteristics of acetone-butanol-ethanol and diesel blend droplets, Energy 139 (2017) 853-861.

[98] E. Elbeshbishy, B.R. Dhar, H. Hafez, H.-S. Lee, Acetone-butanol-ethanol production in a novel continuous flow system, Bioresour. Technol. 190 (2015) 315-320.

[99] Y.-S. Jang, J.Y. Lee, J. Lee, J.H. Park, J.A. Im, M.-H. Eom, J. Lee, S.-H. Lee, H. Song, J.-H. Cho, Enhanced butanol production obtained by reinforcing the direct butanol-forming route in Clostridium acetobutylicum, MBio 3 (2012) e00314-00312.

[100] Y. Tashiro, K. Takeda, G. Kobayashi, K. Sonomoto, A. Ishizaki, S. Yoshino, High butanol production by Clostridium saccharoperbutylacetonicum N1-4 in fed-batch culture with $\mathrm{pH}$ stat continuous butyric acid and glucose feeding method, J. Biosci. Bioeng. 98 (2004) 263268.

[101] X. Li, Z.-G. Li, Z.-P. Shi, Metabolic flux and transcriptional analysis elucidate higher butanol/acetone ratio feature in $A B E$ extractive fermentation by Clostridium acetobutylicum using cassava substrate, Bioresources and Bioprocessing 1 (2014) 13.

[102] X. Li, Z. Shi, Z. Li, Increasing butanol/acetone ratio and solvent productivity in ABE fermentation by consecutively feeding butyrate to weaken metabolic strength of butyrate loop, Bioproc. Biosyst. Eng. 37 (2014) 1609-1616.

[103] Y.-C. Chang, W.-J. Lee, S.-L. Lin, L.-C. Wang, Green energy: Water-containing acetone-butanol-ethanol diesel blends fueled in diesel engines, Appl. Energ. 109 (2013) 182-191.

[104] H. Wu, M. Huo, N. Zhou, K. Nithyanandan, C.-F. Lee, C. Zhang, J. Lin, An experimental investigation of the combustion characteristics of acetone-butanol-ethanol-diesel blends with different ABE component ratios in a constant volume chamber, SAE Tech. Pap. 201401-1452 (2014).

[105] S.J.M. Algayyim, A.P. Wandel, T. Yusaf, S. Al-Lwayzy, Butanol-acetone mixture blended with cottonseed biodiesel: Spray characteristics evolution, combustion characteristics, engine performance and emission, P. Combust. Inst. 37 (2019) 4729-4739. 
[106] S.J.M. Algayyim, A.P. Wandel, T. Yusaf, S. Al-Lwayzy, I. Hamawand, Impact of butanolacetone mixture as a fuel additive on diesel engine performance and emissions, Fuel 227 (2018) 118-126.

[107] S.J.M. Algayyim, A.P. Wandel, T. Yusaf, I. Hamawand, The impact of n-butanol and iso-butanol as components of butanol-acetone (BA) mixture-diesel blend on spray, combustion characteristics, engine performance and emission in direct injection diesel engine, Energy 140 (2017) 1074-1086.

[108] H. Wu, K. Nithyanandan, J. Zhang, Y. Lin, T.H. Lee, F.L. Chia-fon, C. Zhang, Impacts of Acetone-Butanol-Ethanol (ABE) ratio on spray and combustion characteristics of ABEdiesel blends, Appl. Energ. 149 (2015) 367-378.

[109] N. Zhou, M. Huo, H. Wu, K. Nithyanandan, F.L. Chia-fon, Q. Wang, Low temperature spray combustion of acetone-butanol-ethanol (ABE) and diesel blends, Appl. Energ. 117 (2014) 104-115.

[110] G. Knothe, Dependence of biodiesel fuel properties on the structure of fatty acid alkyl esters, Fuel Process. Technol. 86 (2005) 1059-1070.

[111] Y. Zhuang, G. Hong, Primary investigation to leveraging effect of using ethanol fuel on reducing gasoline fuel consumption, Fuel 105 (2013) 425-431.

[112] M.K. Balki, C. Sayin, M. Canakci, The effect of different alcohol fuels on the performance, emission and combustion characteristics of a gasoline engine, Fuel 115 (2014) 901-906.

[113] N. Yilmaz, A. Atmanli, Experimental evaluation of a diesel engine running on the blends of diesel and pentanol as a next generation higher alcohol, Fuel 210 (2017) 75-82. [114] T. Zhang, L.J. Nilsson, C. Björkholtz, K. Munch, I. Denbratt, Effect of using butanol and octanol isomers on engine performance of steady state and cold start ability in different types of diesel engines, Fuel 184 (2016) 708-717.

[115] D.H. Qi, K. Yang, D. Zhang, B. Chen, Q. Wei, C.H. Zhang, Experimental investigation of a turbocharged CRDI diesel engine fueled with Tung oil-diesel-ethanol microemulsion fuel, Renew. Energ. 113 (2017) 1201-1207.

[116] M. Yusoff, N. Zulkifli, B. Masum, H. Masjuki, Feasibility of bioethanol and biobutanol as transportation fuel in spark-ignition engine: A review, RSC Adv. 5 (2015) 100184100211.

[117] A. Jamrozik, The effect of the alcohol content in the fuel mixture on the performance and emissions of a direct injection diesel engine fueled with diesel-methanol and dieselethanol blends, Energ. Convers. Manage. 148 (2017) 461-476.

[118] M. Canakci, Combustion characteristics of a turbocharged DI compression ignition engine fueled with petroleum diesel fuels and biodiesel, Bioresour. Technol. 98 (2007) 1167-1175.

[119] M. Karabektas, M. Hosoz, Performance and emission characteristics of a diesel engine using isobutanol-diesel fuel blends, Renew. Energ. 34 (2009) 1554-1559. 
[120] S. Puhan, N. Saravanan, G. Nagarajan, N. Vedaraman, Effect of biodiesel unsaturated fatty acid on combustion characteristics of a DI compression ignition engine, Biomass Bioenergy 34 (2010) 1079-1088.

[121] A. Bilgin, O. Durgun, Z. Sahin, The effects of diesel-ethanol blends on diesel engine performance, Energ. Source. 24 (2002) 431-440.

[122] M. Canakci, A.N. Ozsezen, E. Alptekin, M. Eyidogan, Impact of alcohol-gasoline fuel blends on the exhaust emission of an SI engine, Renew. Energ. 52 (2013) 111-117.

[123] F. Li, B. Yi, W. Fu, L. Song, T. Liu, H. Hu, Q. Lin, Experimental study on spray characteristics of long-chain alcohol-diesel fuels in a constant volume chamber, J. Energy Inst. (2017).

[124] D.B. Hulwan, S.V. Joshi, Performance, emission and combustion characteristic of a multicylinder DI diesel engine running on diesel-ethanol-biodiesel blends of high ethanol content, Appl. Energ. 88 (2011) 5042-5055.

[125] Q. Fang, J. Fang, J. Zhuang, Z. Huang, Effects of ethanol-diesel-biodiesel blends on combustion and emissions in premixed low temperature combustion, Appl. Therm. Eng. 54 (2013) 541-548.

[126] D. Qi, K. Yang, D. Zhang, B. Chen, Combustion and emission characteristics of dieseltung oil-ethanol blended fuels used in a CRDI diesel engine with different injection strategies, Appl. Therm. Eng. 111 (2017) 927-935.

[127] T.J. Jacobs, D.N. Assanis, The attainment of premixed compression ignition lowtemperature combustion in a compression ignition direct injection engine, P. Combust. Inst. 31 (2007) 2913-2920.

[128] W. Tutak, K. Lukács, S. Szwaja, Á. Bereczky, Alcohol-diesel fuel combustion in the compression ignition engine, Fuel 154 (2015) 196-206.

[129] X. Li, X. Qiao, L. Zhang, J. Fang, Z. Huang, H. Xia, Combustion and emission characteristics of a two-stroke diesel engine operating on alcohol, Renew. Energ. 30 (2005) 2075-2084.

[130] A. Datta, B.K. Mandal, Impact of alcohol addition to diesel on the performance combustion and emissions of a compression ignition engine, Appl. Therm. Eng. 98 (2016) 670-682.

[131] Q. Zhang, M. Yao, Z. Zheng, H. Liu, J. Xu, Experimental study of n-butanol addition on performance and emissions with diesel low temperature combustion, Energy 47 (2012) 515-521.

[132] J. Lei, L. Shen, Y. Bi, H. Chen, A novel emulsifier for ethanol-diesel blends and its effect on performance and emissions of diesel engine, Fuel 93 (2012) 305-311.

[133] D. Kannan, S. Pachamuthu, M. Nurun Nabi, J.E. Hustad, T. Løvås, Theoretical and experimental investigation of diesel engine performance, combustion and emissions analysis fuelled with the blends of ethanol, diesel and jatropha methyl ester, Energ. Convers. Manage. 53 (2012) 322-331. 
[134] H. Aydin, C. Illkılıç, Effect of ethanol blending with biodiesel on engine performance and exhaust emissions in a Cl engine, Appl. Therm. Eng. 30 (2010) 1199-1204.

[135] K.M. Van Geem, A. Cuoci, A. Frassoldati, S.P. Pyl, G.B. Marin, E. Ranzi, An experimental and kinetic modeling study of pyrolysis and combustion of acetone-butanolethanol (ABE) mixtures, Combust. Sci. Technol. 184 (2012) 942-955.

[136] G. Broustail, F. Halter, P. Seers, G. Moréac, C. Mounaïm-Rousselle, Experimental determination of laminar burning velocity for butanol/iso-octane and ethanol/iso-octane blends for different initial pressures, Fuel 106 (2013) 310-317.

[137] Q. Li, E. Hu, Y. Cheng, Z. Huang, Measurements of laminar flame speeds and flame instability analysis of 2-methyl-1-butanol-air mixtures, Fuel 112 (2013) 263-271.

[138] J. Van Lipzig, E. Nilsson, L. De Goey, A.A. Konnov, Laminar burning velocities of $n-$ heptane, iso-octane, ethanol and their binary and tertiary mixtures, Fuel 90 (2011) 27732781.

[139] E. Varea, V. Modica, B. Renou, A.M. Boukhalfa, Pressure effects on laminar burning velocities and Markstein lengths for isooctane-ethanol-air mixtures, P. Combust. Inst. 34 (2013) 735-744.

[140] X. Zhang, C. Tang, H. Yu, Q. Li, J. Gong, Z. Huang, Laminar flame characteristics of isooctane/n-butanol blend-air mixtures at elevated temperatures, Energy Fuels 27 (2013) 2327-2335.

[141] A.K. Agarwal, H. Karare, A. Dhar, Combustion, performance, emissions and particulate characterization of a methanol-gasoline blend (gasohol) fuelled medium duty spark ignition transportation engine, Fuel Process. Technol. 121 (2014) 16-24.

[142] A.O. Emiroğlu, M. Şen, Combustion, performance and emission characteristics of various alcohol blends in a single cylinder diesel engine, Fuel 212 (2018) 34-40.

[143] A.O. Emiroğlu, M. Şen, Combustion, performance and exhaust emission characterizations of a diesel engine operating with a ternary blend (alcohol-biodieseldiesel fuel), Appl. Therm. Eng. 133 (2018) 371-380.

[144] E. Galloni, F. Scala, G. Fontana, Influence of fuel bio-alcohol content on the performance of a turbo-charged, PFI, spark-ignition engine, Energy 170 (2019) 85-92.

[145] H. Chen, B. Xie, J. Ma, Y. Chen, NOx emission of biodiesel compared to diesel: Higher or lower?, Appl. Therm. Eng. 137 (2018) 584-593.

[146] Z. Huang, J. Xia, D. Ju, X. Lu, D. Han, X. Qiao, Z. Huang, A six-component surrogate of diesel from direct coal liquefaction for spray analysis, Fuel 234 (2018) 1259-1268.

[147] F. Li, W. Fu, B. Yi, L. Song, T. Liu, X. Wang, C. Wang, Y. Lei, Q. Lin, Comparison of macroscopic spray characteristics between biodiesel-pentanol blends and diesel, Exp. Therm. Fluid. Sci. 98 (2018) 523-533.

[148] L.A. Graham, S.L. Belisle, C.-L. Baas, Emissions from light duty gasoline vehicles operating on low blend ethanol gasoline and E85, Atmos. Environ. 42 (2008) 4498-4516. 
[149] L. Sileghem, V.A. Alekseev, J. Vancoillie, K.M. Van Geem, E.J.K. Nilsson, S. Verhelst, A.A. Konnov, Laminar burning velocity of gasoline and the gasoline surrogate components iso-octane, n-heptane and toluene, Fuel 112 (2013) 355-365.

[150] O. Doğan, The influence of $n$-butanol/diesel fuel blends utilization on a small diesel engine performance and emissions, Fuel 90 (2011) 2467-2472.

[151] C.T. Chong, S. Hochgreb, Measurements of laminar flame speeds of acetone/methane/air mixtures, Combust. Flame 158 (2011) 490-500.

[152] T. Wallner, A. Ickes, K. Lawyer, Analytical Assessment of $C_{2}-C_{8}$ Alcohols as SparkIgnition Engine Fuels, in: Proceedings of the FISITA 2012 World Automotive Congress, Springer Berlin Heidelberg, Berlin, Heidelberg, 2013, pp. 15-26.

[153] P.S. Veloo, Y.L. Wang, F.N. Egolfopoulos, C.K. Westbrook, A comparative experimental and computational study of methanol, ethanol, and $\mathrm{n}$-butanol flames, Combust. Flame 157 (2010) 1989-2004.

[154] S. Zhang, T.H. Lee, H. Wu, J. Pei, W. Wu, F. Liu, C. Zhang, Experimental and kinetic studies on laminar flame characteristics of acetone-butanol-ethanol (ABE) and toluene reference fuel (TRF) blends at atmospheric pressure, Fuel 232 (2018) 755-768.

[155] B. Masum, H.H. Masjuki, M.A. Kalam, S. Palash, M. Habibullah, Effect of alcoholgasoline blends optimization on fuel properties, performance and emissions of a SI engine, J. Clean. Prod. 86 (2015) 230-237.

[156] M. Kapusuz, H. Ozcan, J.A. Yamin, Research of performance on a spark ignition engine fueled by alcohol-gasoline blends using artificial neural networks, Appl. Therm. Eng. 91 (2015) 525-534.

[157] A. Elfasakhany, A.-F. Mahrous, Performance and emissions assessment of n-butanolmethanol-gasoline blends as a fuel in spark-ignition engines, Alex. Eng. J. 55 (2016) 30153024.

[158] Y. Li, K. Nithyanandan, J. Zhang, C.-F. Lee, S. Liao, Combustion and emissions performance of a spark ignition engine fueled with water containing acetone-butanolethanol and gasoline blends, SAE Tech. Pap. 2015-01-0908 (2015).

[159] Y. Li, K. Nithyanandan, T.H. Lee, R.M. Donahue, Y. Lin, C.-F. Lee, S. Liao, Effect of water-containing acetone-butanol-ethanol gasoline blends on combustion, performance, and emissions characteristics of a spark-ignition engine, Energ. Convers. Manage. 117 (2016) 21-30.

[160] C. Sayin, I. Kilicaslan, M. Canakci, N. Ozsezen, An experimental study of the effect of octane number higher than engine requirement on the engine performance and emissions, Appl. Therm. Eng. 25 (2005) 1315-1324.

[161] K. Nithyanandan, H. Wu, M. Huo, C.-F. Lee, A preliminary investigation of the performance and emissions of a port-fuel injected SI engine fueled with Acetone-ButanolEthanol (ABE) and gasoline, SAE Tech. Pap. 2014-01-1459 (2014).

[162] K. Nithyanandan, F.L. Chia-fon, H. Wu, J. Zhang, Performance and emissions of acetone-butanol-ethanol (ABE) and gasoline blends in a port fuel injected spark ignition 
engine, in: ASME 2014 Internal Combustion Engine Division Fall Technical Conference, American Society of Mechanical Engineers, Columbus, IN, USA 2014, pp. 1-11.

[163] K. Nithyanandan, J. Zhang, L. Yuqiang, H. Wu, C.-F. Lee, Investigating the impact of acetone on the performance and emissions of acetone-butanol-ethanol (ABE) and gasoline blends in an SI engine, SAE Tech. Pap. 2015-01-0909 (2015).

[164] J. Zhang, K. Nithyanandan, Y. Li, C.-F. Lee, Z. Huang, Comparative study of highalcohol-content gasoline blends in an SI engine, SAE Tech. Pap. 2015-01-0891 (2015).

[165] K. Nithyanandan, J. Zhang, Y. Li, H. Wu, T.H. Lee, Y. Lin, F.L. Chia-fon, Improved SI engine efficiency using acetone-butanol-ethanol (ABE), Fuel 174 (2016) 333-343.

[166] Y. Li, L. Meng, K. Nithyanandan, T.H. Lee, Y. Lin, F.L. Chia-fon, S. Liao, Experimental investigation of a spark ignition engine fueled with acetone-butanol-ethanol and gasoline blends, Energy 121 (2017) 43-54.

[167] Y. Li, K. Nithyanandan, Z. Ning, C.-F. Lee, H. Wu, Regulated and unregulated emissions from a spark ignition engine fueled with acetone-butanol-ethanol (ABE)-gasoline blends, SAE Tech. Pap. 2017-01-2328 (2017).

[168] Y. Li, Z. Ning, F.L. Chia-fon, J. Yan, T.H. Lee, Effect of acetone-butanol-ethanol (ABE)gasoline blends on regulated and unregulated emissions in spark-ignition engine, Energy 168 (2019) 1157-1167.

[169] Y.-z. An, S.-p. Teng, Y.-q. Pei, J. Qin, X. Li, H. Zhao, An experimental study of polycyclic aromatic hydrocarbons and soot emissions from a GDI engine fueled with commercial gasoline, Fuel 164 (2016) 160-171.

[170] Y. Luo, L. Zhu, J. Fang, Z. Zhuang, C. Guan, C. Xia, X. Xie, Z. Huang, Size distribution, chemical composition and oxidation reactivity of particulate matter from gasoline direct injection (GDI) engine fueled with ethanol-gasoline fuel, Appl. Therm. Eng. 89 (2015) 647655.

[171] B.M. Graves, C.R. Koch, J.S. Olfert, Morphology and volatility of particulate matter emitted from a gasoline direct injection engine fuelled on gasoline and ethanol blends, J. Aerosol Sci. 105 (2017) 166-178.

[172] G.D.J. Guerrero Peña, Y.A. Hammid, A. Raj, S. Stephen, T. Anjana, V. Balasubramanian, On the characteristics and reactivity of soot particles from ethanol-gasoline and 2,5dimethylfuran-gasoline blends, Fuel 222 (2018) 42-55.

[173] C. Russo, A. D'Anna, A. Ciajolo, M. Sirignano, The effect of butanol isomers on the formation of carbon particulate matter in fuel-rich premixed ethylene flames, Combust. Flame 199 (2019) 122-130.

[174] C. Hergueta, M. Bogarra, A. Tsolakis, K. Essa, J.M. Herreros, Butanol-gasoline blend and exhaust gas recirculation, impact on GDI engine emissions, Fuel 208 (2017) 662-672. [175] X. Yu, Z. Guo, L. He, W. Dong, P. Sun, W. Shi, Y. Du, F. He, Effect of gasoline/n-butanol blends on gaseous and particle emissions from an SI direct injection engine, Fuel 229 (2018) 1-10. 
[176] C. Russo, A. D'Anna, A. Ciajolo, M. Sirignano, Analysis of the chemical features of particles generated from ethylene and ethylene/2, 5 dimethyl furan flames, Combust. Flame 167 (2016) 268-273.

[177] M. Sirignano, A. Ciajolo, A. D'Anna, C. Russo, Chemical features of particles generated in an ethylene/ethanol premixed flame, Energy Fuels 31 (2017) 2370-2377.

[178] Z. Xu, X. Li, C. Guan, Z. Huang, Characteristics of exhaust diesel particles from different oxygenated fuels, Energy Fuels 27 (2013) 7579-7586.

[179] J. Song, M. Alam, A.L. Boehman, U. Kim, Examination of the oxidation behavior of biodiesel soot, Combust. Flame 146 (2006) 589-604.

[180] T.H. Lee, Y. Lin, X. Meng, Y. Li, K. Nithyanandan, Combustion characteristics of acetone, butanol, and ethanol (ABE) blended with diesel in a compression-ignition engine, SAE Tech. Pap. 2016-01-0884 (2016).

[181] J. Song, C. Zhang, An experimental study on the performance and exhaust emissions of a diesel engine fuelled with soybean oil methyl ester, Proc. Inst. Mech. Eng. Pt. D: J. Automobile Eng. 222 (2008) 2487-2496.

[182] A.K. Agarwal, D.K. Srivastava, A. Dhar, R.K. Maurya, P.C. Shukla, A.P. Singh, Effect of fuel injection timing and pressure on combustion, emissions and performance characteristics of a single cylinder diesel engine, Fuel 111 (2013) 374-383.

[183] A.C. Hansen, Q. Zhang, P.W.L. Lyne, Ethanol-diesel fuel blends - A review, Bioresour. Technol. 96 (2005) 277-285.

[184] D.-g. Li, H. Zhen, L. Xingcai, Z. Wu-gao, Y. Jian-guang, Physico-chemical properties of ethanol-diesel blend fuel and its effect on performance and emissions of diesel engines, Renew. Energ. 30 (2005) 967-976.

[185] E. Alptekin, M. Canakci, Characterization of the key fuel properties of methyl esterdiesel fuel blends, Fuel 88 (2009) 75-80.

[186] A. Schwab, M. Bagby, B. Freedman, Preparation and properties of diesel fuels from vegetable oils, Fuel 66 (1987) 1372-1378.

[187] Y.-C. Chang, W.-J. Lee, T.S. Wu, C.-Y. Wu, S.-J. Chen, Use of water containing acetonebutanol-ethanol for NOx-PM (nitrogen oxide-particulate matter) trade-off in the diesel engine fueled with biodiesel, Energy 64 (2014) 678-687.

[188] H. Wu, K. Nithyanandan, T.H. Lee, C.-f.F. Lee, C. Zhang, Spray and combustion characteristics of neat acetone-butanol-ethanol, n-butanol, and diesel in a constant volume chamber, Energy Fuels 28 (2014) 6380-6391.

[189] H. Wu, K. Nithyanandan, N. Zhou, T.H. Lee, F.L. Chia-fon, C. Zhang, Impacts of acetone on the spray combustion of Acetone-Butanol-Ethanol (ABE)-Diesel blends under low ambient temperature, Fuel 142 (2015) 109-116.

[190] X. Ma, F. Zhang, K. Han, B. Yang, G. Song, Evaporation characteristics of acetonebutanol-ethanol and diesel blends droplets at high ambient temperatures, Fuel 160 (2015) 43-49. 
[191] Z. Zhao, Z. Xu, J. Liu, M. Wang, C.-F. Lee, W. Chang, J. Hou, Experimental and numerical investigation of soot mechanism of acetone-butanol-ethanol (ABE) with various oxygen concentrations, SAE Tech. Pap. 2015-01-0389 (2015).

[192] Y. Lin, T. Lee, K. Nithyanandan, J. Zhang, Y. Li, C.-F. Lee, Experimental investigation and analysis of combustion process in a diesel engine fueled with acetone-butanolethanol/diesel blends, SAE Tech. Pap. 2016-01-0737 (2016).

[193] S. Zhang, Z. Xu, T. Lee, Y. Lin, W. Wu, C.-F. Lee, A semi-detailed chemical kinetic mechanism of acetone-butanol-ethanol (ABE) and diesel blends for combustion simulations, SAE Int. J. Engines 9 (2016) 631-640.

[194] J. Fu, J. Shu, Z. Zhao, J. Liu, F. Zhou, Comparative analysis of soot formation processes of diesel and ABE (Acetone-Butanol-Ethanol) based on CFD coupling with phenomenological soot model, Fuel 203 (2017) 380-392.

[195] J. Luo, Y. Zhang, J. Wang, Q. Zhang, Effect of acetone-butanol-ethanol addition to diesel on the soot reactivity, Fuel 226 (2018) 555-563.

[196] V.M. Ortiz-Martínez, P. Andreo-Martínez, N. García-Martínez, A.P. de los Ríos, F.J. Hernández-Fernández, J. Quesada-Medina, Approach to biodiesel production from microalgae under supercritical conditions by the PRISMA method, Fuel Process. Technol. 191 (2019) 211-222.

[197] H. An, W.M. Yang, S.K. Chou, K.J. Chua, Combustion and emissions characteristics of diesel engine fueled by biodiesel at partial load conditions, Appl. Energ. 99 (2012) 363-371. [198] X. Gu, G. Li, X. Jiang, Z. Huang, C.-f. Lee, Experimental study on the performance of and emissions from a low-speed light-duty diesel engine fueled with $\mathrm{n}$-butanol-diesel and isobutanol-diesel blends, Proc. Inst. Mech. Eng. Pt. D: J. Automobile Eng. 227 (2012) 261271.

[199] C. Shen, W.L. Cheng, C.-F. Lee, Micro-explosion modeling of biofuel-diesel blended droplets, SAE Int. J. Engines 4 (2011) 1445-1454.

[200] J. Heywood, Internal combustion engine fundamentals, McGraw-Hill, 1988.

[201] J.M. Desantes, J. Arrègle, J.V. Pastor, A. Delage, Influence of the fuel characteristics on the injection process in a DI diesel engine, SAE Tech. Pap. 980802 (1998) 1185-1195. [202] Ö. Can, I. Celikten, N. Usta, Effects of ethanol addition on performance and emissions of a turbocharged indirect injection Diesel engine running at different injection pressures, Energ. Convers. Manage. 45 (2004) 2429-2440.

[203] D. Rakopoulos, C. Rakopoulos, E. Giakoumis, A. Dimaratos, D. Kyritsis, Effects of butanol-diesel fuel blends on the performance and emissions of a high-speed DI diesel engine, Energ. Convers. Manage. 51 (2010) 1989-1997.

[204] G. Labeckas, S. Slavinskas, Performance and emission characteristics of a direct injection diesel engine operating on KDV synthetic diesel fuel, Energ. Convers. Manage. 66 (2013) 173-188.

[205] S.W. Kruczyński, Performance and emission of $\mathrm{Cl}$ engine fuelled with camelina sativa oil, Energ. Convers. Manage. 65 (2013) 1-6. 
[206] K. Muralidharan, D. Vasudevan, Performance, emission and combustion characteristics of a variable compression ratio engine using methyl esters of waste cooking oil and diesel blends, Appl. Energ. 88 (2011) 3959-3968.

[207] K. Vasu, D. Gupta, S. Naseer, Performance and emission characteristics of n-butanol and Iso-butanol diesel blend comparison, SAE Tech. Pap. 2015-01-2819 (2015).

[208] F. Wu, C.K. Law, An experimental and mechanistic study on the laminar flame speed, Markstein length and flame chemistry of the butanol isomers, Combust. Flame 160 (2013) 2744-2756.

[209] X. Gu, Z. Huang, S. Wu, Q. Li, Laminar burning velocities and flame instabilities of butanol isomers-air mixtures, Combust. Flame 157 (2010) 2318-2325.

[210] S. Fernando, C. Hall, S. Jha, NOx reduction from biodiesel fuels, Energy Fuels 20 (2006) 376-382.

[211] S.K. Hoekman, C. Robbins, Review of the effects of biodiesel on NOx emissions, Fuel Process. Technol. 96 (2012) 237-249.

[212] K. Varatharajan, M. Cheralathan, R. Velraj, Mitigation of NOx emissions from a jatropha biodiesel fuelled DI diesel engine using antioxidant additives, Fuel 90 (2011) 27212725.

[213] J. Zheng, J.A. Caton, Effects of operating parameters on nitrogen oxides emissions for a natural gas fueled homogeneous charged compression ignition engine $(\mathrm{HCCl})$ : Results from a thermodynamic model with detailed chemistry, Appl. Energ. 92 (2012) 386-394.

[214] G. Chen, Y. Shen, Q. Zhang, M. Yao, Z. Zheng, H. Liu, Experimental study on combustion and emission characteristics of a diesel engine fueled with 2,5-dimethylfurandiesel, n-butanol-diesel and gasoline-diesel blends, Energy 54 (2013) 333-342.

[215] J.T. Moss, A.M. Berkowitz, M.A. Oehlschlaeger, J. Biet, V. Warth, P.-A. Glaude, F. Battin-Leclerc, An experimental and kinetic modeling study of the oxidation of the four isomers of butanol, J. Phys. Chem. A 112 (2008) 10843-10855.

[216] L.M. Pickett, D.L. Siebers, Soot in diesel fuel jets: effects of ambient temperature, ambient density, and injection pressure, Combust. Flame 138 (2004) 114-135.

[217] L.M. Pickett, D.L. Siebers, C.A. Idicheria, Relationship between ignition processes and the lift-off length of diesel fuel jets, SAE Tech. Pap. 2005-01-3843 (2005) 1714-1731.

[218] J. Luo, Y. Zhang, Q. Zhang, J. Liu, J. Wang, Evaluation of sooting tendency of acetonebutanol-ethanol (ABE) fuels blended with diesel fuel, Fuel 209 (2017) 394-401.

[219] T. Kadota, H. Yamasaki, Recent advances in the combustion of water fuel emulsion, Prog. Energy Combust. Sci. 28 (2002) 385-404.

[220] W.B. Fu, L.Y. Hou, L. Wang, F.H. Ma, A unified model for the micro-explosion of emulsified droplets of oil and water, Fuel Process. Technol. 79 (2002) 107-119.

[221] M.M. Maricq, Chemical characterization of particulate emissions from diesel engines: A review, J. Aerosol Sci. 38 (2007) 1079-1118.

[222] S.-L. Lin, W.-J. Lee, C.-F. Lee, S.-J. Chen, Energy savings and emission reduction of nitrogen oxides, particulate matter, and polycyclic aromatic hydrocarbons by adding 
water-containing acetone and neat soybean oil to a diesel-fueled engine generator, Energy Fuels 24 (2010) 4522-4533.

[223] Y.-C. Lin, W.-J. Lee, C.-C. Chen, C.-B. Chen, Saving energy and reducing emissions of both polycyclic aromatic hydrocarbons and particulate matter by adding bio-solution to emulsified diesel, Environ. Sci. Technol. 40 (2006) 5553-5559.

[224] N. Surawski, B. Miljevic, G. Ayoko, B. Roberts, S. Elbagir, K. Fairfull-Smith, S. Bottle, Z. Ristovski, Physicochemical characterization of particulate emissions from a compression ignition engine employing two injection technologies and three fuels, Environ. Sci. Technol. 45 (2011) 5498-5505.

[225] D. Qi, H. Chen, L. Geng, Y.Z. Bian, X.C. Ren, Performance and combustion characteristics of biodiesel-diesel-methanol blend fuelled engine, Appl. Energ. 87 (2010) 1679-1686.

[226] C. Cheung, R. Zhu, Z. Huang, Investigation on the gaseous and particulate emissions of a compression ignition engine fueled with diesel-dimethyl carbonate blends, Sci. Total Environ. 409 (2011) 523-529.

[227] K.H. Song, P. Nag, T.A. Litzinger, D.C. Haworth, Effects of oxygenated additives on aromatic species in fuel-rich, premixed ethane combustion: a modeling study, Combust. Flame 135 (2003) 341-349.

[228] H. Wu, T.H. Lee, C.-f. Lee, F. Liu, B. Sun, Optical soot measurement of bio-butanol upstream product, $A B E$ (Acetone-Butanol-Ethanol), under diesel-like conditions, Fuel 181 (2016) 300-309.

[229] K.E. Nord, D. Haupt, Reducing the emission of particles from a diesel engine by adding an oxygenate to the fuel, Environ. Sci. Technol. 39 (2005) 6260-6265.

[230] F. Wu, J. Wang, W. Chen, S. Shuai, A study on emission performance of a diesel engine fueled with five typical methyl ester biodiesels, Atmos. Environ. 43 (2009) 1481-1485.

[231] C.S. McEnally, L.D. Pfefferle, Sooting tendencies of oxygenated hydrocarbons in laboratory-scale flames, Environ. Sci. Technol. 45 (2011) 2498-2503.

[232] E. Sukjit, J.M. Herreros, K.D. Dearn, R. García-Contreras, A. Tsolakis, The effect of the addition of individual methyl esters on the combustion and emissions of ethanol and butanol -diesel blends, Energy 42 (2012) 364-374.

[233] D.C. Rakopoulos, C.D. Rakopoulos, E.G. Giakoumis, R.G. Papagiannakis, D.C. Kyritsis, Experimental-stochastic investigation of the combustion cyclic variability in HSDI diesel engine using ethanol-diesel fuel blends, Fuel 87 (2008) 1478-1491.

[234] D.C. Rakopoulos, C.D. Rakopoulos, R.G. Papagiannakis, D.C. Kyritsis, Combustion heat release analysis of ethanol or $n$-butanol diesel fuel blends in heavy-duty DI diesel engine, Fuel 90 (2011) 1855-1867.

[235] J. Wu, K.H. Song, T. Litzinger, S.-Y. Lee, R. Santoro, M. Linevsky, M. Colket, D. Liscinsky, Reduction of PAH and soot in premixed ethylene-air flames by addition of ethanol, Combust. Flame 144 (2006) 675-687. 
[236] J. Sun, J.A. Caton, T.J. Jacobs, Oxides of nitrogen emissions from biodiesel-fuelled diesel engines, Prog. Energy Combust. Sci. 36 (2010) 677-695.

[237] C. Kumar, M.G. Babu, L.M. Das, Experimental investigations on a karanja oil methyl ester fueled DI diesel engine, SAE Tech. Pap. 2006-01-0238 (2006). 